\title{
ON THALAMIC AND TECTAI NUCLEI AND FIBER PATHS IN THE BRAIN OF THE AMERICAN ALLIGATOR
}

\author{
G. CARL HUBER AND ELIZABETH CAROLINE CROSBY \\ Department of Anatomy, University of Michigan
}

THIR'TY-FOUR FIGURES

CONTENTS

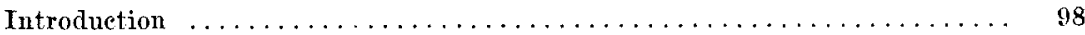

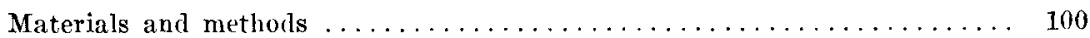

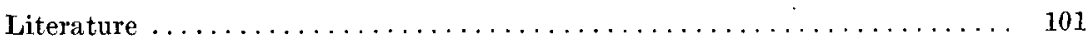

Nuclear masses $\ldots \ldots \ldots \ldots \ldots \ldots \ldots \ldots \ldots \ldots \ldots \ldots \ldots \ldots \ldots \ldots \ldots \ldots \ldots$

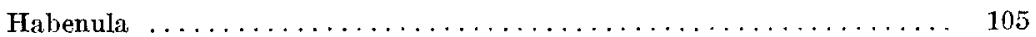

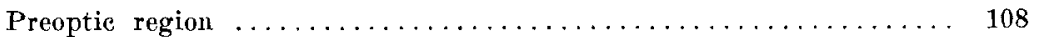

Area ventralis anterior $\ldots \ldots \ldots \ldots \ldots \ldots \ldots \ldots \ldots \ldots \ldots \ldots \ldots \ldots \ldots$

Interstitial nucleus of the olfactory projection tract $\ldots \ldots \ldots \ldots \ldots \ldots, 110$

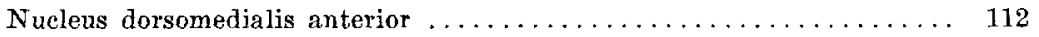

Subhabenular region $\ldots \ldots \ldots \ldots \ldots \ldots \ldots \ldots \ldots \ldots \ldots \ldots \ldots \ldots \ldots \ldots \ldots$

Oval nucleus $\ldots \ldots \ldots \ldots \ldots \ldots \ldots \ldots \ldots \ldots \ldots \ldots \ldots \ldots \ldots \ldots \ldots \ldots \ldots$

Corpus geniculatum laterale $\ldots \ldots \ldots \ldots \ldots \ldots \ldots \ldots \ldots \ldots \ldots \ldots \ldots$

Nucleus dorsolateralis anterior $\ldots \ldots \ldots \ldots \ldots \ldots \ldots \ldots \ldots \ldots \ldots \ldots$

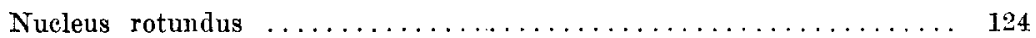

Nucleus medialis $\ldots \ldots \ldots \ldots \ldots \ldots \ldots \ldots \ldots \ldots \ldots \ldots \ldots \ldots \ldots \ldots$

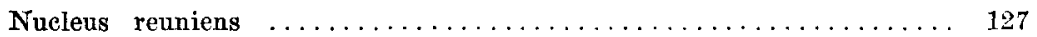

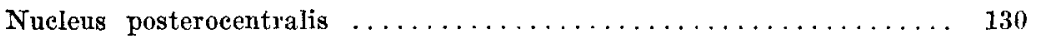

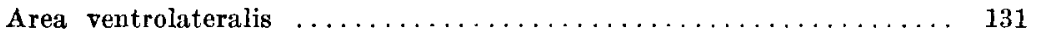

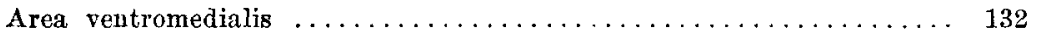

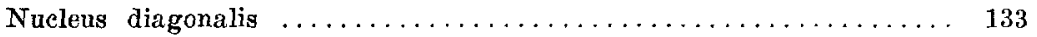

Nueleus posterodorsalis $\ldots \ldots \ldots \ldots \ldots \ldots \ldots \ldots \ldots \ldots \ldots \ldots \ldots \ldots \ldots$

Genieulato pretectale of Beceari $\ldots \ldots \ldots \ldots \ldots \ldots \ldots \ldots \ldots \ldots \ldots \ldots$

Nucleus lentiformis mesencephali $\ldots \ldots \ldots \ldots \ldots \ldots \ldots \ldots \ldots \ldots \ldots \ldots$

Nucleus pretectalis $\ldots \ldots \ldots \ldots \ldots \ldots \ldots \ldots \ldots \ldots \ldots \ldots \ldots \ldots$

Nucleus of the dorsal supraoptic decussation $\ldots \ldots \ldots \ldots \ldots \ldots \ldots \ldots . \ldots 138$

Nucleus entopeduncularis $\ldots \ldots \ldots \ldots \ldots \ldots \ldots \ldots \ldots \ldots \ldots \ldots \ldots \ldots \ldots$

Nucleus periventricularis hypothalami $\ldots \ldots \ldots \ldots \ldots \ldots \ldots \ldots \ldots \ldots$

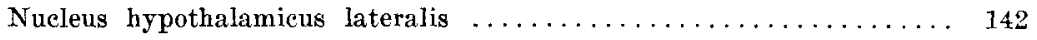

Nucleus hypothalamicus ventralis $\ldots \ldots \ldots \ldots \ldots \ldots \ldots \ldots \ldots \ldots \ldots \ldots \ldots$

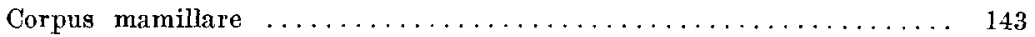

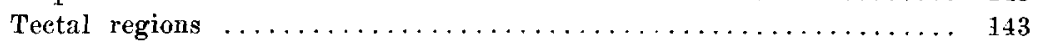

97

THE JOURNAL OF COMPARATIVE NEUROLOGY, VOH, 40, NO. 1 


\begin{tabular}{|c|c|}
\hline 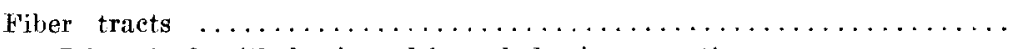 & 144 \\
\hline Résumé of epithalamic and hypothalamie connections .. & 144 \\
\hline Basal forebrain bundle $\ldots \ldots \ldots \ldots \ldots \ldots \ldots \ldots \ldots \ldots \ldots$ & 148 \\
\hline Optic tract (figs. $3-7,9,10,12-14,16-28) \ldots \ldots \ldots$ & 164 \\
\hline Teeto-thalamie and thalamo-tectal paths .... & 171 \\
\hline 1. Unerossed teeto-thalamic and thalamo-tectal paths $\ldots \ldots \ldots$ & 173 \\
\hline $\begin{array}{l}\text { 2. Crossed tecto-thalamic and thalamo-tectal paths (Supraoptic } \\
\text { decussations) } \ldots \ldots \ldots \ldots \ldots \ldots \ldots \ldots \ldots \ldots \ldots\end{array}$ & 181 \\
\hline Lemniseus systems $\ldots \ldots \ldots \ldots \ldots \ldots \ldots \ldots \ldots \ldots \ldots \ldots \ldots \ldots$ & 189 \\
\hline 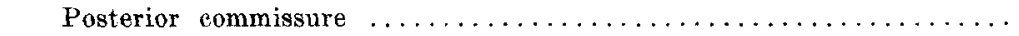 & 196 \\
\hline Commissure of the superior colliculus (figs. 23 and 26) $\ldots$ & 198 \\
\hline Fasciculus longitudinalis medialis (figs. 14-16, 26-31). & 199 \\
\hline $\begin{array}{l}\text { Fasciculus geniculatus descendens (figs. } 17 \text { and 18), Faseiculus pretec- } \\
\text { talis descendens (figs. } 17,18) \ldots \ldots \ldots \ldots \ldots \ldots \ldots \ldots \ldots\end{array}$ & 201 \\
\hline Tractus thalamo-bulbaris (figs. $26-30$ ) $\ldots \ldots \ldots \ldots \ldots \ldots \ldots \ldots$ & 201 \\
\hline Descending paths from teetal centers... & 202 \\
\hline Mesencephalie periventrieular system & 204 \\
\hline Fiber connections of the nueleus isthmi & 206 \\
\hline Cerebellar connections $\ldots \ldots \ldots \ldots \ldots$ & 208 \\
\hline Trigeminal connections & 212 \\
\hline ussion & 215 \\
\hline liography & 224 \\
\hline
\end{tabular}

\section{INTRODUCTION}

The cerebral cortex and the thalamus are, in their development, very closely interrelated within the vertebrate series. Similarly the development and differentiation of the thalamic nuclei are dependent to a great degree upon their connections with the lower centers. So intimate are these relationships that any attempt at an understanding of the factors concerned in the evolution of the forebrain must be based on a proper conception of the structure and the functions of thalamic, tectal and bulbar centers.

Several years ago a paper on the forebrain of Alligator mississippiensis was published by one of the authors of this communication (Crosby, '17). At that time it was realized that for a thorough understanding of the significance of the various fiber paths it was necessary to have a more complete knowledge of those lower centers with which the telencephalon is interrelated. Consequently plans were made for a relatively detailed study of the thalamus and midbrain in the alligator. The work has met with many interruptions and 
the results attained have not been wholly satisfactory. However, quite a number of rather suggestive fiber paths have been traced out; paths whose courses and connections, it is felt, give further insight into the underlying factors operating in forebrain and thalamic development. Some of these fiber tracts have not been previously described for reptiles, so far as the authors have been able to ascertain; many more of them have been only partially described and are here given a much more detailed accounting. For the sake of completeness and clearness in the discussion brief summaries have been given of certain tracts which have already been figured and described for various reptiles. Accounts of nuclear arrangement are presented to the extent necessary to enable a clear understanding of the origin, termination and significance of the fiber paths. The aim of the present paper, then, is to show somewhat in detail for Reptilia, the interrelation of forebrain and thalamus and of thalamus and midbrain, with a view of obtaining a better understanding of their functional significance and the factors underlying their evolution.

This investigation was begun by Miss Crosby at the University of Chicago during the summer of 1919 . It was undertaken at the suggestion of Professor C. Judson Herrick, to whom she desires to express her deep obligation for helpful suggestions and kindly criticisms throughout the entire prog. ress of the work. She also wishes to take this opportunity of thanking Professor Robert R. Bensley, Director of the Anatomical Laboratories at the University of Chicago, for his kindness in granting her the privileges of the laboratories for several summers. The major portion of the work has been done at the Anatomical Laboratory of the University of Michigan where Dr. Huber has become associated with the work and in this contribution assumes joint responsibility for the descriptions and interpretations of the tracts and nuclei. 
MATERIALS AND METHODS

For the most part, Alligator mississippiensis was employed in the present study. The animals used were young and small, varying in length from 9 inches to 1 foot. A number of series of adult turtle, chiefly Chrysemys marginata, were also available and these proved extremely useful both as a basis for the comparison of the two reptilian types and for supplementing and checking the findings obtained from the alligator material.

Much of the work on fiber paths was done on material prepared, with some slight modifications, after the silver methods of Cajal. Alligator brains so prepared were cut serially in several planes. A transverse series, from which part of the drawings were made, was very kindly loaned by Dr. Paul S. McKibben. Several series of sections of alligator brains, stained after Weigert's method, the property of Professor Herrick, were at our disposal and were serviceable in checking certain medullated fiber paths. A transversely cut series of the alligator brain stained in earmine, originally the property of Professor C. L. Herrick but now belonging to his brother, was available.

There were especially prepared for this study of forebrain, thalamus and tectum, series of sections of six alligator brains stained in toluidin blue; three of which are transversely cut, two cut in sagittal plane and one in frontal plane. Certain of the toluidin blue series were counterstained in erythrosin. There were prepared series of sections of two alligator brains, stained for myelin, after embedding in paraffin and fixing the paraffin sections to the slides. One of these series is cut transversely, the other in the sagittal plane. There are available five series of sections of alligator brains stained after modified Cajal silver methods, including two sagittal, one transverse and one frontal series. There are at hand three series of sections of alligator brains incompletely stained after the Cox chrome-mercury method and two incomplete series, one transversely cut, the other cut in sagittal plane; both are well stained after the Golgi method. 
Of turtle material (Chrysemys marginata) the following series of brain sections are at hand:-two series stained in toluidin blue, one cut transversely and the other cut in sagittal plane and two series stained after a modified Ranson pyridine-silver method, cut in sagittal plane and exceptionally well differentiated.

The silver preparations permitted a study of the nonmedullated as well as certain medullated fibers. The series stained for medullated fibers were useful in checking certain medullated fiber paths. The toluidin blue material was used more particularly for nuclear study and orientation, though certain of the fiber paths stand out by contrast in staining.

The outlines for the drawings and the position of the nuclei and of the larger tracts were obtained by use of the Edinger projection apparatus. The finer details were added and the drawings completed by use of the higher powers of the microscope. The cell drawings from the Golgi material were made by the use of a camera lucida.

\section{LITERATURE}

The reptilian brain has received quite extensive consideration from various observers and it is beyond the scope of the present paper to attempt anything like a complete review of this literature. Under the account of each fiber tract and nucleus, references have been given both to text and figures in the literature, which seemed pertinent to the description or interpretation of the material at hand. There are certain works, however, dealing with various phases of the subject which deserve more special attention and are here given brief mention.

In 1877 Rabl-Rückhard figured the gross structure of the brain of adult Alligator mississippiensis. About thirteen years later similar figures of the gross relations in the brain of the young alligator, together with some brief notes on the microscopic structure were published by C. L. Herrick ('90). A few years later Mrs. Susanna Phelps Gage ('95) gave a most excellent description with figures of the turtle brain, 
comparing it with that of the English sparrow. Various figures and descriptions of the gross relations are to be found scattered throughout the literature. Photographs of the brain of Alligator sclerops as well as those of other reptiles may be found in de Lange's paper ('11) and two drawings of the brain of Alligator mississippiensis made by Mr. Streedain are shown in the paper by Crosby ('17). Dissections and models of the turtle brain, particularly of its more anterior portion, are to be found in Johnston's contributions ('15).

Many observers have contributed to the knowledge of the more minute structure of the reptilian brain. Edinger, between 1888 and 1899, published a series of studies on the reptilian forebrain, thalamus and midbrain which did much to lay the foundation for an understanding of their microscopic structure. In Spain, Ramón y Cajal ('11), his brother Pedro ('96, '97 and earlier dates), and associated students have contributed a considerable body of work on reptilian brains, particularly, though not exclusively, in the field of cell structure and cell arrangement. Kappers and de Lange have added much to our present knowledge of the reptilian central nervous system, while to Kappers and observers associated with him at the Amsterdam Institute belong the major credit for our present knowledge of the positions and relations of the nuclei of the cranial nerves in Reptilia. A condensed account of their more important contributions together with the references to the original papers is to be found in Kappers' "Vergleichende Anatomie des Nervensystems" ('20-'21). This book has proved very useful and abundant reference is made to it throughout the text of the present paper. The invaluable contributions of Elliot Smith ('10 quoted in particular) to our knowledge of the central nervous system are so generally known as to require no special mention. They are concerned in reptiles mainly with forebrain structure and evolution and consequently do not apply so directly to the subject matter considered here. Among American workers, Adolf Meyer's ('92) most careful description 
of the forebrain in reptiles is important. Johnston (' 15 , '16, '23) has done a great amount of work on the reptilian nervous system, particularly that of turtles; most of his attention having thus far been given to the telencephalon. One of Johnston's latest papers ('23), which is a "Further study of the evolution of the forebrain," summarizes much of his work in this region and puts the reptilian structures into relation with those found in other forms. In the same volume of The Journal of Comparative Neurology is a very interesting paper by Dr. Marion Hines ('23) which is concerned primarily with the development of the telencephalon in the hitherto little known brain of Sphenodon punctatum. Albert Reese ('08, '10, '15) has made a special study of the American alligator. His articles are concerned both with its adult anatomy and its embryological development, including the development of the nervous system. His book ('15) also contains data regarding the feeding habits and manner of life of this reptile.

The contributions here briefly listed may serve to demonstrate the wide interest manifested in the structure of the reptilian brain and the various laboratories which have contributed. The papers here listed contain references to many others, special mention of which would unduly and unnecessarily extend these pages. A considerable number of the above mentioned papers we have not had occasion to quote directly in the text of the present contribution and yet the material in them has undoubtedly colored, to an appreciable degree, the interpretation of our material.

\section{NUCLEAR MASSES}

In this communication the account given of the nuclei is presented primarily as a background for the description and interpretation of the fiber tracts. Consequently while certain cellular groups are quite completely described, others are only briefly discussed or simply given a label in the figures. The nuclei most fully described are of necessity, considering the character of the paper, those of the diencephalic areas, par- 
ticularly those of the thalamus proper. The tectal centers, out of consideration for space, are only briefly discussed. The majority of the subthalamic and tegmental areas have not been considered under the account of the nuclear material, although certain ones of them have been labelled in the figures. Furthermore these centers have been briefly described in connection with their associated fiber tracts wherever these tracts have been included in the paper. Reference is here made to the papers of de Lange ('12) and the recent work of Beccari ('23) pertaining to these regions.

Even an attempt at partial plotting of the diencephalic nuclear masses in reptiles presents many difficulties and invites misinterpretations, since many of the nuclear masses are not sharply circumscribed but grade one into the other without distinct demarcation. Thus the nuclear boundaries must be determined, in part at least, on the basis of fiber connections, as well as on differential cell characteristics. However, our most serious obstacle in the presentation of our material has proved to be that of a consistent nomenclature. A study of the figures and descriptions in the literature and a comparison of these with our alligator material convinces us that there is unquestionably a considerable variation of pattern (particularly in the dorsal thalamus) within the reptilian group. Undoubtedly this means the exaggeration of certain nuclear masses in one form and their partial suppression in another. With this variation in size there are associated more or less distinct differences in position, so that position alone can not be depended upon as a guide in determining homologies. Furthermore, for certain of these nuclear masses, particularly in the posterior part of the thalamus, complete fiber connections have not been determined either by others or by ourselves. Finally, when the same form is taken into consideration, in the current nomenclature, not only has a single nuclear group been called by a variety of names but totally different groups have been designated by the same name. In certain instances, consequently, to avoid misunderstandings and the mistakes of doubtful homologies, we have adopted a new nomenclature. 
In attempting to compare the dorsal thalamus of the alligator with that of birds or mammals even greater difficulties presented themselves. Kappers ('21) has discussed the evidence for certain probable homologies. Our findings are explained in part by his conclusions, in part they do not appear to accord with them.

The names of Kölliker ('93), Edinger and Wallenberg ('99), Malone ('10) and many others are associated with the study of the thalamic areas in birds and mammals. Ingvar ('23) has written a most suggestive paper on the homologies existing between these latter forms. The difficulties encountered by us in establishing comparisons are not due, then, to a lack of most excellent previous work on the thalamus but are due, in large part, to confusion arising out of differences in terminology and in methods of study and in part to the fact that anything approaching a complete statement of the fiber connections is as yet unavailable. The research plans of this laboratory involve a detailed study of the diencephalon of birds and of certain mammals and when such a program has been carried to completion we hope to be able to contribute somewhat to the establishment of certain homologies with greater certainty than is now possible. The homologies found in the descriptions and discussion must, for the present, be regarded in some measure as tentative.

\section{Habenula}

The habenula in reptiles consists of two main nuclear masses: a medial or internal nucleus and a lateral or external nucleus. De Lange ('13) described these briefly and figured them in Draco volans. The form relations in Alligator mississippiensis appear somewhat different in details than those described by de Lange. They show an interesting resemblance to those figured for the albino rat by Gurdjian ('25). A relatively complete account of these nuclei, as found in the alligator, follows.

Anteriorly, the medial nucleus consists of two main portions (fig. 1, a and b) :-1.) a pars dorsolateralis and, 2) a pars 
ventromedialis, the two being separated from each other by a lateral habenular nucleus. Then a group of cells appears between the two divisions of the medial nucleus and gradually unites them. The whole medial nucleus at this level surrounds the lateral nucleus on all but the ventrolateral side, forming a kind of cap over it (fig. 1, c and d). As one approaches the habenular commissure, the ventromedial portion swings further ventralward and becomes separated from the remainder of the medial habenular nucleus by the fibers of the habenular commissure (fig. $1, \mathrm{e}$ and $\mathrm{d}$ ). This ventromedial portion persists until near the end of the above mentioned commissure (fig. 1,d). It is possible that the ventromedial portion of the medial habenular nucleus is comparable to the interstitial nucleus found associated with the habenular commissure in forms where that tract is smaller.

In general the cells of the medial nucleus are of medium size and stain deeply, particularly those of the dorsolateral and dorsomedial portions. They all appear to receive fibers of stria medullaris. A separate slip, which, from its position in the stria, is in all probability the medial cortico-habenular tract, enters pars dorsolateralis of the same side.

The lateral habenular nucleus (fig. 1, a-e) consists of smaller cells with an admixture of certain larger, triangular shaped cells, all of which are scattered among the incoming fibers of stria medullaris. It does not present as much nuclear differentiation as.does the medial habenular nucleus. Nucleus habenularis lateralis lies at first lateral to the medial habenular nucleus and then is capped by it. The lateral nucleus extends caudad to the region of the habenular commissure (fig. 1, e).

It will be seen from the foregoing account that the habenula (particularly its medial or internal nucleus) is highly developed in the alligator. The lateral nucleus is less clearly differentiated. It may or may not be the homologue of the external nucleus of Mammalia. So far as the medial nucleus is concerned, the arrangement of cell masses is in many respects comparable to that found in the albino rat by Gurd- 

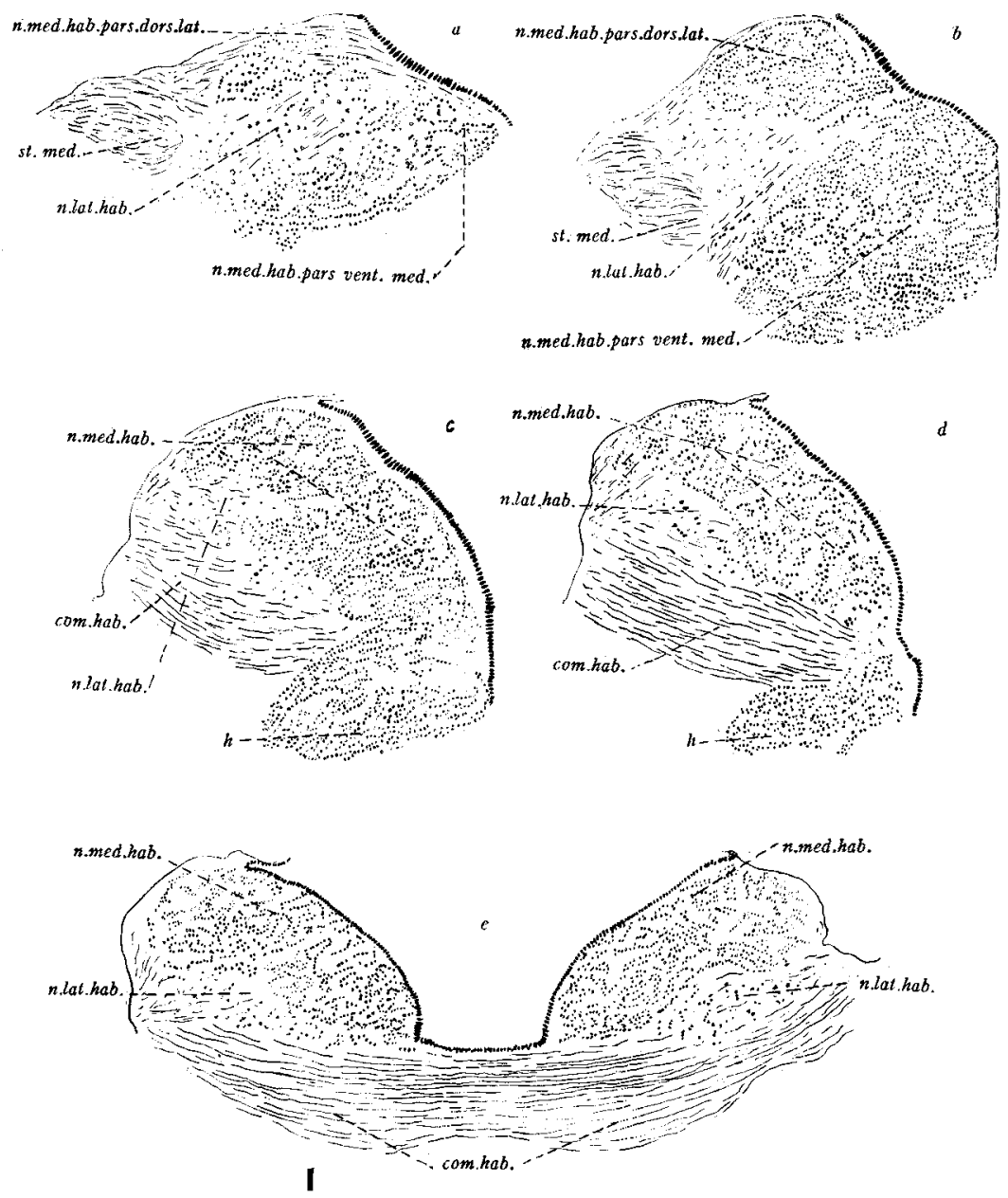

Fig. 1 A series of transverse sections through the habenular nuclei at various levels to show the relations of the nuclear groups. The dorsolateral and ventromedial portions of the medial habenular nucleus are seen separated from each other cephalad by the lateral nucleus ( $a$ and $b$ ) but later become continuous, forming a cap over that nucleus (c and $d$ ). The separation of a part ( $h$ ) of the ventromedial portion from the main mass by the habenular commissure is seen in $c$ and $d$. The posterior portion of the habemula is evident in e. Toluidin blue preparations. $\times 45$. com.hab., commissura habenularum; $h$, that part of the ventromedial portion of the medial habenular nucleus which is separated from the main mass by the habenular commissure; n.lat.hab., nucleus lateralis habenulae; n.med.hab., nucleus medialis habenulae; n.med.hab.pars dors.lat., nucleus medialis habenulae pars dorsolateralis; n.med.hab.pars vent.med., nucleus medialis habenulae pars ventromedialis; st.med., stria medullaris. 
jian ('25). There is found in the alligator a larger habenular commissure than in the rat and with the larger commissure the exaggeration of its interstitial nucleus, represented by the posterior part of the ventromedial division of nucleus medialis. The nuclear differentiation in the habenula is founded quite probably on a difference in distribution of the incoming fibers but we have not as yet all the details with reference to this (see account of stria medullaris, p. 145).

Formerly Crosby ('17) identified three cell groups in the habenula of the alligator, which groups she termed the dorsal, ventral and medial nuclei of that center. These are simply other and quite as suitable names for the major portions of the medial habenular nucleus of the present account; thus, pars dorsolateralis corresponds to the dorsal, pars ventromedialis to the medial and pars ventromedialis $b$ to the ventral group. The present nomenclature was adopted to facilitate comparison with mammalian forms.

The habenula with its fiber tract, the stria medullaris, makes up the major portion of the epithalamus in the alligator. Reese ('10) has shown that there is no pineal body or epiphysis in the American alligator. He claims that the structure so termed by some observers is really a paraphysis. $\mathrm{He}$ bases his conclusions on embryological data. We have at present no material for determining the question.

\section{Preoptic region}

The anterior extension of the third ventricle known as recessus preopticus has been described for reptiles by various observers, for example by Edinger ('99, as recessus opticus) and by Röthig ('11), and is present in Alligator mississippiensis. Caudad to the tuberculum olfactorium and cephalad to the typical hypothalamic centers, the major portion of the region on either side of the recessus preopticus is termed the preoptic area (fig. 2). Its main nuclear mass consists of deeply stained cells which form the nucleus periventricularis preopticus of our terminology. Internal to these are certain more scattered, smaller and less deeply stained cells. An- 
teriorly around the ventricle and continued posteriorly along its ventral side for some distance are the densely packed and deeply staining cells (fig. 2, gr.a) which Röthig has labeled ' $a$ ' in his figures of Emys. He regards these as continuous with his pars magnocellularis of the nucleus preopticus, the homologue probably of our pars periventricularis of that nucleus. There is no sharp boundary between the hypothalamic and preoptic centers in our material other than that furnished by the characteristic linear arrangement of cells in the nucleus periventricularis hypothalami (compare figures 2 and 3 ).

\section{Area ventralis anterior}

The region dorsomedial to nucleus periventricularis preopticus and posterior to the hippocampal commissure is occupied by a scattered mass of cells which lies in part among the fibers of pars preoptica of the stria terminalis and is apparently in synaptic relation with it (figs. 2 and 3 ). The bed nucleus of the hippocampal commissure becomes more or less fused with this area. This bed nucleus in this region is really a continuation of the main nuclear mass posteriorward along the fibers of tractus cortico-habenularis medialis. In the cell preparations it can be differentiated clearly from it by the smaller type of the commissural cells. As the nucleus dorsomedialis anterior thalami appears the area ventralis anterior lies ventral to it and below the sulcus medius of the diencephalon. Nucleus ovalis is dorsolateral to the area. Farther caudad the area ventralis anterior gradually merges into a more definite, deeper staining band of cells which lies dorsal to the nucleus of the olfactory projection tract and which disappears in front of the tractus thalamo-striatalis anterior. This band of cells, designated from its shape, the area triangularis (fig. 4) lies in intimate relation with the lateral geniculate body. The functional significance of area triangularis it is impossible to determine from the preparations at present available, since they are not favorable for an understanding of its fiber connections. 


\section{Interstitial nucleus of the olfactory projection tract}

A ventromedial nucleus (fig. 3 ) at the ventromedial angle of the hemisphere has been described previously for alligator (Crosby, '17). It may be an especially differentiated portion of the nucleus of the lateral olfactory tract. Among other fiber connections it gives rise to the olfactory projection tract (figs. 19-25) a bundle of fibers which forms a connection between the posteromedial wall of the hemisphere and preoptic, hypothalamic and probably tegmental centers. This olfactory projection tract is accompanied by a well defined interstitial nucleus (figs. 3-5) which can be seen as a band of cells fusing with the ventromedial nucleus laterally. This band of cells then accompanies the fibers of the projection tract medialward and somewhat caudad, lying above the forebrain bundles and below the area triangularis.

Fig. 2 Section through the posterior part of nucleus preopticus. The plane is transverse but the ventral portion is somewhat further caudad than the dorsal portion. Toluidin blue preparation. $\times 15$. a.vent.ant., area ventralis anterior; gr.a., group a, of Röthig; bed n.hip.com., bed nneleus of hippocampal commissure; ch.op., chiasma opticum; $F . B$., forebrain bundle; n.perivent.preop., nucleus periventricularis preopticus; n.perivent.hyp., nucleus periventrieularis hypothalami; rec.preop., recessus preopticus; str., striatum.

Fig. 3 Transverse section through the extreme anterior end of nucleus dorsomedialis anterior. Nucleus ventromedialis of the hemisphere is given and its relation to olfactory projection tract and its interstitial nucleus is clearly indicated. Toluidin blue preparation. $\times 15$. a.vent.ant., area ventralis anterior; bed n.hip.com., bed nueleus of hippocampal commissure; F.B., forebrain bundle; n.ant.hyp, nucleus anterior hypothalami; n.dors.med.ant., nucleus dorsomedialis anterior; n.perivent.hyp., nucleus periventricularis hypothalami; n.vent.med., nucleus ventromedialis of the hemisphere; olf.proj.tr. + inters.n., olfactory projeetion tract and interstitial nuclous; $r$, indication of linear cell arrangement marking the beginning of the nucleus periventrieularis hypothalami; str., striatum; tr.cort.hab.lat.post, tractus cortico-habenularis lateralis posterior; tr.op., tractus opticus ; $V . I I I$, ventriculus tertius.

Fig. 4 Transverse section through the anterior end of nucleus dorsolateralis anterior. Toluidin blue preparation. $\times 15$. a.triang., area triangularis; F.B., forebrain bundle; nant.hyp., nucleus anterior hypothalami; n.dors.lat.ant., nucleus dorsolateralis anterior; n.dors.med.ant., nucleus dorsomedialis anterior; n.ov., nucleus ovalis; n.perivent.hyp., nucleus periventricularis hypothalami; olf., proj.tr. + inters.n., olfactory projection tract and interstitial nueleus; s.med., sulcus medius; st.med., stria medullaris; tr.cort.hab.lat.post., tractus corticohabenularis lateralis posterior; tr.op., tractus opticus. 

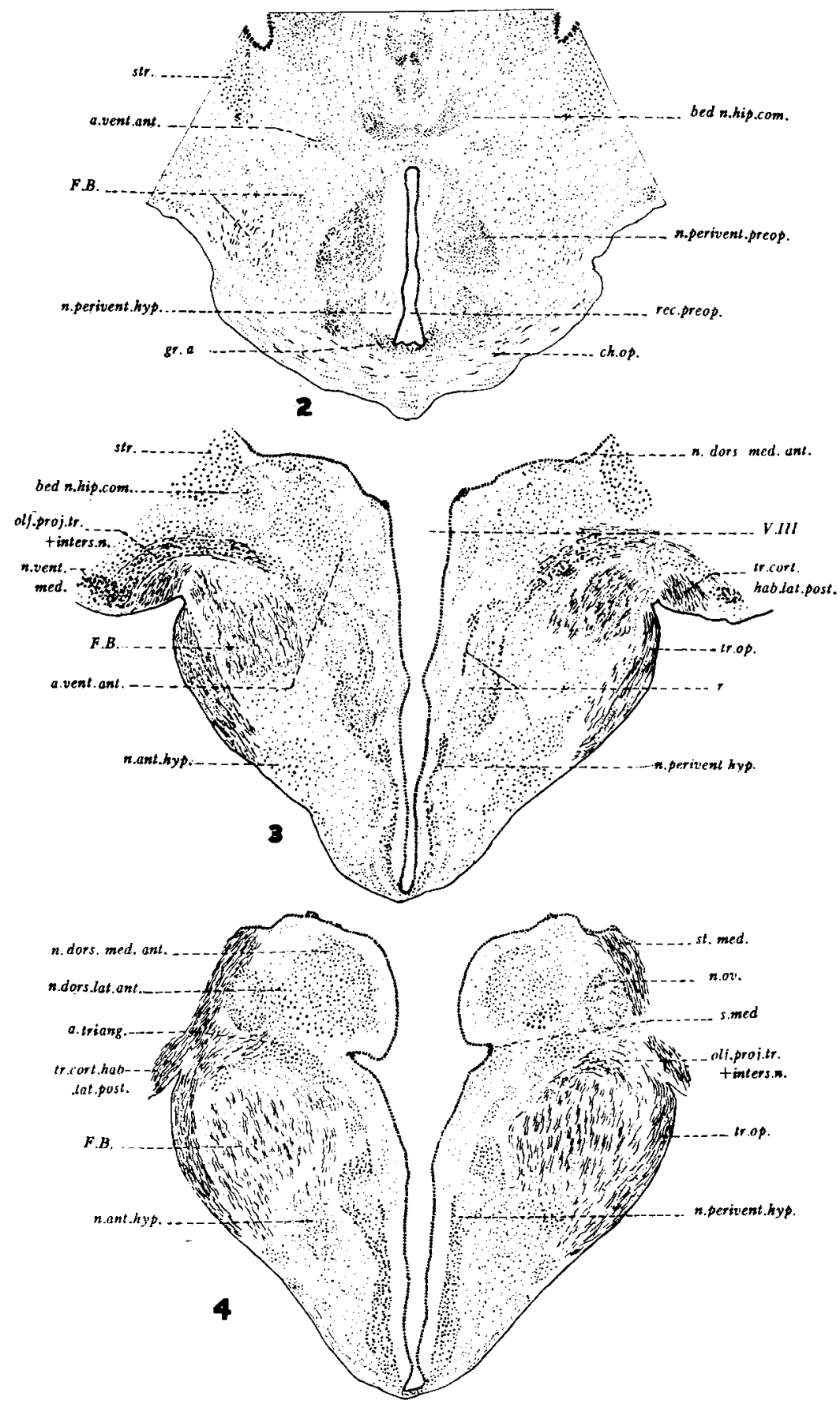
In a former communication one of us (Crosby, '17) expressed the opinion that the olfactory projection tract terminated in the hypothalamic regions. It appears to us now that it gives collaterals and probably stem fibers to both preoptic and hypothalamic area, but better sagittal sections than were previously available have convinced us that a large part of the bundle reaches mesencephalic regions, though its final termination it has not been possible to ascertain. Johnston ('15) has figured a similar condition in turtle.

\section{Nucleus dorsomedialis anterior}

Near the beginning of the diencephalon (fig. 3) the nucleus dorsomedialis anterior thalami consists of scattered cells which soon become arranged into a definite nuclear mass which occupies the more dorsomedial portion of the area, medial and ventromedial to the stria medullaris. Farther caudad this cell mass increases in size and occupies the major portion of the dorsal thalamic field and in this region presents a distinctly rounded form when viewed in cross section (fig. 4). The oval nucleus lies lateral to nucleus dorsomedialis anterior but is soon separated from it by the nucleus dorsolateralis anterior which intervenes between the two nuclear masses. Behind that level the anterior dorsomedial nucleus becomes gradually narrower and more elongated (fig. 5) and is there found to occupy, for a considerable distance, the whole of the dorsomedial field below the stria medullaris and incoming habenula and medial to nucleus dorsolateralis anterior. In our preparations, in a plane near the beginning of the habenula (fig. 6), the nucleus dorsomedialis anterior appears very indistinctly separated from the nucleus medialis anterior thalami although behind that point it is relatively distinct again. After this separation, in cross sectional view, the nucleus dorsomedialis anterior assumes a somewhat triangular form and then decreases rapidly in size and, as one approaches the region of the habenular commissure, gradually disappears (fig. 7). In this posterior region it is not clearly separable from the nuclear masses of the subhabenular area. 
A cell mass designated as nucleus anterior has been described for reptiles by a number of observers (Edinger, '99; de Lange, '11; Kappers, '21; Beccari, '23, and others). Judging from these several descriptions the nucleus may not be the same in different reptilian forms. However, the description and limits given to nucleus dorsomedialis anterior in this communication include only a part of the so-called nucleus anterior described by these observers for Crocodilia and closely related forms where presumably the condition would be much the same as in Alligator mississippiensis. Nucleus dorsomedialis anterior is, however, the same nuclear mass as that designated by Crosby ('17) as nucleus anterior. The modified name is adopted here to avoid confusion with other reptilian forms. Nucleus dorsomedialis anterior and, in part at least, nucleus dorsolateralis anterior of our nomenclature are regarded by Kappers in Crocodilus porosus ('21, p. 865, fig. 464) as a single nuclear mass and termed by him nucleus anterior. A more detailed discussion of this question is to be found under our description of nucleus dorsolateralis anterior (p. 122).

The cells of the nucleus dorsomedialis anterior are of medium size with an intermingling of some larger cells (fig. 8, b) and in the toluidin blue preparations appear oral in outline. The nuclear mass is connected with the posterior end of the striatum complex, that region which in turtle and Mammalia, according to Johnston ('23), affords in part a bed nucleus for the fibers of stria terminalis. However, this connection between the striatum and the anterior dorsomedial nucleus is by means of relatively few, short, scattered fibers; at least our material shows no well defined tract. Kappers and de Lange describe a definite strio-thalamic connection between the striatal regions of the forebrain and their anterior thalamic nucleus through the lateral forebrain bundle, and on the basis of this connection consider the anterior nucleus a part of the neothalamus. It is evident that a few fibers from both the anterior and the intermediate thalamostriatal tracts do reach the nucleus dorsomedialis anterior 
but they are certainly few in number and relatively inevident in our material. It is nucleus dorsolateralis anterior of our nomenclature (the lateral part of nucleus anterior according to the terminology of Kappers and de Lange), which receives lateral forebrain fibers. Should there prove to be in the alligator a distinct strio-thalamic or thalamo-striatal bundle associated with the nuclear mass which we have designated as nucleus dorsomedialis anterior, our material does not show it. Nucleus dorsomedialis anterior has also connections with the nucleus dorsolateralis anterior and probably with the tectum by way of the diencephalie periventricular system (p. 173). Scattered fibers from the preoptic area reach nucleus dorsomedialis anterior but in our material we have not been able to demonstrate a mamillo-thalamic tract. Kappers

Fig. 5 A typical section through the anterior portion of the diencephalon at the level of greatest development of nucleus dorso-lateralis anterior. The section shows the differentiation between nucleus dorsomedialis anterior and nucleus dorsolateralis anterior. Toluidin blue preparation. $\times 15$. a.triang., area triangularis; corp.gen.lat., corpus geniculatum laterale; F.B., forebrain bundle; hab., habenula; n.dec.supraop.dors., nucleus decussationis supraoptici dorsalis; n.dors.lat.ant., nucleus dorsolateralis anterior; n.dors.med.ant., nucleus dorsomedialis anterior; n.lat.hyp., nueleus lateralis hypothalami; n.perivent.hyp., nucleus periventricularis hypothalami; n.tr.tect.thal.cruc., nucleus tracti tecto-thalamici eruciati; olf.proj.tr. + inters.n., olfactory projection traet and interstitial nucleus; st.med., stria medullaris; tr.op., tractus opticus.

Fig. 6 Section in the transverse plane through the diencephalon just anterior to nucleus rotundus. The section is slightly further caudad on the left side. The decrease in size medialward of the nucleus dorsolateralis anterior, as the plane of the nucleus rotundus is reached (which is just making its appearance on the left side), is shown in the figure; also, the differentiation of lateral part of the nucleus dorsolateralis anterior $(b)$ is indicated. Toluidin blue preparation. $\times 15$. a.vent.lat, area ventrolateralis; a.vent.med., area ventromedialis; $b$, differentiated lateral portion of nucleus dorsolateralis anterior; com.hyp., commissura hypothalami; corp.gen.lat., corpus geniculatum laterale; F.B., forebrain bundle; hab., habenula; n.dec.supraop.dors., nueleus decussationis supraoptici dorsalis; n.dors.lat.ant., nucleus dorsolateralis anterior; n.dors.med.ant., nueleus dorsomedialis anterior; n.lat.hyp., nueleus lateralis hypothalami; n.med.ant.thal., nucleus medialis anterior thalami; n.microcell., nueleus microcellularis; n.perivent. hyp., nueleus periventricularis hypothalami; n.reuns.pars cent., nucleus reuniens pars centralis; n.reuns.pars dif., nucleus reuniens pars diffusa; n.rot., nucleus rot.undus; n.tr.tect.thal.cruc., nueleus tracti tecto-thalamiei crueiati; st.med., stria medularis; trop., tractus optieus; tr.thal.strinterm., traetus thalamo-striatalis intermedius; $\nabla . M I$, ventrieulus tertius. 

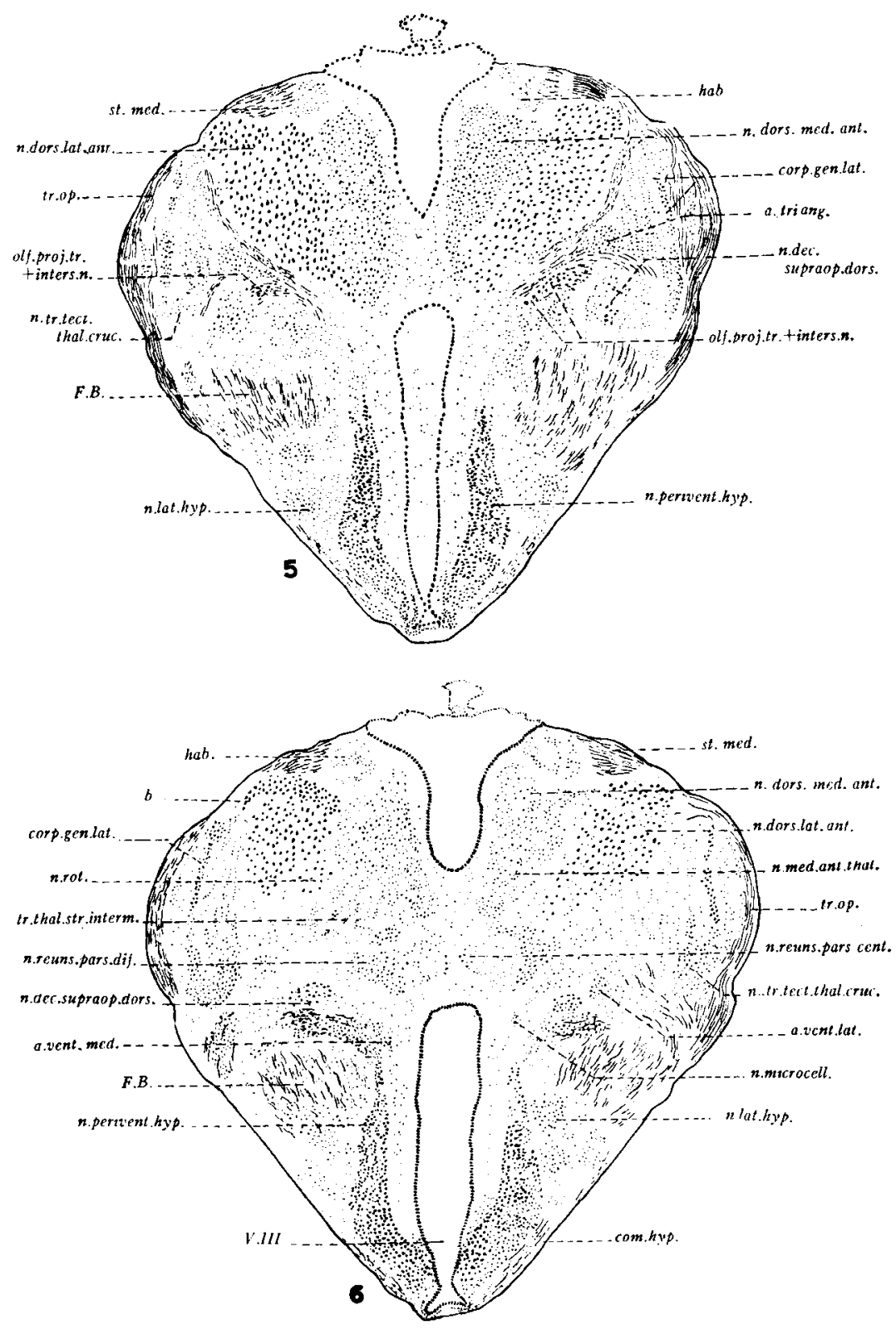


\section{has questioned the presence of this last mentioned tract in} reptiles, being apparently of the opinion that in these forms the anterior thalamic nucleus is connected more particularly

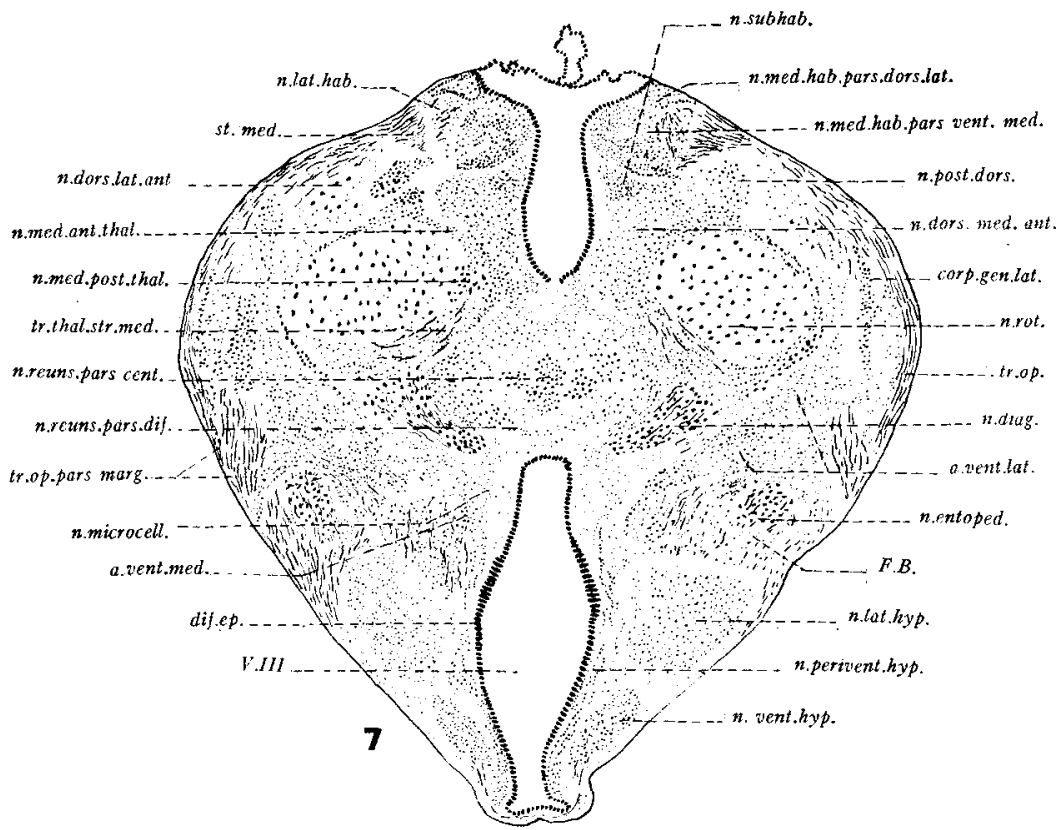

Fig. 7 A section through the middle of nucleus rotundus showing the majority of the larger nuclei of the dorsal thalamus and giving their relative positions with regard to one another. More than any other figure of the present paper this figure demonstrates the nuclear pattern of the dorsal thalamus of the alligator. Toluidin blue preparation. $\times 15$. a.vent.lat., area ventrolateralis; a.vent.med., area ventromedialis; corp.gen.lat., corpus geniculatum laterale; dif. $e p$, differentiated ependyma; $F . B$., forebrain bundle; n.diag., nucleus diagonalis; n.dors.lat.ant., nucleus dorsolateralis anterior; n.dors.med.ant., nucleus dorsomedialis anterior; n.entoped., nueleus entopeduncularis; n.lat.hab., nucleus lateralis habenulae; n.lat.hyp., nucleus lateralis hypothalami; n.med.ant.thal., nucleus medialis anterior thalami; n.med.hab.pars dors.lat., nucleus medialis habenulae pars dorsolateralis; n.med.hab.pars vent.med., nucleus medialis habenulae pars ventromedialis; n.med.post.thal., nucleus medialis posterior thalami; n.microcell., nucleus microcellularis; n.perivent.hyp., nucleus periventricularis hypothalami; n.post.dors., nucleus posterodorsalis; n.reuns.pars cent., nucleus reuniens pars centralis; n.reuns. pars dif., nucleus reuniens pars diffusa; n.rot., nucleus rotundus; n.subhab., nucleus subhabenularis; n.vent.hyp., nueleus ventralis hypothalami; st.med., stria medullaris ; tr.op., tractus opticus; tr.op.pars marg., tractus opticus pars marginalis; tr.thal.str.med., tractus thalamo-striatalis medialis; V.III, ventriculus tertius. 
with somatic centers than with olfactory or other visceral centers, although he states that there is an interconnection with the hypothalamus. However, de Lange ('13) has figured, in Draco volans, a tract which he designates as the tractus mamillo-thalamicus and which, so far as one may judge from a figure, appears to present the required relations for that tract; Edinger ('99) and Beccari ('23) have shown a similar fiber bundle in Varanus. Since de Lange and Beccari include both the nucleus dorsomedialis anterior and the nucleus dorsolateralis anterior of our terminology under the name of nucleus anterior one can not state positively with which of the two former nuclear groups the mamillo-thalamic tract is connected, if present. From their illustrations it appears to be related with nucleus dorsomedialis anterior. So far as we know, the direction of conduction has not been checked for reptilian forms. Nucleus dorsomedialis anterior is related further by short, scattered fibers with the neighboring thalamic nuclei, particularly with nucleus dorsolateralis anterior and nucleus medialis.

\section{Subhabenular region}

In Draco volans and some other reptiles a small nucleus has been described, lying between the habenula and the nucleus dorsomedialis anterior. From the size of its cells this nucleus was termed by de Lange ('13) nucleus magnocellularis. Kappers ('21) has designated the area as regio subhabenularis. In the alligator this region under the habenula is occupied by more than one cell group; the anterior portion has a small, deeply staining nuclear mass whose cells, in our material, are of medium size, but which probably corresponds with the nucleus magnocellularis described for other reptiles by de Lange. We have termed it the nucleus subhabenularis (fig. 7). It may represent only a differentiated portion of the nucleus dorsomedialis anterior thalami, with which it lies in intimate relation.

The posterior part of the region between the above described nucleus and the beginning of the posterior commis- 


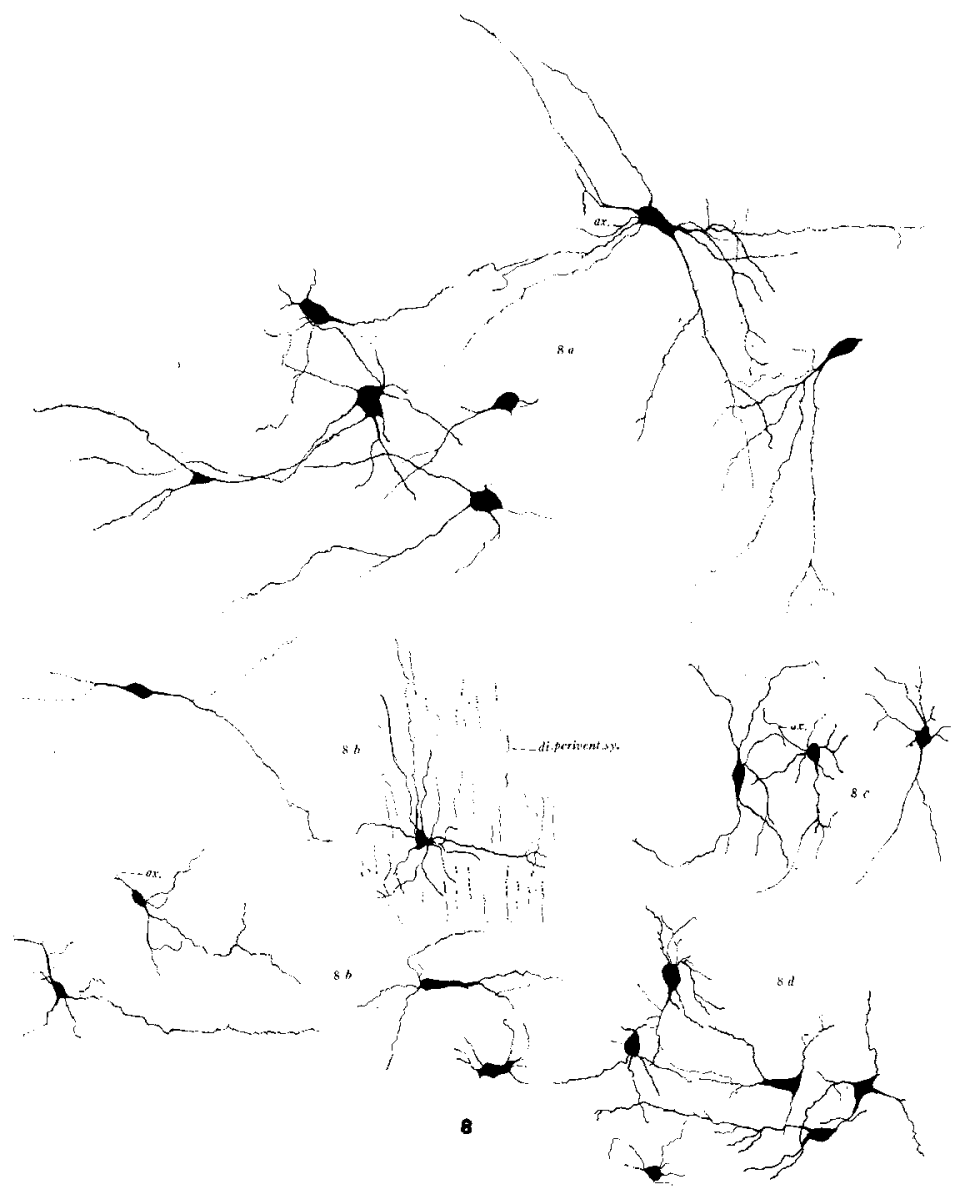

Fig. 8 Neurons drawn from material prepared aceording to the Golgi impregnation method. The purpose of the illustration is to contrast the various neuron types found in four main nuclear masses of the dorsal thalamus. $\times 120$.

a. This figure indicates the cell character of nucleus dorsolateralis anterior. All the neurones here shown were impregnated in one section of the nucleus and were drawn under the camera lucida in their relative positions. The axone (ax.) indicated appears to become a part of the tractus thalamo-striatalis anterior. The wide spread of the dendrites should be noted, some of these processes extending even into the region occupied by the cell bodies of nucleus dorsomedialis anterior and there coming into synaptic relation with fibers of the diencephalic periventricular system.

b. The neurons of nucleus dorsomedialis anterior are shown here. A comparison with (a) will show that there is a striking difference in shape and size of the cells of nucleus dorsolateralis anterior and nucleus dorsomedialis anterior. 
sure is occupied by a mass of scattered cells which goes over without break into the more definitely organized periventricular gray of the mesencephalon. From its shape we have termed it nucleus angularis subhabenularis (fig. 9). Nothing at present is known of its functional significance.

\section{Oval nucleus}

Near the anterior end of the diencephalon is a distinct, deeply staining but relatively small group of cells, the somewhat round or oval shape of which has suggested the name we have applied to it. The oval nucleus (figs. 4 and 19) lies between the tractus cortico-habenularis lateralis posterior and the stria terminalis. Fibers from the preoptic regions to the stria medullaris (tractus olfacto-habenularis medialis) pass partly dorsal to it and in part appear to enter it and intermingle with its cells. We do not have direct evidence that actually synapses with its cells occur, although our material certainly suggests it. Similarly, collaterals from tractus cortico-habenularis lateralis posterior turn in toward the cells of the oval nucleus.

\section{Corpus geniculatum laterale}

Just caudad to the oval nucleus and in somewhat the same relative position is a mass of cells which constitutes the main optic center in the reptilian thalamus. This is the lateral geniculate body which has been identified by various students of the reptilian brain, including Bellonei ('88), C. L. Herrick ('93), Edinger ('99 and '08), de Lange ('13), Kappers ('21),

Note the relation of the dendritic processes to the fibers of the diencephalic periventricular system (di.perivent.sy.).

c. The cells of pars centralis of nucleus reuniens are shown in the drawing. This nucleus was not richly impregnated in our preparations and it may well have cell types additional to those illustrated here. The axone (ax.) becomes a part of the tractus thalamo-striatalis internus.

d. A comparison of this figure with that of (b) shows that in many ways the cells of nucleus rotundus resemble those of nucleus dorsolateralis anterior. Our preparations show a relatively shorter spread of dendrites, however, in the cells of nucleus rotundus. 
Beccari ('23) and others. Anteriorly it begins just behind the level of the oval nucleus (fig. 5) lying ventrolateral to nucleus dorsolateralis anterior and dorsolateral to the olfactory projection tract and the lateral forebrain bundle and medial to the marginal optic tract. From this anterior region it extends back to a cross sectional level through about the middle of the habenula, occupying, throughout its course, approximately the same position. Its extent is indicated in part in figure 16.

The optic tract fibers enter the lateral geniculate body from both its medial and lateral borders (figs. 19-22), a smaller bundle breaking off from the main tract to enter the nuclear mass on the ventral and medial sides. From the more dorsal portion of the nucleus extends the ventrolateral tecto-thalamic tract (figs. 21-22). This tract, which extends to the tectum and probably conducts in both directions, in so far as it is related to the lateral geniculate body, may be regarded as functionally homologous with the mammalian brachium of the corpus quadrigeminum anterius or the peduncle of the superior colliculus, but the tract carries with it fibers related to other thalamic centers as well (see account of tract on p. 180).

The lateral geniculate body consists of a dense, deeply staining, perpendicular band of cells (figs. 5-7, 16) surrounded on either side by more scattered cell masses of which the outer portion is the stratum moleculare of Beccari ('23). The cells of the nucleus are of medium size; those of the central band staining very deeply in toluidin blue preparations. This is the band of cells concerning which Beccari speaks as consisting of 'cellule a dippio pennacchio.' The extension of the dendritic processes of this layer in the two directions had previously been noted by Edinger ('08) and Cajal ('11) and is apparent in our Cox preparation for Alligator mississippiensis.

The preceding description indicates that the lateral geniculate body is very large in reptiles and that it extends throughout the major portion of the thalamus. This relatively large 
size of the nucleus is undoubtedly to be associated with the great number of incoming optic fibers and the high degree of differentiation of the optic tectum in these forms. Two more or less separate cell groups are associated with the main nuclear mass of corpus geniculatum laterale.

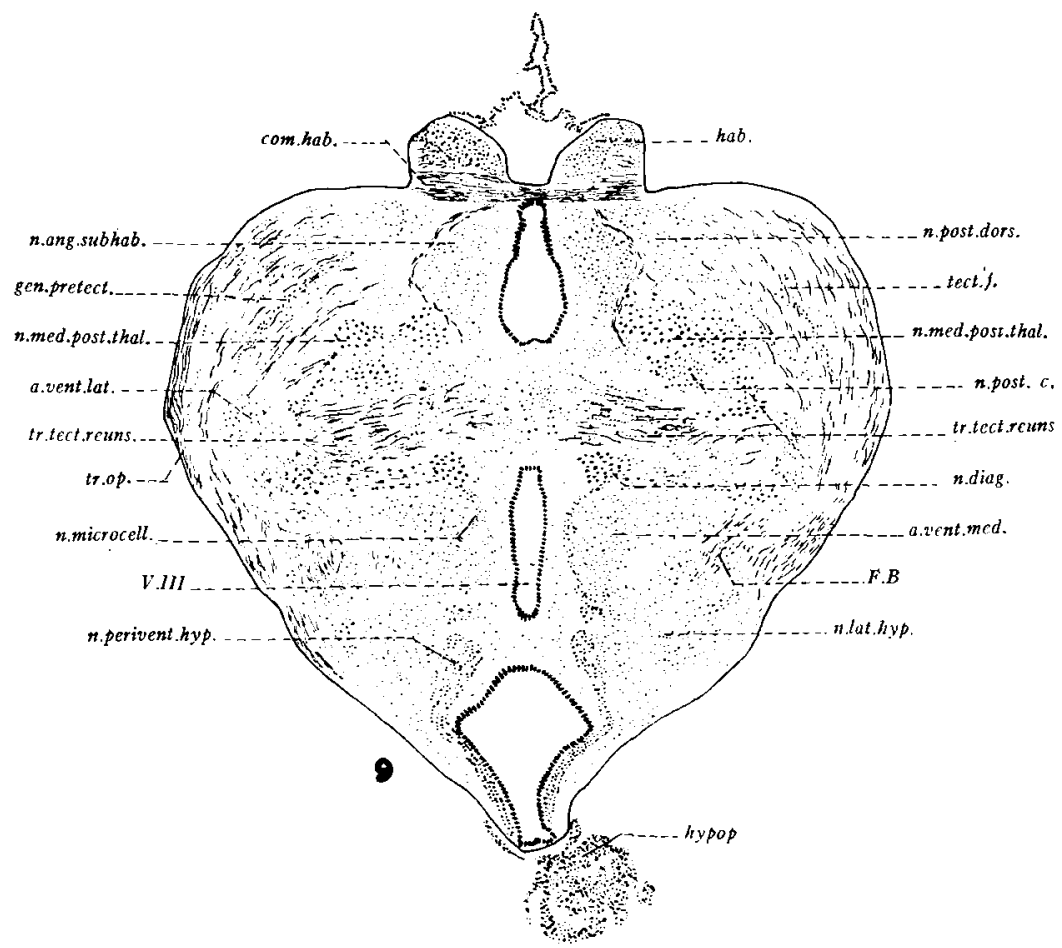

Fig. 9 Transverse section showing the positions of nucleus medialis posterior and nucleus posterocentralis. On the right side may be seen two portions of the nucleus diagonalis separated by the fibers of tractus tecto-reuniens. The two portions of this nucleus are continuous with each other at a plane slightly in front of the level of the present figure. Toluidin blue preparation. $\times 15$. a.vent.lat., area ventrolateralis ; a.vent.med., area ventromedialis; com.hab., commissura habenularum; F.B., forehrain bundle; gen.pretect., geniculato pretectale of Beccari; hab., habenula; hypop., hypoplysis; n.ang.subhab., nucleus angularis subhabenularis; n.diag., nucleus diagonalis; n.lat.hyp., nucleus lateralis hypothalami; n.med.post.thal., nucleus medialis posterior thalami; n.microcell., nucleus microcellularis; n.perivent.hyp., nucleus periventricularis hypothalami; n.post.c., nucleus posterocentralis ; n.post.dors., nucleus posterodorsalis ; tect.f., tectal fibers, including fibers of the supraoptic system; tr.op., tractus opticus; tr.tect.reuns., tractus tecto-reuniens; $V . I I I$, ventriculus tertius. 
The first of these, the area triangularis, lies in the region just anterior to the separation of the anterior thalamostriatal path from the remainder of the forebrain bundle, and bounds the lateral geniculate on its medial border. This area (figs. 4 and 5) appears as a more differentiated mass of cells intimately associated with area ventralis anterior on the one hand and quite as indefinable from corpus geniculatum laterale on the other. Both fiber and cell material, at present at our disposal, are inadequate for deciding the function of this cell group.

The second cell mass (figs. 5, 6, 22) associated with the lateral geniculate body, possibly to be considered a differentiated portion of that mass, is the nucleus of the crossed tectothalamic path. This nuclear group consists of a round mass of cells just ventral to the lateral geniculate body and intermingled somewhat with the scattered cells of its stratum moleculare but exhibiting none of the linear arrangement characteristic of that nucleus. As the name implies, it is in synaptic relation with the tractus tecto-thalamicus cruciatus; it also is related to tractus tecto-thalamicus ventrolateralis.

\section{Nucleus dorsolateralis anterior}

In the figures of Alligator sclerops and Crocodilus porosus Kappers ('21) evidently considers the main portion of the dorsal region in the cephalic end of the thalamus (dorsomedial to the lateral geniculate body and back to about the level of the nucleus rotundus and the nucleus medialis) as occupied by the nucleus anterior. In the cell material which we have for Alligator mississippiensis the region is occupied medialward by the smaller-celled nucleus dorsomedialis anterior and lateralward by a pyramidal celled nucleus which we had previously termed nucleus lateralis. The nucleus lateralis of that account included, however, both nucleus dorsolateralis anterior, and in part, nucleus rotundus of the present nomenclature, and on that basis was regarded as under the influence of somatic systems ascending from lower centers, either directly by lemniscus systems or indirectly 
by way of the tectum. A more detailed analysis of the fiber connections and some relatively slight nuclear differentiation have led us to divide the group into a posterior nucleus rotundus particularly closely associated with the tectum and possibly receiving directly trigeminal lemniscus fibers and an anterior nucleus dorsolateralis anterior which has a much less evident tectal connection and no direct lemniscal connection in our material. Both nucleus rotundus and nucleus dorsolateralis anterior receive a tract from the forebrain bundle. We have dropped the term nucleus lateralis since various observers have used this name for different nuclear masses within the reptilian thalamus. Moreover we are not prepared at present to state that the nucleus dorsolateralis anterior of our terminology is the homologue of the mammalian nucleus lateralis, though this is possible. That it may be the equivalent of some avian nucleus or represent the somatic part of nucleus anterior deserves more special consideration. We are prepared, however, to maintain that it represents in cell type and fiber connections as distinct an entity as compared with the nucleus dorsomedialis anterior as does any nuclear group within the reptilian thalamus. As a matter of fact, so far as similarity in connections and cell types are taken as criteria, it bears much more resemblance to nucleus rotundus and is much more intimately associated with that nuclear mass than with nucleus dorsomedialis anterior. The broad connection of nucleus dorsolateralis anterior with the lateral areas of the forebrain leaves no doubt that it belongs to the somatic thalamus (see discussion, p. 220).

Nucleus dorsolateralis anterior begins near the anterior end of the diencephalon (fig. 4) and has a position medial to the lateral geniculate body from which latter cell mass it is separated for a considerable distance by tecto-thalamic paths. In its cephalic portion it is irregularly triangular in shape as seen in cross sectional view. At first it is in close apposition with the nucleus dorsomedialis anterior thalami and distinctly lateral to it. The difference in cellular characteristics of the two nuclei makes them easily distinguishable from 
each other (compare fig. 8, a and b). The cells of the anterior dorsomedial nucleus in toluidin blue preparations, as was previously stated, appear mainly round or oval in outline; those of nucleus dorsolateralis anterior have in the same preparations a triangular or pyramidal shape and are larger. Gradually the nucleus dorsolateralis anterior begins to occupy a larger percentage of the dorsal portion of the thalamus and there is an extension of it medialward so that it reaches the ventromedial part of the dorsal thalamic region (fig. 5). Nucleus dorsolateralis anterior also extends dorsolaterally (figs. 5-6). This extension occurs as the optic tract, on its way to the tectum, swings lateral to the nucleus. The cells in the extension, while obviously of the same type and apparently belonging to nucleus dorsolateralis anterior, exhibit a certain massing which is suggestive of future nuclear differentiation. Furthermore this region appears to receive terminal fibers and collaterals from the optic tract. This differentiated portion of the nucleus dorsolateralis anterior may be forecasting an optic thalamic center of higher forms.

Gradually the cells of the ventromedial portion of nucleus dorsolateralis anterior become more scattered (fig. 6) and ultimately disappear as the fibers from the lateral forebrain bundle for nucleus rotundus reach the region (fig. 6). Laterally the nucleus dorsolateralis anterior persists as far caudad as the anterior portion of the nucleus rotundus (fig. 7). In the character of the individual cells the two nuclei greatly resemble each other, although the cells of nucleus dorsolateralis anterior are the more closely packed together. (Comparison of the two nuclei should be made in figs. 7, 8, a and d, and 11).

\section{Nucleus rotundus}

Judging from the descriptions and figures in the literature and from our own preparations of alligator and turtle, nucleus rotundus forms a prominent mass of cells in the brains of many reptiles. The first account of the reptilian nucleus rotundus of which we are aware is that given by Stieda ('75) 
who figures such a nucleus in Varanus and describes it as 'einen kugelrunden Complex.' He apparently recognized its interrelation with the forebrain through what we now regard as the lateral forebrain bundle, if one may judge from the illustrations and the incomplete account which he gives. Other early workers (C. L. Herrick, '91, and Humphrey, '94)

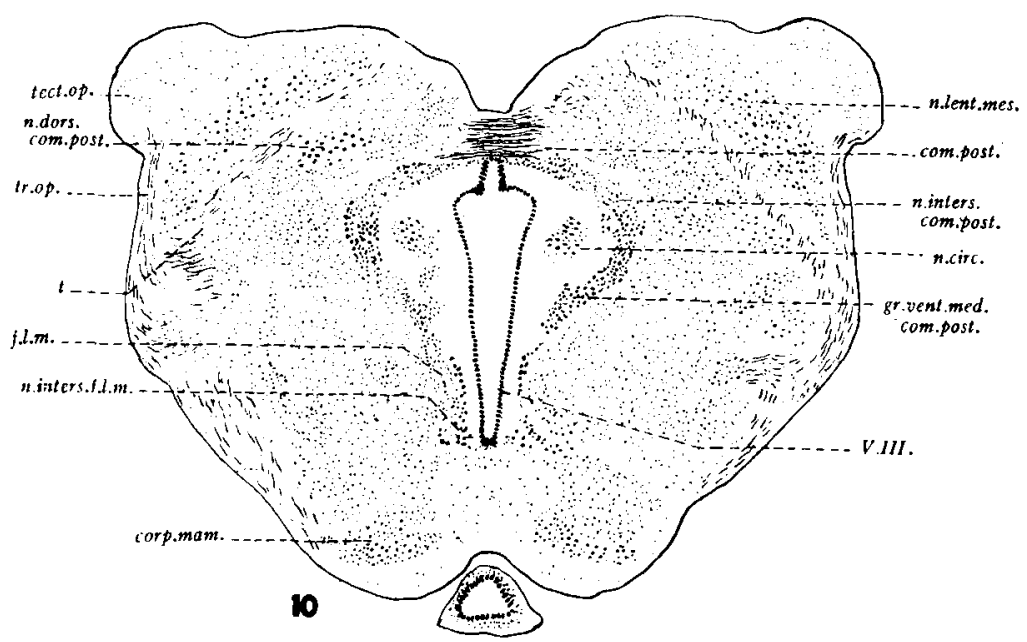

Fig. 10 Transverse section stained with toluidin blue; designed particularly to show nucleus dorsalis commissurae posterior and nucleus lentiformis mesencephali. $\times 15$. com.post., commissura posterior; corp.mam., corpus mamillaris; f.l.m., fasciculus longitudinalis medialis; gr.vent.med.com.post., ventromedial group of interstitial nucleus of the commissura posterior; n.circ., nucleus circularis; n.dors.com.post., nucleus dorsalis commissurae posterioris; n.inters.com.post., nucleus interstitialis commissurae posterioris; n.inters.f.l.m., nucleus interstitialis fasciculi longitudinalis medialis; n.lent.mes., nucleus lentiformis mesencephali; $t$, optic fibers intermingled with other tectal fibers turning medialward toward the tectum; tect.op., tectum opticum; tr.op., tractus opticus; V.1II, ventriculus tertius.

evidently recognized its presence although they described it under other names. Edinger ('08), de Lange ('13) and Kappers ('21) located this nucleus in Alligator lucius, Alligator sclerops and Crocodilus porosus respectively, where presumably the conditions are most nearly analogous with those found in Alligator mississippiensis. In these forms the nucleus is found near the middle of the diencephalon. It is re- 
garded by de Lange as the homologue of the whole and by Kappers as probably a part (nucleus medialis b) of the nucleus medialis of Mammalia (see discussion, p. 219).

Nucleus rotundus is clearly present in our material (figs. $7,11,16,17,18,22$ ) as a very evident, spherical mass of cells whatever the plane of the section. As in related reptilian forms, it appears in the middle regions of the diencephalon. It consists of large cells (fig. 8, d) similar in type to those of nucleus dorsolateralis anterior, from which it is not clearly separate at its anterior border. It receives a distinct component from the lateral forebrain bundle, the fibers of which surround as well as enter the cell mass and help to give it its characteristic shape. Associated with it, probably to be considered a part of it, is nucleus medialis posterior (figs. 7 and 9).

\section{Nucleus medialis}

Nucleus rotundus is surrounded on all sides by nerve cells intermingled with ineoming fibers of the lateral forebrain bundle (figs. 7, 11, 16,17, 18 and 22). These outer cells group into two main nuclear masses, a smaller-celled nucleus which we have termed nucleus medialis anterior and a larger-celled group designated as nucleus medialis posterior. Kappers ('21) figured a nucleus medialis in Crocodilus.

Nucleus medialis anterior (figs. 6, 7, 11, 16). This nucleus is first seen as a group of medium sized and deeply staining cells overlapping nucleus rotundus anteriorly and then collecting into a rather densely packed nuclear mass, dorsal and dorsomedial to nucleus rotundus. In this portion it is ventrolateral to nucleus dorsomedialis anterior thalami and not sharply differentiable from that cell group. Gradually it assumes a $V$-shape (fig. 7) with the point of the $V$ extending toward the ventricle and the nucleus rotundus lying between the extended arms, the two arms of the $\mathrm{V}$ being connected on the lateral side of nucleus by scattered cells. Further caudad, at a plane somewhat in front of the habenular commissure, nucleus medialis posterior makes its appearance as 
a large-celled nuclear mass near the inner angle of the $V$ between the cells of nucleus medialis anterior and nucleus rotundus (fig. 7). Tractus thalamo-striatalis intermedius (p. 153) connects nucleus medialis anterior with the striatum. It may also receive some fibers from tractus thalamostriatalis medialis.

Nucleus medialis posterior (figs. 7, 9, 11 and 16). Nucleus medialis posterior replaces nucleus medialis anterior and occupies the same relative position as did the latter farther cephalad; that is, it too forms a V-shaped mass of cells in the angle of which lies nucleus rotundus. Nucleus medialis posterior and nucleus rotundus are thus in intimate association with each other, consist of the same type of cells and possibly could be considered divisions of the same nuclear mass. Nucleus medialis posterior lies at first medial to the main mass of nucleus rotundus (fig. 7) but when the posterior end of that nuclear mass is reached, the former nucleus swings immediately posterior to the latter and forms a rather conspicuous, large celled group in this region of the thalamus (figs. 9, 11). One might consider the nucleus medialis posterior as forming a thickened capsule of nerve cells posteromedially around the main mass of nucleus rotundus. The striatum and the nucleus medialis posterior are connected by the tractus thalamo-striatalis medialis ( $p .153$ ); the tectum and the nucleus by the medial tecto-thalamic tract (p. 178).

\section{Nucleus reuniens}

The nucleus reuniens was described first for reptiles by Rabl-Rückhard who in $\mathbf{1 8 9 4}$ gave an account of it as observed in the snake. A brief description of it in several reptiles, including Alligator, was given by Edinger ('99). He states in regard to it: "Beim Alligator und Krokodil liegt nun mitten in den relativ sparlichen Nervenzellen, welche sich hier in der Bruche befinden ein mächtiger wohl abgeschlossener Kern, der Nucleus reuniens." He refers here evidently" to the pars centralis of our description. Our pars diffusa we believe to be a part of Edinger's nucleus diffusus but a 


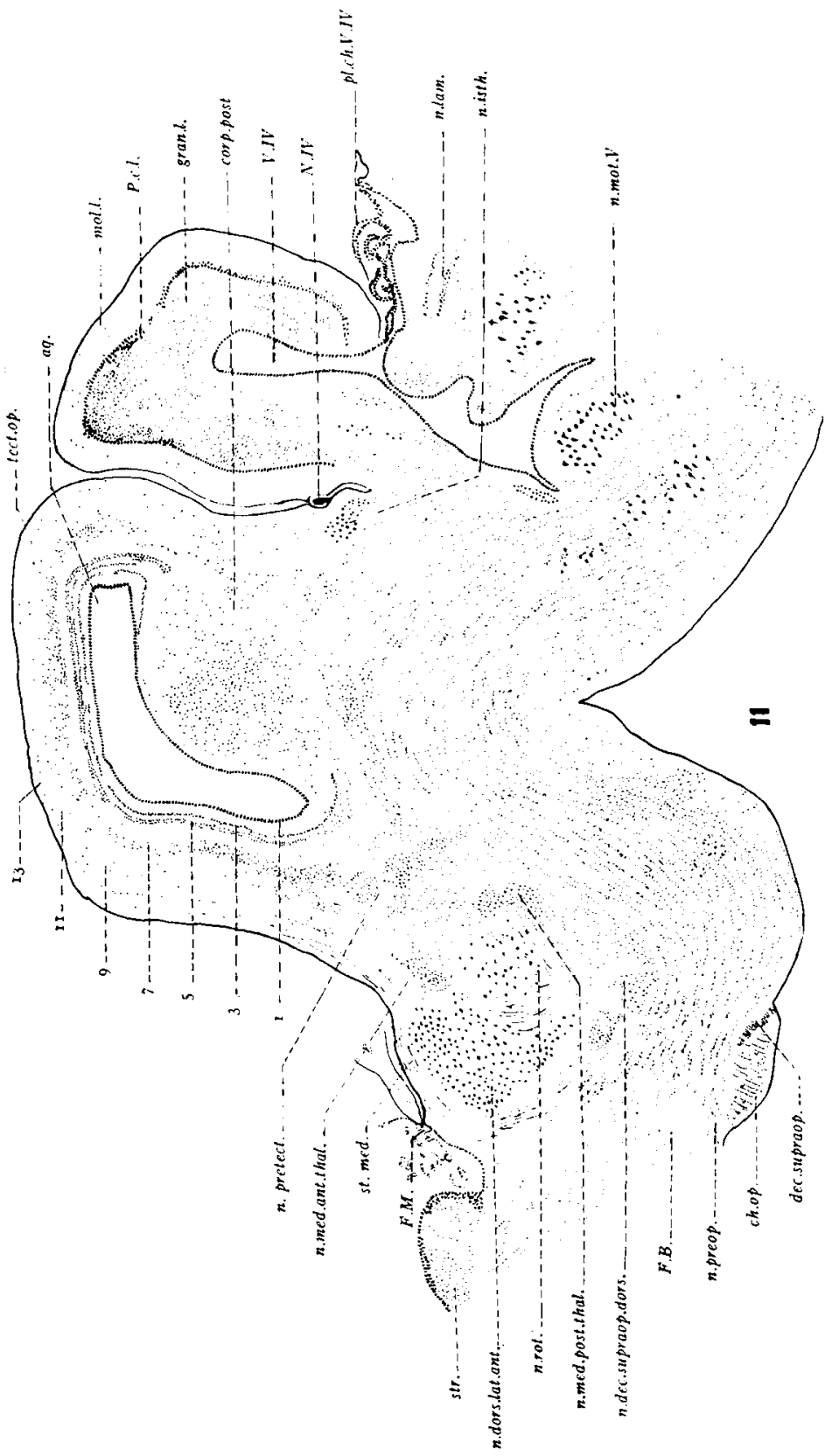


much more limited cell mass than the one so designated by him. Many other workers on Reptilia have figured nucleus reuniens, including Kappers ('21) and Beccari ('23). It is particularly well developed in crocodiles and alligators but appears to be absent in turtles.

Nucleus reuniens (figs. 6, 7,9 and 22) in the alligator consists of a main, more dense cellular core surrounded more or less completely by scattered cells which extend outward toward nucleus medialis anterior and posterior and nucleus diagonalis. The main core of cells we have termed pars centralis of nucleus reuniens while, for lack of a better name, we have called the scattered cells the pars diffusa of that nucleus.

Pars centralis appears cephalad in front of the level of the habenular commissure. As followed in transverse series, it is at first a rounded mass of cells in the midline between the two dorsal thalami. It lies slightly ventromedial to the medial nuclei of either side and is separated from those nuclei in front by pars diffusa and tractus thalamo-striatalis medialis (fig. 7). Behind the level of that tract, it is separated from both the posterior medial thalamic nucleus and nucleus diagonalis by the pars diffusa of the nucleus reuniens. Gradually the pars centralis elongates, becomes oblong in outline and occupies a considerably larger field. Farther

Fig. 11 This figure is from a sagittal series stained with toluidin blue. $\times 15$. The section is taken through the level of the foramen of Monro (F.M.) and sufficiently far lateralward to show the relations of nucleus dorsolateralis anterior and nucleus rotundus. In this and in a number of the following figures a part (or in some cases all) of the layers of the optic tectum are numbered, following the nomenclature of Cajal ('96) for chameleon (footnote, p. 143). aq., aqueduct; ch.op., chiasma opticum; corp.post., corpus quadrigeminum posterius; dec. supraop., decussatio supraoptica; F.B., forebrain bundle; F.M., foramen of Monro; gran.l., granular layer; mol.l., molecular layer; n.dec.supraop.dors., nucleus decussationis supraopticae dorsalis; n.dors.lat.ant., nucleus dorsolateralis anterior; n.isth., nueleus isthmi; n.lam., nucleus laminaris (of VIII); n.med. ant.thal., nucleus medialis anterior thalami; n.med.post.thal., nucleus medialis posterior thalami; n.mot.V, nucleus motoris $\mathrm{V}$; n.preop., nucleus preoptieus; n.pretect., nucleus pretectalis; n.rot., nueleus rotundus; $N . I V$, IV th nerve; P.c.l., Purkinje cell layer; pl.ch.J.IV, plexus choroideus ventriculi quarti; st.med., stria medullaris; str., striatum; tect.op., tectum opticum; $V . I V$, ventriculus quartus. 
caudad the cells of the more ventral portion become scattered and merge ultimately into pars diffusa. Shortly behind this region the remainder of pars centralis disappears. The cells of this portion are more closely packed and some of them appear slightly angular in the toluidin blue preparations.

As stated before, pars diffusa consists of scattered cells between the pars centralis of nucleus reuniens on the one hand and the nuclei medialis anterior and posterior on the other. The cells of that portion are slightly smaller and probably more nearly round in cell outline. In general there is little evidence of cellular arrangement, although one or two small groups, the significance of which at present is not known, may be seen.

Nucleus reuniens, particularly pars centralis, receives thalamo-striatal fibers from the lateral forebrain bundle. It also is related with the tectum by means of a relatively large fiber tract, the tecto-reuniens. Specific connections to the pars diffusa have not been established. Probably it receives the same type of incoming impulses and sends fibers to the same tracts as does pars centralis.

\section{Nucleus posterocentralis}

In our preparations, nucleus posterocentralis (fig. 9) appears at first ventral to nucleus medialis posterior and in close relation with that nuclear mass. The two are distinguishable from each other by a slight but evident difference in cell character and cell staining. When the posterior limit of the nucleus medialis posterior is reached, the nucleus posterocentralis gradually swings dorsalward and occupies the central portion of the dorsal field in this region.

Nucleus posterocentralis is probably the nucleus lentiformis of Kappers ('21) and the nucleus lentiformis thalami of Beccari ('23). There is sufficient difference in the form relations of Varanus and Alligator mississippiensis so that one must have regard here for a possible mistake in homology. Nucleus posterocentralis most certainly is not the nucleus lentiformis described by Edinger ('99) and de Lange 
('13) nor the nucleus lentiformis mesencephali of Beccari ('23). The nucleus lentiformis of Edinger and de Lange we have described under the same name (see p. 137). Consequently we wish to avoid the use of the term for the present nuclear mass. Nucleus posterocentralis appears to us to be homologous with the nucleus posterior figured by Cajal ('11, p. 400 , fig. 261) for rabbit. However, the term nucleus pos-

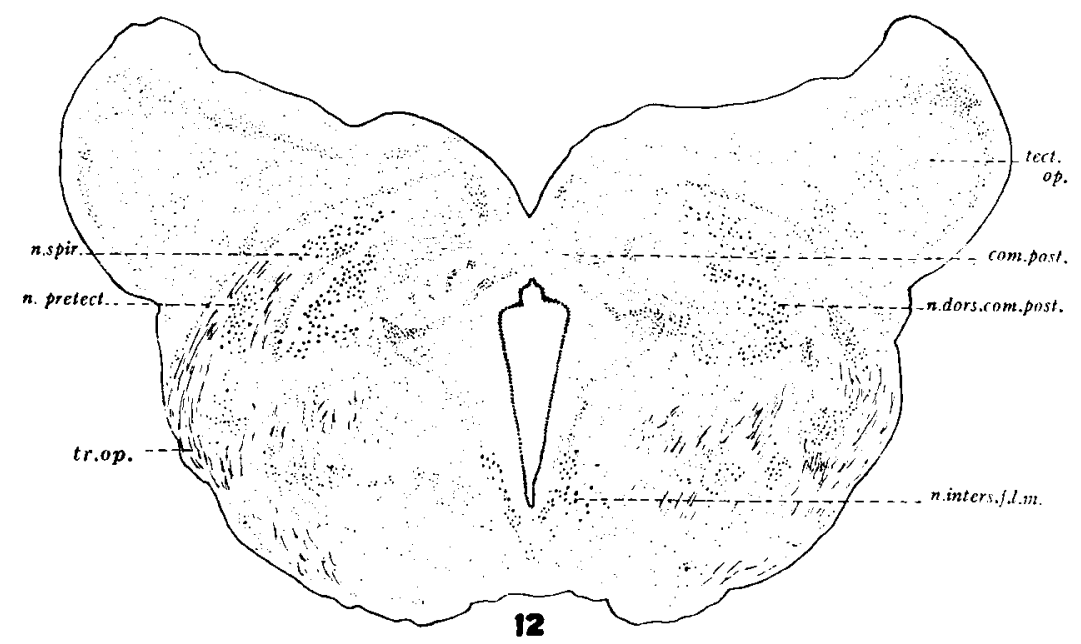

Fig. 12 Transverse section showing particularly nucleus dorsalis commissurae posterioris. The positions of nucleus pretectalis and of nucleus spiriformis (Edinger, '08) should be noted. Toluidin blue preparation. $\times 15$. com.post., commissura posterior; n.dors.com.post., nucleus dorsalis commissurae posterioris; n.inters.f.l.m., nueleus interstitialis fasciculi longitudinalis medialis; n.pretect., nucleus pretectalis; n.spir., nucleus spiriformis; tect.op., tectum opticum; tr.op., tractus opticus.

terior has been applied to nucleus pretectalis by Bellonci ('88) and other workers on reptilian brains. Therefore to avoid confusion we have adopted a new name for the cell mass, that of nucleus posterocentralis.

\section{Area ventrolateralis}

Kappers ('21) has figured in Crocorlilia the region ventral and ventrolateral to nucleus rotundus and medial to the lateral geniculate body as occupied by the nucleus ventrolateralis 
(figs. 7 and 9). On the basis of its position he regards this cell mass as the homologue of the combined nucleus lateralis and nucleus ventralis of Mammalia. The area in our preparations is occupied chiefly by fiber tracts with some intermingled cells and in the alligator does not show any distinct nuclear pattern. However, there is in the more ventral part of the area, a rather loosely arranged group of cells which forms a more or less definite nuclear mass; the cells being in part in linear arrangement horizontally across the field, suggesting accompanying fiber paths. From this relatively more compact nuclear group scattered cells, intermingled with many fibers (in part, tecto-thalamic paths), extend dorsalward between nucleus rotundus and the lateral geniculate body. The cells are of medium size and resemble somewhat, in the toluidin blue preparations, the cell staining and outline of the last mentioned nucleus. If this area is to be regarded as the homologue of nucleus ventralis and particularly nucleus lateralis as Kappers thought, these nuclei are certainly not well differentiated in Alligator mississippiensis. It would seem to us that such a homology was at least open to serious question.

\section{Area ventromedialis}

The area ventromedialis (figs. 7 and 9) lies dorsal to the medial forebrain bundle. It appears at first as a small round mass of cells about the level of the anterior end of nucleus reuniens. It increases in size caudalward and ultimately consists of a mass of medium sized cells intermingled and bordered on the medial side by very tiny cells. These small cells (nucleus microcellularis, figs. 7 and 9) on the medial side increase in number and ultimately connect the nucleus ventromedialis proper with the hypothalamic periventricular nucleus. The ventromedial area disappears at a plane through about the middle of the posterior commissure. It probably includes, in part at least, the interstitial nucleus of the fasciculus geniculatus descendens (Beccari, '23). Behind this level the cells of nucleus microcellularis become scattered and gradually disappear from the field. 


\section{Nucleus diagonalis}

Nucleus diagonalis (figs. 7 and 9) begins anteriorly in Alligator mississippiensis as a small mass of cells just ventrolateral to the cephalic portion of nucleus reuniens. As one follows the nucleus diagonalis caudad it becomes somewhat elongated or comma shaped, with the thicker portion in the original position and the curved part extending dorsolateralward. The lateral portion then increases in size and becomes round in outline with a more scattered cell arrangement due to the intermingling of fibers and cells. As this lateral extension of the nucleus increases in size it lies at first ventromedial to the medial thalamo-striatal component of the lateral forebrain bundle (fig. 7). Gradually it becomes separated from the more medial portion of the nucleus, which latter portion maintains its original position until ultimately it consists of two parts separated by the tractus tectoreuniens; after this the two portions diminish rapidly in size, lose their characteristic deep staining qualities and disappear.

There is evidence, not completely satisfactory, that the nucleus diagonalis is related to pretectal or possibly tectal centers by a fiber tract which swings dorsolaterally, ventrolateral to the nucleus rotundus, and joins the ventrolateral tectothalamic path. The sweep of the fibers is best seen in the cell preparations. The medial portion of the nucleus appears to receive or to give fibers to the tractus tecto-reuniens. In general the cells of the nucleus diagonalis take a deep stain in the toluidin blue preparations and are pyramidal or triangular in outline.

\section{Nucleus posterodorsalis}

Just ventrolateral to the habenula, dorsal to the posterior portion of nucleus dorsolateralis and dorsolateral to nucleus medialis anterior is a small nuclear mass which is termed, for the present, nucleus posterodorsalis (figs. 7 and 9). Cephalad it begins slightly in front of the habenular commissure and is present throughout most of the extent of that tract. 


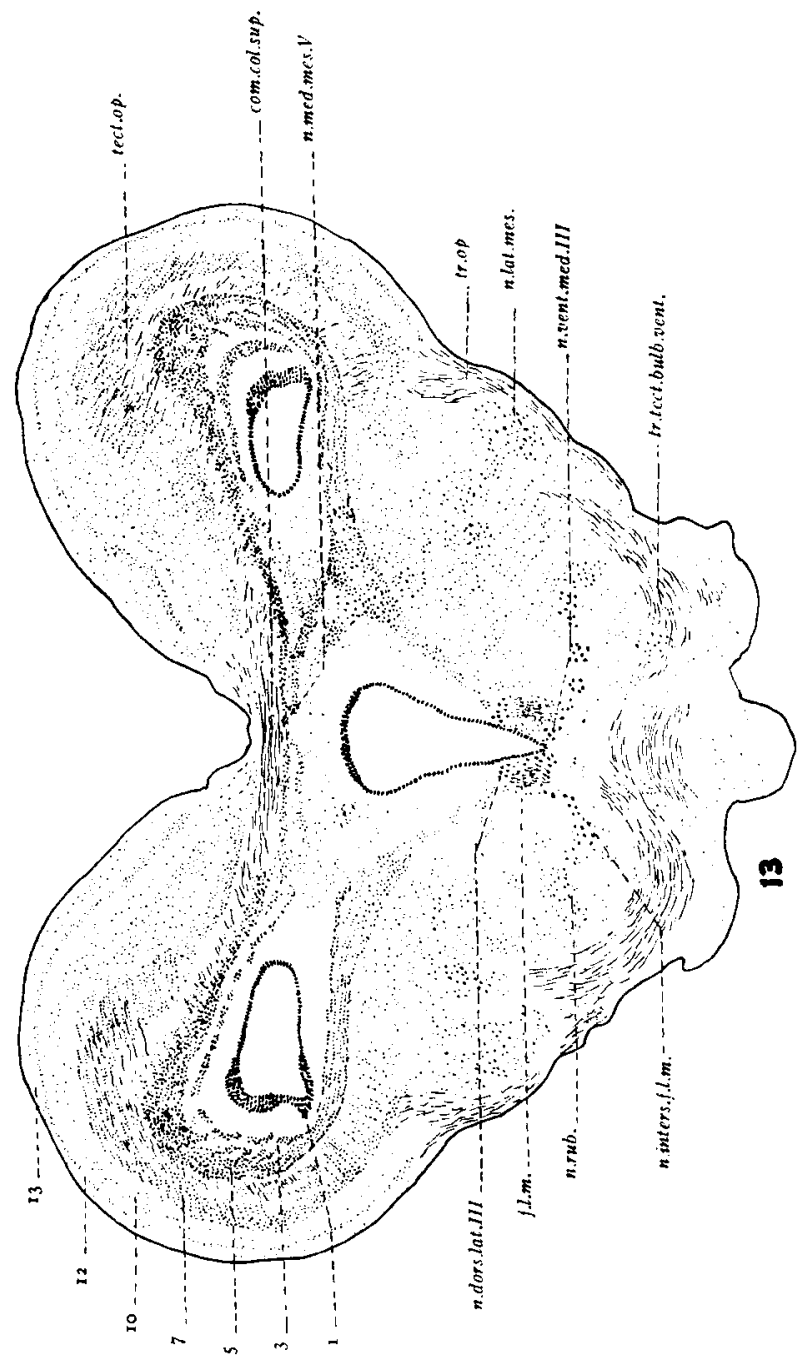


It is a small nuclear mass of round form and consists of cells which resemble those of nucleus medialis anterior with which it lies in close relation. It is related with fibers of the tectothalamic paths. Its significance is not understood at present.

The nucleus posterodorsalis in Alligator mississippiensis appears to be intimately associated with tectal tracts, in particular with those of the ventrolateral tecto-thalamic bundle. How many of the fibers actually synapse in the nucleus it has not been possible for us to determine.

\section{Geniculato pretectale of Beccari}

The group of cells termed the geniculato pretectale by Beccari ('23), presumably because the linear arrangement of the cells suggests the lateral geniculate body, is not so evident in our preparations as in those of Varanus described by that author. However it can be identified in our material (fig. 9), its outer cells consisting of a narrow row of deeper staining cells and its inner layer of lighter staining, more scattered ones which are more or less continuous with the nuclear mass of nucleus posterodorsalis. The nucleus appears to be in the path of the tecto-thalamic bundles (fig. 9). It is apparently associated with a path which extends toward the bulbar regions (figs. 17-18). This has been described as the fasciculus pretectalis descendens by Beccari. Our material is not favorable for a study of this fasciculus and we are uncertain of its exact origin or termination. Our material suggests that the fibers of this fasciculus are associated with fibers from the nucleus pretectalis which also run bulbward.

Fig. 13 Transverse section, stained with toluidin blue, through the optic tectum and nucleus ruber. $\times 15$. com.col.sup., commissura colliculi superioris; f.l.m., fasciculus longitudinalis medialis; n.inters.f.l.m., nucleus interstitialis fasciculi longitudinalis medialis; n.lat.mes., nueleus lateralis mesencephali; n.med. mes.V., nueleus medialis of mesencephalie $\mathrm{V}$; n.dors.lat.III, nucleus dorsolateralis of IIIrd nerve; n.rub., nucleus ruber; n.vent.med.III, nucleus ventromedialis of IIIrd nerve (just beginning) ; tect.op., tectum opticum; tr.tect.bulb.vent., tractus tecto-bulbaris ventralis; tr.op., tractus opticns; $1-13$, mostly alternate numbers, these numbers indicate the tectal layers according to Cajal (footnote, p. 143). 


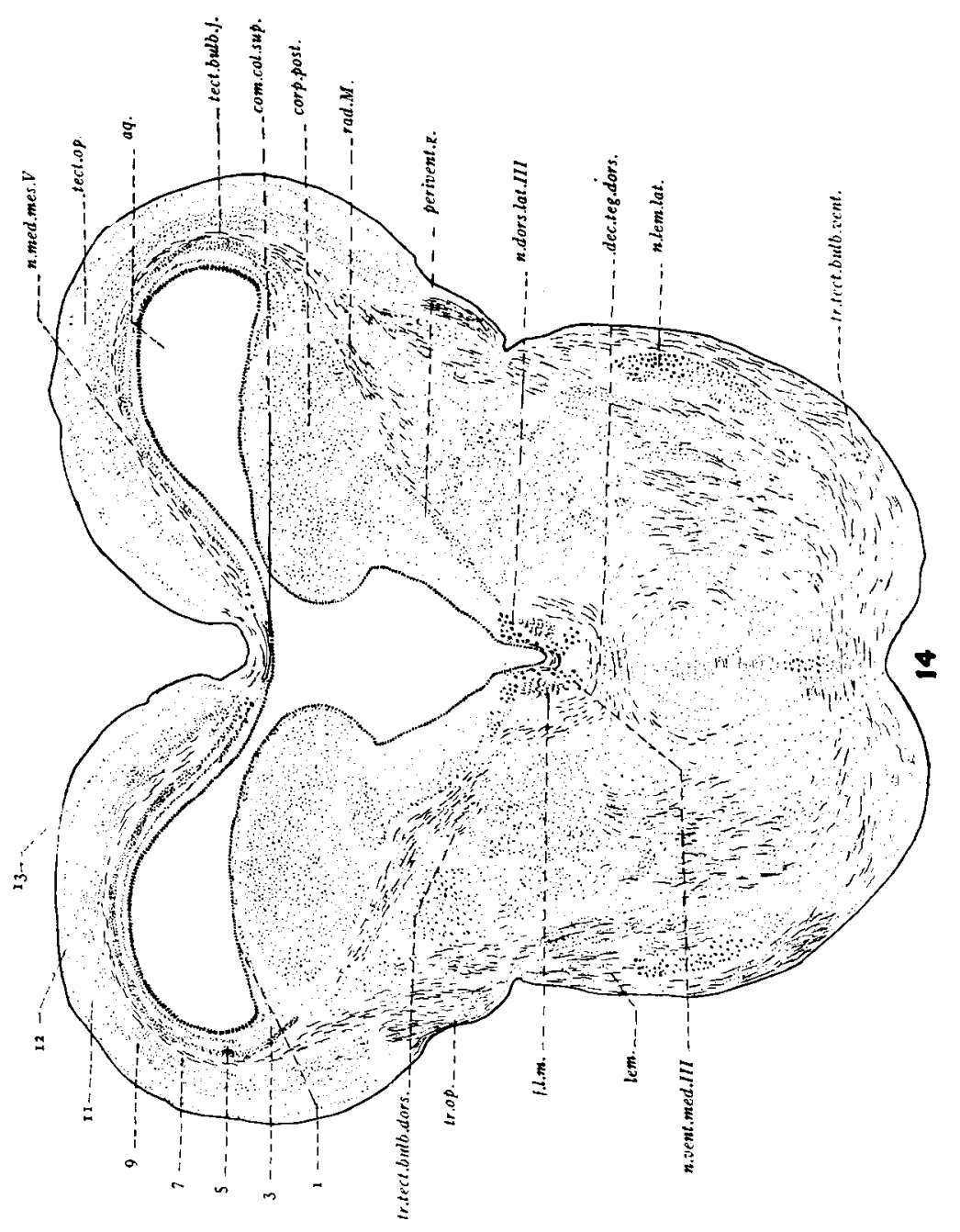




\section{Nucleus lentiformis mesencephali}

A nucleus lentiformis (fig. 10) has been described in various reptiles by de Lange ('13). It lies just above the posterior commissure and is bounded laterally by optic fibers. It is associated with the fibers of the ventrolateral tecto-thalamic tract and those of the dorsal supraoptic decussation, certain bundles of these tracts passing anterior to it while others appear to send collaterals and possibly stem fibers into it. It is connected by short fibers with the tectum. As seen in toluidin blue preparations, nucleus lentiformis consists of a scattered group of cells, its nuclear boundary being ill-defined. This loose arrangement is probably due to the numerous small fiber bundles passing among the cells. The larger cells seen in de Lange's preparations (based on Varanus, judging from the figures) are present and are more lightly stained in our material.

\section{Nucleus pretectalis}

The pretectal nucleus (figs. 11, 12) was described by Edinger ('99 and '08) who regarded it as connected with the lateral geniculate body and with nucleus rotundus. Such connections are evident in our preparations as a part of the tectothalamic paths from these regions, which thus in part synapse in nucleus pretectalis and in part pass directly to the tectum. With these connections de Lange is also in agreement. Fibers of the dorsal supraoptic commissure (transverse decussation

Fig. 14 Transverse section through the optic tectum and corpus quadrigeminum posterius. Attention is called to the relation of the inner cell layers of the optic teetum with the cell mass of corpus quadrigeminum posterius. Toluidin blue preparation. $\times 15$. aq., aqueduet; com.col.sup., commissura colliculi superioris; corp.post., corpus quadrigeminum posterius; dec.teg.dors., decussatio tegmentalis dorsalis; f.l.m., faseiculus longitudinalis medialis; lem., lemniscus; n.dors.lat.III., nucleus dorsolateralis of IIIrd; n.lem.lat., nueleus lemnisei lateralis; n.med.mes.V., nucleus medialis of mesencephalic $\mathrm{V}$; n.vent.med.III., nueleus ventromedialis of IIIrd nerve; perivent.g., periventricular gray; rad.M., radiations of Meynert; tect.bulb.f., tecto-bulbar fibers; tect.op., tectum opticum; tr.op., tractus opticus; tr.tect.bulb.dors., tractus tecto-bulbaris dorsalis; tr.tect.bulb.vent., tractus tectobulbaris ventralis; 1-13 (alternate numbers and 12), layers of tectum (footnote, p. 143). 
of Edinger and de Lange) also reach this nucleus in Reptilia according to Edinger. Our material appears to confirm this statement. In our preparations there is a so-called striotectal tract (see discussion of the lateral forebrain bundle, p. 160) which may have an ending in this nucleus. We are not so certain of this connection, but our silver preparations certainly suggest this relation. Furthermore Schroeder's ('12) drawings of the brain of the hen and Edinger's ('88, '96, '99) findings on reptiles suggest the connection.

Nucleus pretectalis consists of a mass of medium-sized or possibly somewhat larger cells more readily recognized in the silver preparations where the group is rather sharply delimited by the surrounding fiber tracts. Dorsomedial to the nucleus pretectalis and not sharply separated from it in the cell preparations is a small group of rather large-sized cells which Edinger ('08, Band I1, p. 158) has labeled nucleus spiriformis, in Varanus griseus. This nucleus lies ventrally in relation with the nucleus of the posterior commissure. It is intimately related by short scattered fibers with the nucleus pretectalis, of which it is sometimes regarded as a part.

\section{Nucleus of the dorsal supraoptic decussation}

The nucleus of the dorsal supraoptic decussation (figs. 5, 6, 17) lies in the anterior diencephalic region where the anterior thalamo-striatal path turns dorsalward to enter nucleus dorsolateralis anterior. The nucleus of the dorsal supraoptic decussation lies in the angle between the above mentioned tract and the remainder of the thalamo-striatal components of the lateral forebrain bundle. It receives fibers from the dorsal supraoptic commissure, although some of the fibers of that complex do not appear to enter into synaptic relation with it. Fibers run with the non-synapsing portions to the pretectal and tectal regions. This nuclear mass is not the nucleus described by Edinger as the nucleus of the transverse decussation. The nucleus of the dorsal supraoptic commissure receives collaterals and possibly stem fibers from the dorsal portion of the lateral forebrain bundle. 


\section{Nucleus entopeduncularis}

Nucleus entopeduncularis (figs. 7 and 17) described by Edinger ('99) for Varanus griseus, and by de Lange ('13) for Varanus salvator and Draco volans is situated

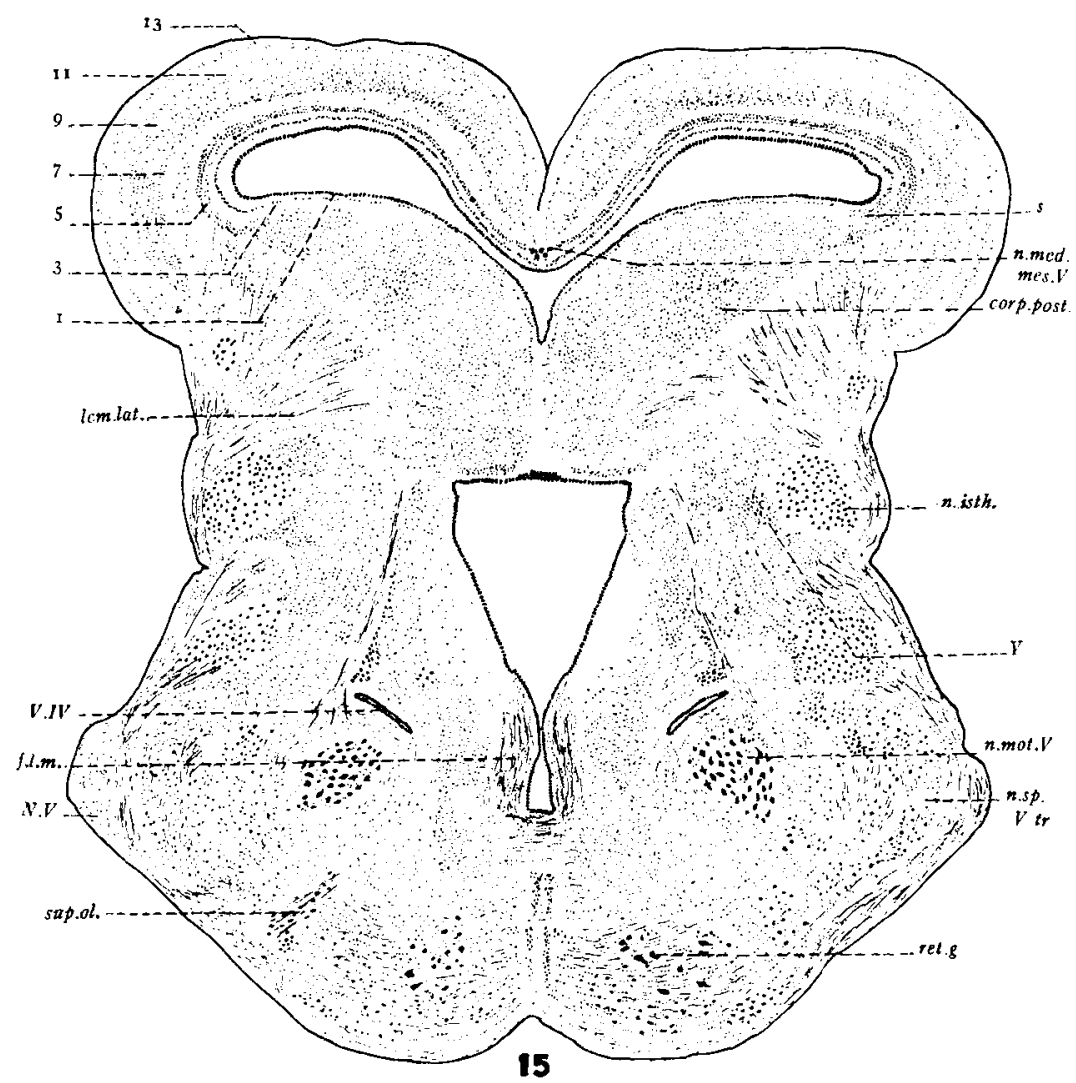

Fig. 15 Transverse section dorsally cut through the posterior end of the tectal areas and ventrally through motor Vth nucleus. A glance at the sagittal section (fig. 11) given on page 128 will enable a clear understanding of the plane of section which is further caudad on the ventral than on the dorsal side. Toluidin blue preparation. $\times 15$. corp.post., corpus quadrigeminum posterius; f.l.m., fasciculus longitudinalis medialis; lem.lat., lemniseus lateralis (includes other ascending sensory fibers here, in all probability); n.isth., nueleus isthmi; n.med.

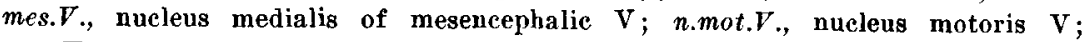
n.sp.V tr., nucleus of spinal $V$ th tract; $N . V$, Vth nerve; ret.g., reticular gray; $s$, indicates relation of optic tectum to corpus quadrigeminum posterius; sup.ol., superior olive; $V . I V$, ventriculus quartus; $F$, medial cell group of nucleus isthmi; 1-13 (alternate numbers), layers of optic tectum (footnote, p. 143). 
at about the level of the anterior end of nucleus reuniens in Alligator mississippiensis. It lies among the fibers of the lateral forebrain bundle (fig. 17) and undoubtedly is in synaptic relation with the ventral portion of that bundle as other observers have stated. It is characterized in the alligator, as in other reptiles, by its large multipolar cells. Just dorsal to nucleus entopeduncularis there is a similar cell mass entirely disconnected but somewhat similar in cell type. This latter nucleus (nucleus $Z$ ) is in synaptic relation with fibers of the tecto-reuniens system (p. 178).

\section{Nucleus periventricularis hypothalami}

The nucleus periventricularis hypothalami (figs. 3-7, 9) appears at the anterior end of the hypothalamus just dorsal to the optic chiasma and in our series at first ventral to the more scattered portion of the preoptic nucleus which it replaces. Cells of the interstitial nucleus of the projection tract of Cajal fuse with its anterior portion and fibers of the tract end in part in this periventricular hypothalamic region. Certain of the lateral and medial olfacto-habenular fibers may arise from the anterior end of the region. At first nucleus periventricularis hypothalami is round in outline as seen in cross-section; gradually it assumes a triangular form with the apex pointed dorsalward. Gradually this dorsal apex fuses with a mass of cells following the ventricle in the ven-

Fig. 16 Drawing made from a horizontal section through the level of nucleus dorsolateralis anterior and nucleus dorsomedialis anterior (i.e., dorsal thalamus) cephalad and the level of the cochlear VIIIth nuclei caudad. The figure is intended to show particularly the relations of nucleus dorsomedialis anterior and nucleus dorsolateralis anterior. Toluidin blue preparation. $\times 15$. corp.gen.lat., corpus geniculatum laterale; f.l.m., fasciculus longitudinalis medialis; lem.lat., lemniscus lateralis; n.ang.subhab., nucleus angularis subhabenularis; n.circ., nuclens circularis; n.diag., nucleus diagonalis;ndorsmagnocell, nueleus dorsalis magnocellularis; n.dors.med.ant., nucleus dorsomedialis anterior; n.dors.lat.ant., nucleus dorsolateralis anterior; n.lam., nucleus laminaris; n.med.ant.thal., nucleus medialis anterior thalami; n.med.post.thal., nucleus medialis posterior thalami; n.rot., nueleus rotundus; n.sp.V.tr., nucleus tracti spinalis $\mathrm{V} ; n . I I I$, nucleus of IIIrd nerve; n.IV, nucleus of IVth nerve; N.VIII, VIIIth nerve: st.med., stria medullaris ; tr.op., tractus opticus. 


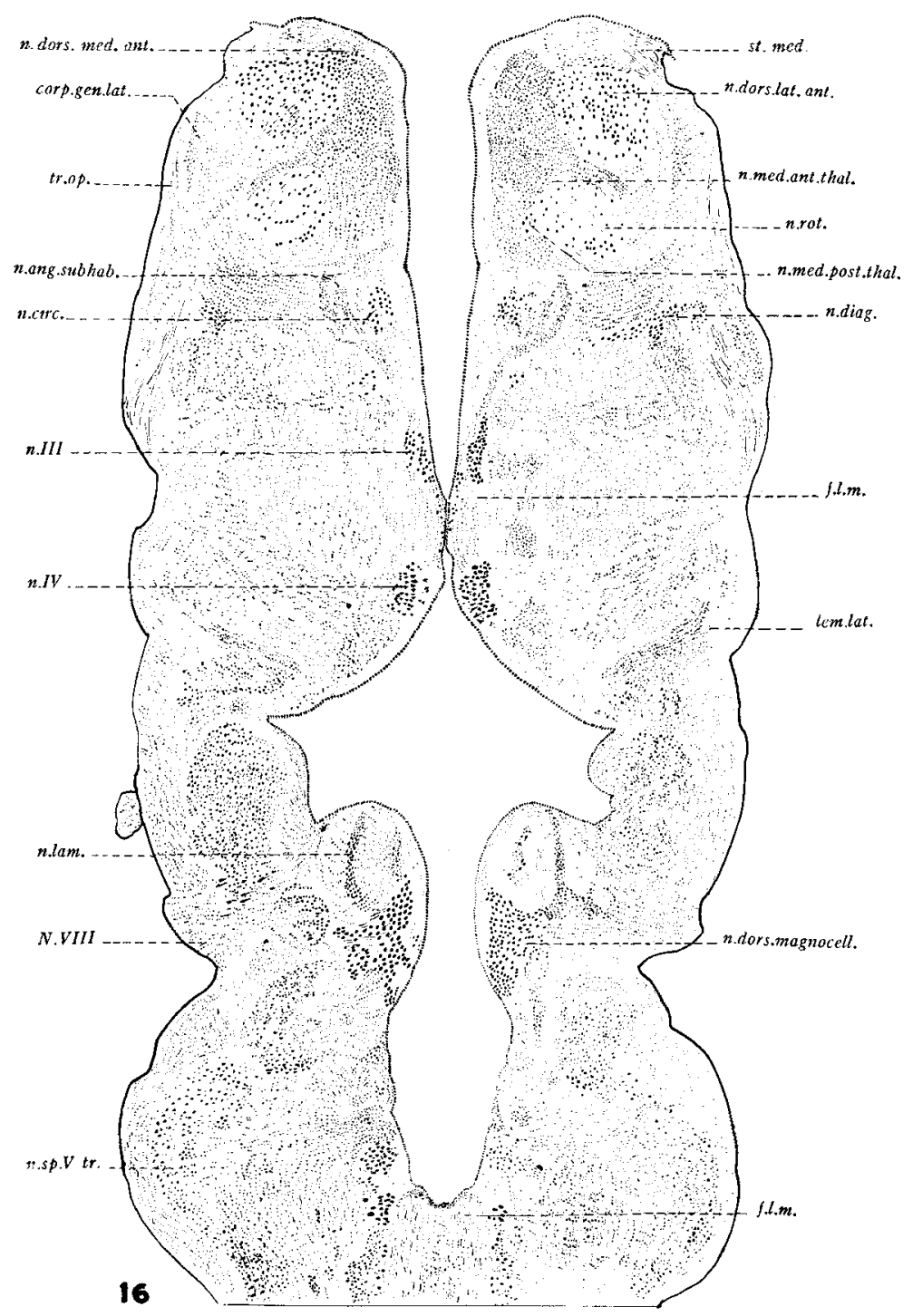


tral half of the diencephalon and the characteristic nucleus periventricularis hypothalami which de Lange ('13) has shown in Draco volans and 'Testudo graeca is formed. It is this more posterior portion of the nucleus which is in relation with the tecto-hypothalamic fibers described under the diencephalic periventricular system (p. 173). The hypothalamic periventricular nucleus can be traced throughout practically the length of the hypothalamus, its changes in form relations being most easily understood from the figures presented.

\section{Nucleus hypothalamicus lateralis}

The lateral hypothalamic nucleus (figs. 5, 6, 7 and 9) is present in the alligator in substantially the same relations as those given by de Lange ('13) for Draco. It appears at a level somewhat in front of the habenular commissure, ventral to the forebrain bundles and lateral to the periventricular hypothalamic nucleus. It disappears caudalward at a plane slightly behind the posterior end of the habenular commissure. It consists of rather scattered medium-sized cells.

A nucleus similar in type and similarly situated but cephalad to the lateral hypothalamic nucleus has been termed nucleus hypothalamicus anterior (figs. 3 and 4). Like the lateral, the anterior hypothalamic nucleus receives terminal fibers from the lateral forebrain bundle. The two nuclei are not sharply delimited and might readily be regarded as a single nuclear mass made up of smaller groups of cells.

\section{Nucleus hypothalamicus ventralis}

The ventral hypothalamic nucleus (fig. 7) is apparently comparable to the one described by de Lange ('13) but is smaller and has one striking characteristic, namely, its evident relation with a ventral hypothalamic commissure system, which passes through the floor of the brain below the third ventricle. The nucleus soon loses any definite outline and fades into a diffuse mass of cells which fills the remainder of the region. 


\section{Corpus mamillare}

As one approaches the posterior end of the hypothalamic region one finds it occupied mainly by a deeply staining, fairly compact nucleus (fig. 10). Probably this is the homologue of the mamillary body. We have been unable to follow the fornix into it, but de Iange ('13) succeeded in doing so for a similarly situated nucleus in the reptiles which he studied and he considers this nuclear mass the anlage of the mammillary body.

\section{Tectal regions}

It is not the purpose of the present paper to go into a detailed account of the tectal areas. A brief account of the general nuclear structure is however demanded by the character and scope of the paper. The roof of the midbrain is formed by two highly developed optic tecta, the superior colliculi or corpora bigemina of the comparative anatomist. These are relatively very highly developed and exhibit more layer differentiation than is described for Nammalia. They are directly comparable with the region in birds. The various layers found in the superior collicular region were first figured in chameleon by Cajal ('96); a similar figure for Draco has been given by de Lange following Bielchowsky ('13). Our own drawings (figs. 13-15, 24-26) indicate the layers and obviate the necessity for a detailed description. ${ }^{1}$

Rolled into the ventricle directly ventral to the superior colliculus throughout its posterior extent is a large gray mass which de Lange and Kappers regard as the homologue of the inferior colliculus or corpus quadrigeminum posterius. It is the torus semicircularis of former observers. Alex Palmgren ('21) questions the homology of this nucleus with the inferior colliculus, basing his arguments on certain developmental relations. We have no material at present for studying the development of this region in the alligator. On the basis of

\footnotetext{
${ }^{1}$ Our Golgi and Cox preparations are inadequate for a detailed study of the finer cellular structure of the optic tectum. Consequently we have indicated the various layers of the tectum by the numbers which Cajal ('96) employed.
} 
the fiber connections of the region, the nuclear mass appears to us homologous with the inferior colliculus of higher forms. The relations of this torus semicircularis, inferior colliculus or corpus quadrigeminum posterius with the superior colliculus are interesting. The inner layers of the latter, accompanied by fiber bundles, extend around the former forming an outer cortex-like layer inside of which is a spherical mass of cells which forms the chief bulk of the corpus quadrigeminum posterius (figs. 11, 13, 14, 15, 24-26).

\section{FIBER TRACTS}

\section{Résumé of epithalamic and hypothalamic connections}

In order to appreciate the differentiation of thalamic areas it is necessary to have an understanding of the epithalamic and hypothalamic centers as well as those of the thalamus proper. The following brief survey notes only a few structures presented for the first time and is intended primarily as a background for a discussion of the factors involved in thalamic development.

Epithalamus. For a number of reptiles the various fiber tracts which are most characteristic of the habenular connections have been described by such observers as de Lange ('11), Edinger ('99 and '08), Kappers ('21) and others. The stria medullaris was described for Alligator mississippiensis by Crosby ('17) and for the details of its course and the figures illustrative of its relations the reader is referred to that paper. In her recent paper on Sphenodon punctatum, Hines ('23) has identified certain of these components, particularly the cortico-habenular and the olfacto-habenular (posterior portion) tracts, finding them in substantially the same relations and using the terminology adopted for the alligator. The same nomenclature is used for these tracts in both Amphibia (Herrick, '10) and Mammalia (Gurdjian, '25, and others) so far as our present knowledge permits of homologies. A brief review of the various components of stria medullaris together with some further details concerning them, based particularly on the study of Alligator mississippiensis and Chrysemys marginata, follows. 
Stria medullaris (figs. $1 \mathrm{a}$ and b, 18-21; also Crosby, '17, pp. 370-2, figs. 18-20; Hines, '23, pp. 527-529, figs. 22-25) is certainly the largest fiber tract reaching the habenula. It consists partly of fibers from cortical centers and partly of fibers from basal centers. Of the cortical tract there are six main divisions: 1) Tractus cortico-habenularis medialis (Crosby, '17, p. 370 and figs. 18-20) arises mainly from the projection cells of the more anterior part of the hippocampal cortex (and in small part from the nucleus commissurae hippocampi), runs caudad from the hemispheres in company with the fornix and then turns dorsocaudad to enter stria medullaris which it accompanies to the habenula. 2 and 3) Tractus cortico-habenularis lateralis anterior and the tractus cortico-habenularis lateralis posterior form really two divisions of a single fiber tract which apparently runs as one bundle in some forms. These include the tract referred to by Hines (.23, p. $499 \mathrm{c}$ ) for Sphenodon punctatum. Kappers and Theunissen ('08, figs. 21 and 22) described this tract together with some fibers of the tractus cortico-habenularis medialis of the present description under the name of the tractus olfacto-habenularis. Their description was based on the lizard, Iguana. Kappers ('21, p. 861) mentions the presence of the tract in the crocodile but the tract is unlabeled in the figure to which he refers. Tractus cortico-habenularis lateralis anterior (Crosby, '17, p. 370 and figs. 16-21) arises from the cortex of the pyriform lobe but also in part from the non-cortical nucleus olfactorius lateralis and nucleus of the diagonal band of Broca. It runs medialward until the medial part of the hemisphere is reached and then turns dorsalward and accompanied by tractus olfacto-habenularis lateralis enters the stria medullaris. Tractus cortico-habenularis lateralis posterior (fig. 19, also Crosby, '17, p. 372 and figs. 20 and 21; Hines, '23, p. 499 b) takes its origin in part from the nucleus of the lateral olfactory tract, in part from the outer and ventral portion of the dorsolateral area of the forebrain, and in part from the overlying cortex; it sends its fibers dorsomedially above and for a time nearly parallel to the 
stria terminalis and then dorsalward into the stria medullaris. 4 and 5) Two pathways, tractus olfacto-habenularis lateralis and tractus olfacto-habenularis medialis (Herrick, '10, p. 541, fig. 69 ; also Crosby, '17, p. 372 and figs. 21 and 22 ), are so termed from the respective positions which they occupy during their course lateral and medial to the forebrain bundles. These two tracts, which form an important part of the stria medullaris, connect the nucleus preopticus throughout most of its extent with the habenula. 6) Tractus olfacto-habenularis posterior (Crosby, '17, fig. 10) is a tract from the nucleus of the lateral olfactory tract and the ventromedial nucleus to the habemula by way of the stria medullaris. A relatively detailed account of the various components as described for Alligator mississippiensis may be found by referring to the 1917 paper (Crosby, pp. 370-2).

In the turtle there are fine fibers from the habenula accompanying the ventrolateral tecto-thalamic tract which apparently reach the tectum. These could not be identified in the alligator material which was available, possibly due to faulty impregnation.

Tractus habenulo-peduncularis has been figured for various reptiles by Edinger ('99), Kappers ('21), Hines ('23) and others. It could be clearly traced in the turtle material at our disposal and is also present in the alligator material (figs. 18, 20 and 21).

There is some evidence of a connection between the habenula and the dorsal thalamus in the turtle material, the fibers accompanying the tractus habenulo-peduncularis for a part of their course. Such a tract was described by Haller as funiculus habenulae posterior. Edinger ('99) described a habenulodiencephalic tract. We were not able to find this tract in our alligator material.

The habenular commissure (figs. 1, c, d and e; 9) consists partly of short connecting fibers between the habenulae of the two sides. It serves primarily as a pathway for crossed fibers of the tractus cortico-habenularis lateralis and possibly of ather components of the stria medullaris. 
The habenula is unquestionably an olfactory correlation center as is evinced by its broad connection with the hippocampus and the basal olfactory centers of the telencephalon. Its fiber relations with the pyriform lobe cortex and tectum (and probably with the thalamus as well) suggest that it receives also indirectly from these centers somatic impulses, and is consequently probably the olfacto-somatic correlation center of the diencephalon.

Hypothalamus. The hypothalamic nuclei and their connections are not fully known in the alligator. From the hippocampal cortex descending impulses reach it by way of the fornix system which has been more or less completely described and figured by a number of observers, among them Edinger ('88 and '96), C. L. Herrick ('90), Adolf Meyer ('92), C. J. Herrick ('10, for alligator), de Lange ('11), Crosby ('17), Kappers ('21) and Hines ('23). The secondary olfactory centers of the medial wall of the hemispheres are placed in relation with the hypothalamus by way of the hypothalamic component of the medial forebrain bundle (figs. 20 and 21) which probably carries impulses in both directions. The ventral olfactory projection tract (Crosby, '17, figs. 18 and 19) connects the nucleus of the lateral olfactory tract and the cortex of the pyriform lobe with the hypothalamus. This tract in the diencephalic regions forms the more ventral part of the medial forebrain bundle. A more complete account of its course and of that of the following tract may be found by reference to the previous paper (Crosby, '17, p. 373 ). The olfactory projection tract was first described by Cajal ('11) for the mouse; it was described for the turtle by Johnston ('15) and for the alligator by Crosby ('17). It connects the ventromedial nucleus of the hemisphere with the hypothalamic and particularly the mesencephalic centers, accompanying the fornix fibers and those of the medial forebrain bundle throughout a part of their course (see account of the interstitial nucleus of the tract, p. 110). These two olfactory projection tracts, the one on the ventral and the other on the dorsal side of the medial forebrain bundle, have 
been described as having practically identical relations in the frog brain by Herrick ('21) who has used the same nomenclature as that employed for the alligator by Crosby ('17). Fibers from the lateral forebrain bundle (tractus strio-hypothalamicus, p. 157) reach the hypothalamus throughout a considerable part of its extent, going particularly to the lateral and anterior hypothalamic nuclei (figs. 4-9). There is probably some connection with the tectum (see the description of the diencephalic periventricular system, p. 173). The two sides are interrelated by short fibers crossing in the postoptic commissure. Undoubtedly there are ascending paths from the tectum of the midbrain or the bulbar regions but their position and course are unknown. Enough of its connections are known to indicate that it is an olfactory center, probably an olfacto-visceral correlation center, if one may judge by analogy with other forms (C. J. Herrick, '05, has shown that in fishes secondary gustatory paths reach this region).

\section{Basal forebrain bundle}

The basal forebrain bundle is one of the great longitudinally conducting fiber bundles of the reptilian brain, serving primarily as a pathway for impulses between the forebrain and the lower centers. It consists of medial and lateral portions which may be more or less sharply distinguished from each other from the standpoints of function and of appearance. Besides these longer conducting pathways, short fibers run in the basal forebrain bundle between the various nuclei of the hypothalamus and between the hypothalamic centers and the tegmental portions of the midbrain.

1. Medial forebrain bundle (figs. 18-25). This bundle is concerned primarily with the interrelating of the basal olfactory centers with the centers of the hypothalamus. It is not entirely concerned, though chiefly, with the integration of olfactory and visceral impulses and with the provision for them of a caudal discharge path. Some of its fibers pass back into the region of the mesencephalon, ending there in 
the tegmental portions. After the diencephalon is reached the medial forebrain bundle is overlapped by the olfactory projection tract (figs. 19-25) and the accompanying fornix fibers. In our material it is not possible to draw a sharp

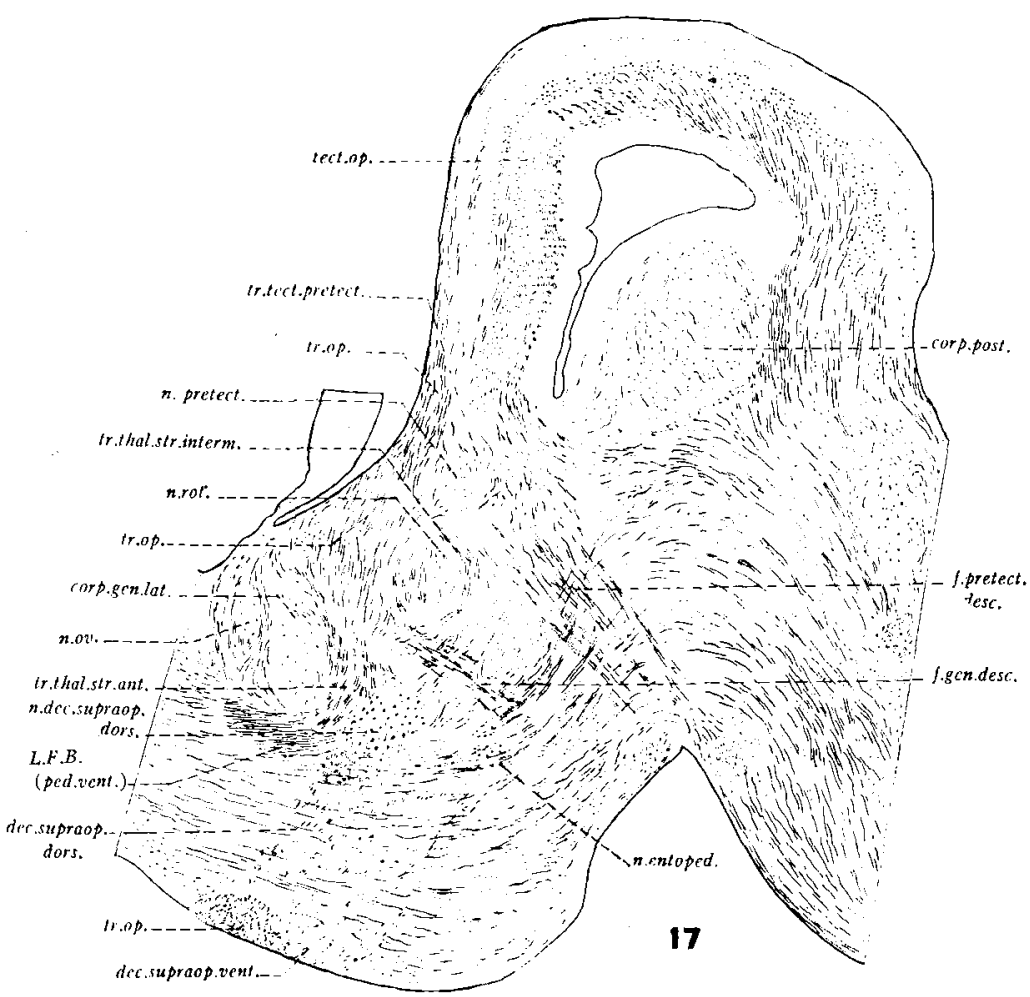

Fig. 17 Figure drawn from a sagittal section through the corpus geniculatum laterale and nueleus rotundus. The drawing illustrates particularly the division of the forebrain bundle into dorsal and ventral peduncles, and the fasciculus geniculatus descendens and fasciculus pretectalis descendens of Beccari's ('23) description. Weigert preparation. $\times 13$. corp.gen.lat, corpus geniculatum laterale; corp.post., corpus quadrigeminum posterius; dec.supraop.dors., decussatio supraoptica dorsalis; dec.supraop.vent., decussatio supraoptica ventralis; f.gen. desc., fasciculus geniculatus descendens; f.pretect.desc., fasciculus pretectalis descendens; L.F.B. (ped.vent.), lateral forebrain bundle (ventral peduncle); n.dec. supraop.dors., nueleus decussationis supraopticae dorsalis; n.entoped., nueleus entopeduncularis; n.ov., nucleus ovalis; n.pretect., nucleus pretectalis ; n.rot., nucleus rotundus; tect.op., tectum opticum; tr.op., tractus opticus; tr.tect.pretect., tractus tecto-pretectalis; tr.thal.strant., tractus thalamo-striatalis anterior; $t r$. thal.str.interm., tractus thalamo-striatalis intermedius. 


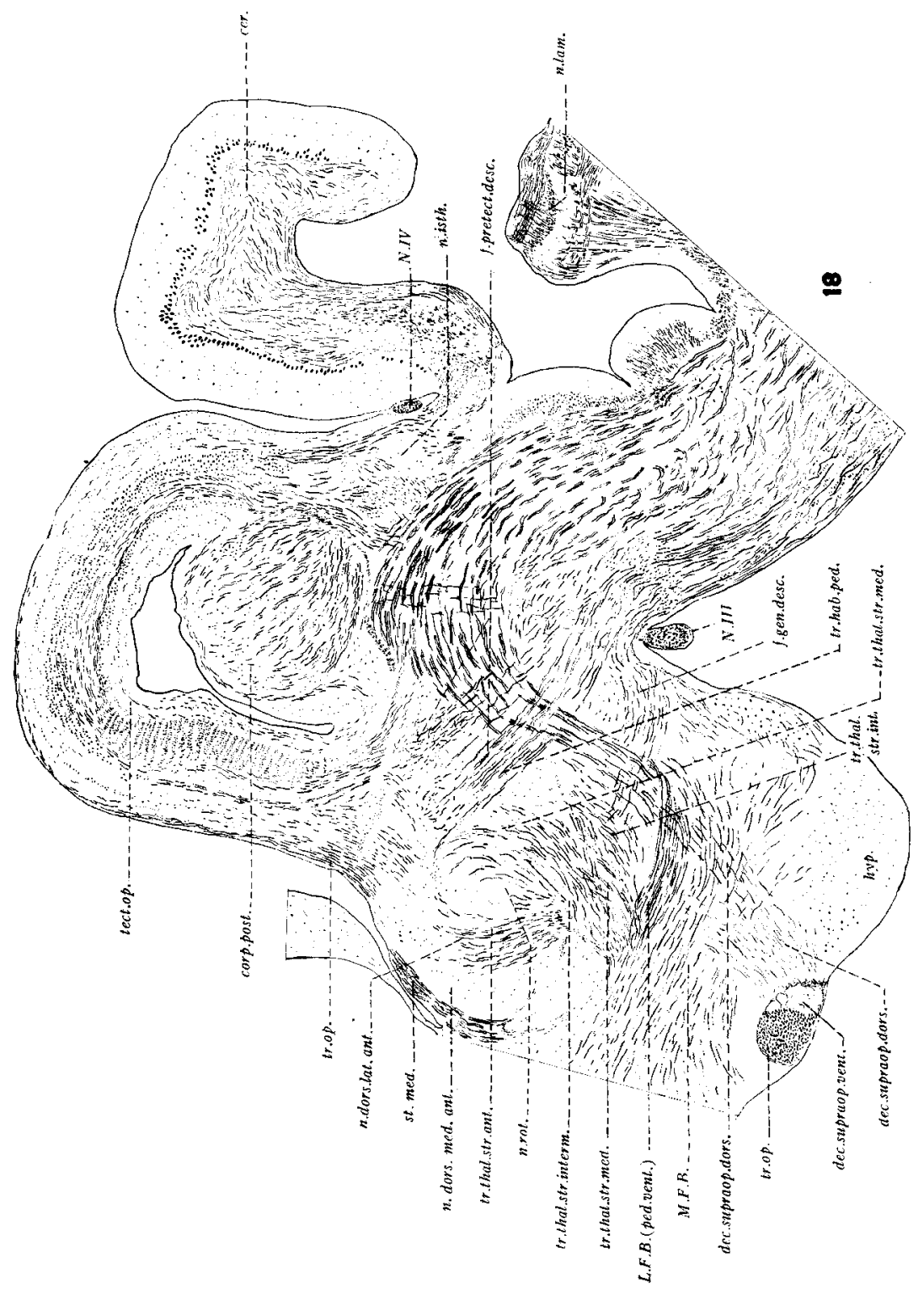


line between the components of the three bundles although the general position of each can be recognized. A quite detailed account of the cells of -origin, the relations and the terminations of the medial forebrain bundle in the brain of Alligator mississippiensis is given by Crosby ('17).

De Lange ('11 and '13) has described this tract in part in several reptiles under the name of tractus septo-mesencephalicus. His description differs somewhat from the one given above. He does not give any termination in the hypothalamic regions, but mentions a possible dorsal portion into the thalamus. The tract has been described for various reptiles including Python and Chelone midas by Edinger ('96) and for Sphenodon by Hines ('23).

Johnston has figured the medial forebrain bundle in turtles (see '15, figs. 52-54). The relations are essentially the same as those given for the alligator in the foregoing description. In the turtle material which was available for study, the bundle was well impregnated and its relations were traced as Johnston had described them. The final termination in the midbrain region could not be definitely established.

2. Lateral forebrain bundle. This bundle has three functions: 1) it affords a pathway (tractus thalamo-striaticus described below) by means of which integrated somatic impulses of the neothalamus may reach the hemisphere; 2) it provides a discharge path from the somatic centers of the

Fig. 18 This figure is drawn from a Weigert haematoxylin stained series and is more medialward than figure 17. It illustrates the thalamo-striatal components of the lateral forebrain bundle and the faseiculus pretectalis descendens of Beccari's ('23) nomenclature. $\times 13$. cer., cerebellum; corp.post., corpus quadrigeminum posterius; dec.supraop.dors., decussatio supraoptica dorsalis; dec.supraop.vent., decussatio supraoptica ventralis; f.gen.desc., fasciculus geniculatus descendens; f.pretect.dese., fasciculus pretectalis descendens; hyp., hypothalamus; M.F.B., medial forebrain bundle; L.F.B.(ped.vent.), lateral forebrain bundle (ventral peduncle); n.dors.lat.ant., nueleus dorsolateralis anterior; n.dors.med.ant., nucleus dorsomedialis anterior; n.isth., nucleus isthmi; n.lam., nucleus laminaris; n.rot., nucleus rotundus; $N . I I I$, IIIrd nerve; N.IV, IVth nerve; st.med., stria medullaris; tec.op., tectum opticum; tr.hab.ped., tractus habenulo-peduncularis ; tr.op., tractus opticus; tr.thal.str.ant., tractus thalamo-striatalis anterior; tr.thal.str.int., tractus thalamo-striatalis internus; tr.thalstr.interm., tractus thalamo-striatalis intermedius; tr.thal.str.med., tractus thalamo-striatalis medialis. 
lateral wall of the forehrain, including the developing somatic cortex, to the thalamus and midbrain; 3 ) it carries impulses between the thalamus and the midbrain. The lateral forebrain bundle, then, is concerned primarily with the integration and discharge of somatic impulses. Its importance increases with the increased development of neothalamic and neocortical areas in the forebrain. It is the forerunner of the internal capsule system found in higher forms.

The lateral forebrain bundle has been described and figured under a variety of names. It was named the peduncle by certain of the earlier observers, such as C. L. Herrick ('90 and '93) and Pedro Ramón y Cajal ('96). It was called the strio-hypothalamic tract by Unger ('06) and by de Lange ('11). In general it consists of two main portions. The dorsal part, which is concerned primarily in the interrelation of the striatum and the dorsal thalamus, has been described by various observers (Edinger, '99; de Lange, '13; Crosby, '17, and others) as the thalamo-striatal component; others have termed it the pedunculus dorsalis (for example, on oceasion, Kappers, '21). De Lange has described and figured the tract as arising from the nucleus rotundus and nucleus anterior and running to the neostriatal regions in Varanus salvator, Draco volans and some other reptiles. Copies of several of de Lange's figures are given by Kappers ('21).

For convenience in description the thalamo-striatal portion of the lateral forebrain bundle has been described as if it ran from forebrain to diencephalon, although it certainly conducts, in part at least, in the opposite direction. Furthermore it has been divided into several components which are to some degree intermingled and cannot at all levels be distinguished from one another.

In the basal region of the hemisphere and its point of entrance into the diencephalon, the lateral forebrain bundle forms a more or less compact mass of fibers (figs. 17-20). However, almost immediately after reaching the diencephalon, the most anterior portion of the dorsal peduncle is given off. This has been termed tractus thalamo-striatalis anterior 
(figs. 17-21). As this anterior part splits off from the main bundle it forms with it a $\mathrm{V}$ in the angle of which is the beginning (in our sagittal series) of a mass of cells, the nucleus of the dorsal supraoptic decussation (fig. 17). This nucleus lies between the thalamo-striatal paths and the remainder of the forebrain bundle. Some of the fibers of the lateral forebrain bundle appear to synapse in this nucleus; however, the major portion of the fibers are not in synaptic relation with it. Tractus thalamo-striatalis anterior runs dorsalward and slightly posterior and then curves cephalad again (fig. 18). It terminates in nucleus dorsolateralis anterior thalami. A few scattered fibers may reach nucleus dorsomedialis anterior but the vast majority of them in our material are confined to nucleus dorsolateralis anterior. This does not quite agree with the statements of de Lange, Kappers or Edinger, who regard this division of the lateral forebrain bundle as passing to nucleus anterior. The difference of opinion is based on a difference of interpretation of the nuclear masses of the dorsal thalamic region, the authors just mentioned regarding both nucleus dorsomedialis anterior and nucleus dorsolateralis anterior of our description as a single nuclear mass.

Caudal and medial to the nuclear mass just described, a second portion (tractus thalamo-striatalis intermedius) of the lateral forebrain bundle is given off. This fiber bundle runs dorsocaudad to nucleus rotundus and the associated nucleus medialis anterior. As it reaches the nucleus it sprays out throughout the area, conforming to the spheric shape of the cell mass. Part of the fibers distribute to the surrounding nerve cells of nucleus medialis and with it form a capsule around nucleus rotundus. Tractus thalamo-striatalis medialis, which is in relation with nucleus medialis posterior and probably with nucleus medialis anterior as well, splits off from the main mass of forebrain fibers and runs dorsomedialward (figs. 18 and 22) curving around nucleus rotundus on the medial side of that nuclear mass and so reaches in part nucleus medialis anterior and farther caudad the anterior portion of nucleus medialis posterior. Tractus 


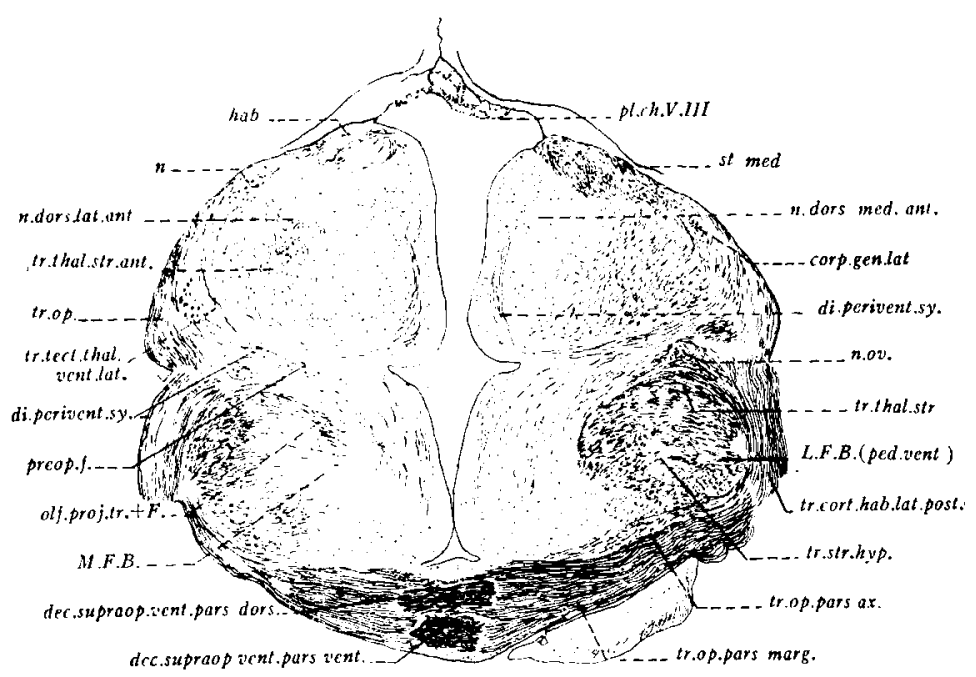

19

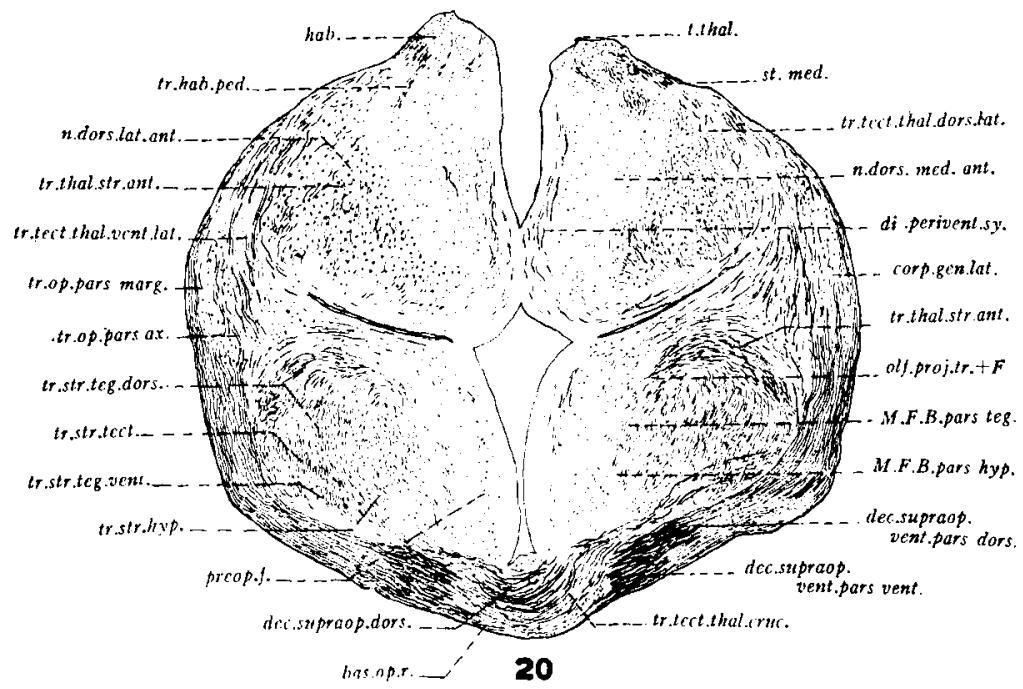

Fig. 19 Transverse section through the anterior end of the diencephalon showing the crossing of the two divisions of the ventral supraoptic decussation. Cajal preparations. $\times 15$. corp.gen.lat., corpus geniculatum laterale; dec.supraop. vent.pars dors., decussatio supraoptica ventralis pars dorsalis; dec.supraop.vent. pars vent., decussatio supraoptica, ventralis pars ventralis; di.perivent.sy., diencephalic periventricular system; hab., habenula; L.F.B.(ped.vent.), lateral forebrain bundle (ventral peduncle); M.F.B., medial forebrain bundle; n, differen- 
thalamo-striatal internus (fig. 18) runs medialward and slightly downward to nucleus reuniens and a part of nucleus diagonalis. We are of the opinion that the nuclear masses of the thalamus more posterior to nucleus rotundus and $n u-$ cleus medialis posterior may receive forebrain fibers of the strio-thalamic type, but the evidence for this is not conclusive.

The direction of conduction for anterior, intermedius and internal strio-thalamic tracts is definitely known to be from thalamus to striatum, -since neuraxes of cells in the thalamic areas supplied by these portions of the thalamo-striatal bundle can be traced out into the tract (fig. $8 \mathrm{c}$ ). They may be accompanied by strio-thalamic fibers as well, but the evidence for this is not clear in our material. In the chameleon Cajal

tiated lateral part of nucleus dorsolateralis anterior; n.dors.lat.ant., nucleus dorsolateralis anterior; n.dors.med.ant, nucleus dorsomedialis anterior; n.ov., nucleus ovalis; olf.proj.tr. $+F$., olfactory projection tract and fornix; pl.ch.V.III, plexus choroideus ventriculi tertii; preop.f., preoptic fibers; st.med., stria medullaris; tr.cort.hab.lat.post., tractus cortico-habenularis lateralis posterior; tr.op., tractus opticus; tr.op.pars ax., tractus opticus pars axillaris; tr.op.pars marg., tractus opticus pars marginalis; tr.str.hyp., tractus strio-hypothalamicus (part of the lateral forebrain bundle); tr.tect.thal.vent.lat., tractus tecto-thalamicus ventrolateralis; tr.thal.str., tractus thalamo-striatalis; tr.thal.str.ant., tractus thalamostriatalis anterior.

Fig. 20 Transverse section slightly caudad to the plane of figure 19, showing the dorsal supraoptic fibers at their decussation. Tractus tecto-thalamicus cruciatus is also indicated as it crosses the midline. Whether or not this latter tract is intermingled with incoming optic fibers we are unable to determine at present. Cajal preparations. $\times 15$. bas.op.r., basal optic root; corp.gen.lat., corpus geniculatum laterale; dec.supraop.dors., decussatio supraoptica dorsalis; dec. supraop.vent.pars dors., decussatio supraoptica ventralis pars dorsalis; dec.supraop. vent.pars vent., decussatio supraoptica ventralis pars ventralis; di.perivent.sy., diencephalie periventricular system; hab., habenula; M.F.B.pars hyp., medial forebrain bundle hypothalamic part; M.F.B.pars teg., medial forebrain bundle, tegmental part; n.dors.lat.ant., nucleus dorsolateralis anterior; n.dors.med.ant., nucleus dorsomedialis anterior; olf.proj.tr. $+F$., olfactory projection tract and fornix; preop.f., preoptic fibers; st.med., stria medullaris; t.thal., taenia thalami; tr.hab.ped., tractus habenulo-peduncularis; tr.op.parsax., tractus opticus pars axillaris; tr.op.pars marg., tractus opticus pars marginalis ; tr.str.hyp., tractus strio-hypothalamicus; tr.str.tect., tractus strio-tectalis; tr.str.teg.dors., tractus strio-tegmentalis dorsalis; tr.str.teg.vent., tractus strio-tegmentalis ventralis; tr.tect.thal.cruc., tractus tecto-thalamicus cruciatus; tr.tect.thal.dors.lat., tractus tecto-thalamicus dorsolateralis; tr.tect.thal.vent.lat., tractus tecto-thalamieus ventrolateralis; tr.thal.str.ant., tractus thalamo-striatalis anterior. 
(96) has shown neuraxes from nucleus rotundus entering the thalamo-striatal tract.

At least five of the main thalamic nuclei-nucleus lateralis, nucleus rotundus, nucleus medialis anterior, nucleus medialis posterior, nucleus reuniens (and the associated part of nucleus diagonalis) - are found to be definitely interrelated with the lateral somatic areas of the forebrain by the above described divisions of the dorsal peduncle of the lateral forebrain bundle. Some few fibers appear to reach nucleus postero-centralis, also, although the tract is not large. Thus the dorsal thalamus and the striatum are intimately interrelated and by way of a synapse in the striatum, the dorsal thalamus and the developing non-olfactory cortex are so connected that the development of the three areas necessarily goes hand in hand.

In his excellent account of reptilian diencephalon Edinger ('99) has described four divisions of the thalamo-striatal part of the forebrain bundle in the alligator. These divisions are in part comparable to those which we have given in the preceding account, but the differences in interpretation of the nuclear areas and the fact that the Edinger figures do not include drawings of alligator material and are not completely labeled for these tracts in other reptiles makes the drawing of accurate comparisons rather difficult. In the following brief statement of Edinger's findings the homologous tracts according to our terminology are given in parentheses. That observer described a tractus anterior to nucleus anterior (pars anterior to nucleus dorsolateralis anterior), tractus medius to nucleus rotundus (probably the exact homologue of our pars intermedius to that nucleus) tractus internus to nucleus diffusus (apparently our pars medialis to nucleus medialis posterior, certainly not the tract to nucleus reuniens) and a tractus lateralis to the lateral geniculate body (this tract we have not been able to identify).

In the basal region of the hemisphere and at its point of entrance into the diencephalon the ventral portion of the lateral forebrain bundle (the ventral peduncle of Kappers) lies 
in close relation with the more dorsal thalamo-striatal paths (figs. 17-21). As these latter split off the main bundle to enter the dorsal thalamus, the ventral portion of the bundle runs directly caudad to the posterior diencephalic and the mesencephalic regions. We have divided this ventral division (figs. 17-26) into three main tracts: tractus strio-hypothalamicus, tractus strio-tegmentalis dorsalis, tractus striotegmentalis ventralis and also a fourth, the tractus striotectalis. The positions of these have been indicated on the figures, although it is not possible to draw sharp lines of demarcation between the various components in the anterior levels of the diencephalon.

Tractus strio-hypothalamicus makes up the more ventromedial and ventral portion of the lateral forebrain bundle. In the diencephalon it swings gradually ventrally, becomes less compact and terminates in the lateral and anterior hypothalamic nuclei (figs. 3, 4, 5, 6, 7, 9). De Lange ('11 and '13) emphasizes this component when he speaks of the lateral forebrain bundle as the tractus strio-hypothalamicus.

Tractus strio-tegmentalis dorsalis after entering the diencephalon swings almost directly caudad until the posterior end of the diencephalon is reached, where it comes into relation with the entopeduncular nucleus (described by Kappers for reptiles as nucleus entopeduncularis posterior and figured by him, '21, p. 862 , fig. 462 in Crocodilus porosus). Nucleus entopeduncularis has been identified by various workers on reptilian brains (Edinger, '99, Beccari, '23 and others). The fibers of the ventral peduncle, particularly of the dorsal tegmental tract (fig. 17), appear to be broken up by this nuclear mass. How great a number of the fibers synapse here we have not been able to determine. Some apparently do not synapse but swing dorsalward into the tegmental region accompanied by fibers from nucleus entopeduncularis. None of our material shows definitely the termination of the tract within the midbrain. The fiber bundles are accompanied for a part of their course by fibers of the dorsal supraoptic decussation and are so intermingled with these and with paths 
between the tectum and lower centers that we have been unable to reach any definite conclusions regarding their ultimate termination.

Tractus strio-tegmentalis ventralis (figs. 20-26) is a smaller bundle of fibers lying ventrolateral to the tractus strio-tectalis and the tr. strio-tegmentalis dorsalis in their course through the diencephalon. This ventral strio-tegmental tract has no

Fig. 21 Cross section through the level of the habenular nuclei not far caudad to the plane of figure 20 . The figure is intended particularly to illustrate the divisions of the supraoptic system. Cajal preparation. $\times 15$. bas.op.r., basal optic root; corp.gen.lat,, corpus geniculatum laterale; dec.supraop.dors., decussatio supraoptica dorsalis; dec.supraop.vent.pars dors., decussatio supraoptica ventralis pars dorsalis; dec.supraop.vent.pars vent., decussatio supraoptica ventralis pars ventralis; di.perivent.sy., diencephalic periventricular system; f.ans., fibrae ansulatae; M.F.B.pars hyp., medial forebrain bundle pars hypothalamica; M.F.B.parsteg., medial forebrain bundle pars tegmentalis; n.dors.lat.ant., nucleus dorsolateralis anterior; n.dors,med.ant., nucleus dorsomedialis anterior; n.med.hab.pars dors.lat., nucleus medialis habenulae pars dorsolateralis; n.med.hab.parsvent.med., uueleus medialis habenulae pars ventromedialis; olf.proj.tr., olfactory projection tract; olf.proj.tr. $+F$., olfactory projection tract and fornix; st.med., stria medullaris; tr.hab.ped., tractus habenulopeduncularis; tr.op., tractus opticus; tr.str.tect., tractus strio-tectalis; tr.str.teg. dors., tractus strio-tegmentalis dorsalis; tr.str.teg.vent., tractus strio-tegmentalis ventralis; tr.tect.thal.oruc., tractus tecto-thalamicus cruciatus; tr.tect.thal.vent. lat., tractus tecto-thalamicus ventrolateralis; tr.thal.str., tractus thalamo-striatalis; tr.thal.strant., tractus thalamo-striatalis anterior.

Fig. 22 This figure presents a number of the tecto-thalamic connections. Cajal preparations. $\times 15$. bas.op.r., basal optic root; com.post., commissura posterior; corp.gen.lat., corpus geniculatum laterale; dec.f.tr.tecto-reuns., decussating fibers of the tractus tecto-reuniens; dec.supraop.dors., decussatio supraoptica dorsalis; decsupraop.vent.parsdors., decussatio supraoptica ventralis par's dorsalis; decsupraop.vent.pars vent, decussatio supraoptica ventralis pars ventralis; f.ans., fibrae ansulatae; $M . F . B .+o l f . p r o j . t r .$, medial forebrain bundle and olfactory projection tract; n.ang.subhab., nueleus angularis subhabenularis; n.dec.supracp.dors., nueleus decussationis supraopticae dorsalis; n.lent.mes., nucleus lentiformis mesencephali; n.med.ant.thal., nucleus medialis anterior thalami; n.perivent.hyp., nucleus periventricularis hypothalami; n.reuns., nucleus reuniens; n.rot., nucleus rotundus; n.tr.tect.thal.cruc., nucleus tracti tecto-thalamici eruciati (probably to be considered a part of the lateral geniculate complex); tect. op., tectum opticum; tr.op., tractus opticus; tr.str.tect., tractus strio-tectalis; $t r$. str.teg.dors., tractus strio-tegmentalis dorsalis; tr.str.teg.vent., tractus striotegmentalis ventralis; tr.tect.reuns., tractus tecto-reuniens; tr.tect.thal.cruc., tractus tecto-thalamieus cruciatus; tr.tect.thal.dors.med.ant., tractus tecto-thalamicus dorsomedialis anterior; tr.tect.thal.med., tractus tecto-thalamicus medialis; tr.tect.thal.vent.lat., tractus tecto-thalamicus ventrolateralis; tr.thal.str.med., tractus thalamo-striatulis medialis. 

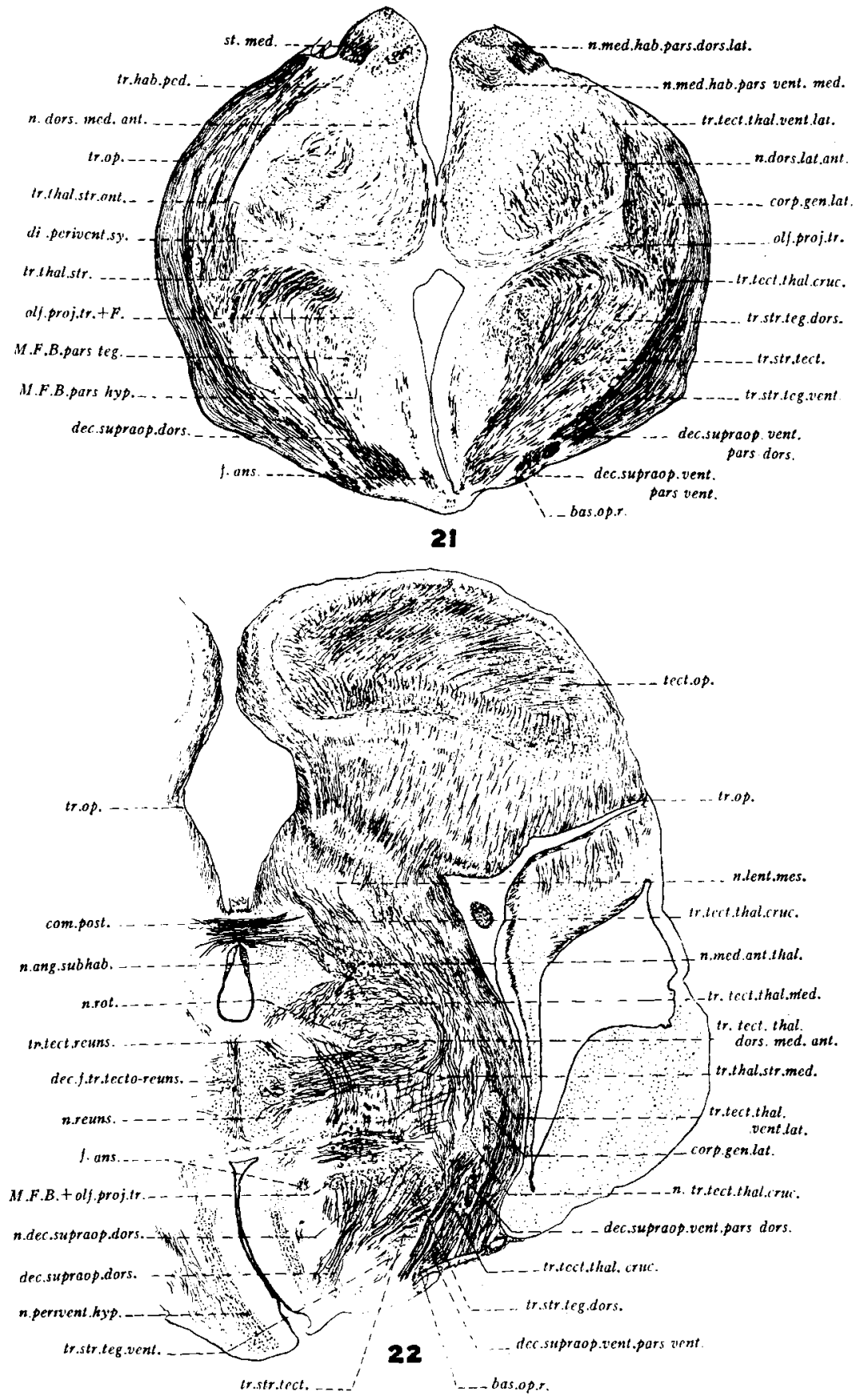
apparent comection with the entopeduncular nucleus. It occupies the extreme ventrolateral portion of the lateral forebrain bundle, ventral to the strio-tectal portion and forms a relatively separate tract throughout its course through thalamus and mesencephalon. In the latter region it swings somewhat farther ventrolateral, occupying then a position close to the surface and begins to send fibers (and possibly receives some as well) to the mesencephalic regions, i.e., the lateral tegmental areas. In the preparations studied none of these fibers could be traced to the tectal areas. Gradually the tract swings ventromedially, distributing to the basal tegmental regions, just lateral to the nucleus ruber. As the posterior part of that nucleus is reached, a few of the fibers swing medialward across the posteriorly running thalamo-bulbospinal path and enter the medial tegmental area. Some of the fibers appear to turn back with the thalamo-bulbo-spinal path although it is an unanswered question, if such is the case, how far they may accompany it. While this connection is not large, it is relatively significant since it suggests the relations of the telencephalic centers of higher forms to the basal tegmental nuclei, particularly to substantia nigra and nucleus ruber. In general this tegmental path is comparable to the strio-tegmental and strio-rubral paths of higher forms. Besides this definite path there are seattered bundles of fibers from the striatum which reach the basal mesencephalic regions.

Tractus strio-tectalis (figs. 20-26). In addition to the above described components of the ventral division of the lateral forebrain bundle which reach the mesencephalon, there is a more lateral portion (just dorsal to the ventral strio-tegmental bundle) whose analysis has caused us some difficulty and whose ultimate termination is still somewhat open to question. This component, which we have termed tentatively the tractus strio-tectalis, occupies the more lateral portion of the ventral part of the lateral forebrain bundle and is somewhat intermingled, as are the majority of the forebrain tracts, with the fiber bundles of the dorsal supra- 
optic commissure (fig. 25). Behind the level of the posterior commissure, where the anterior regions of the mesencephalon are reached, these fibers begin to swing dorsalward (fig. 25)

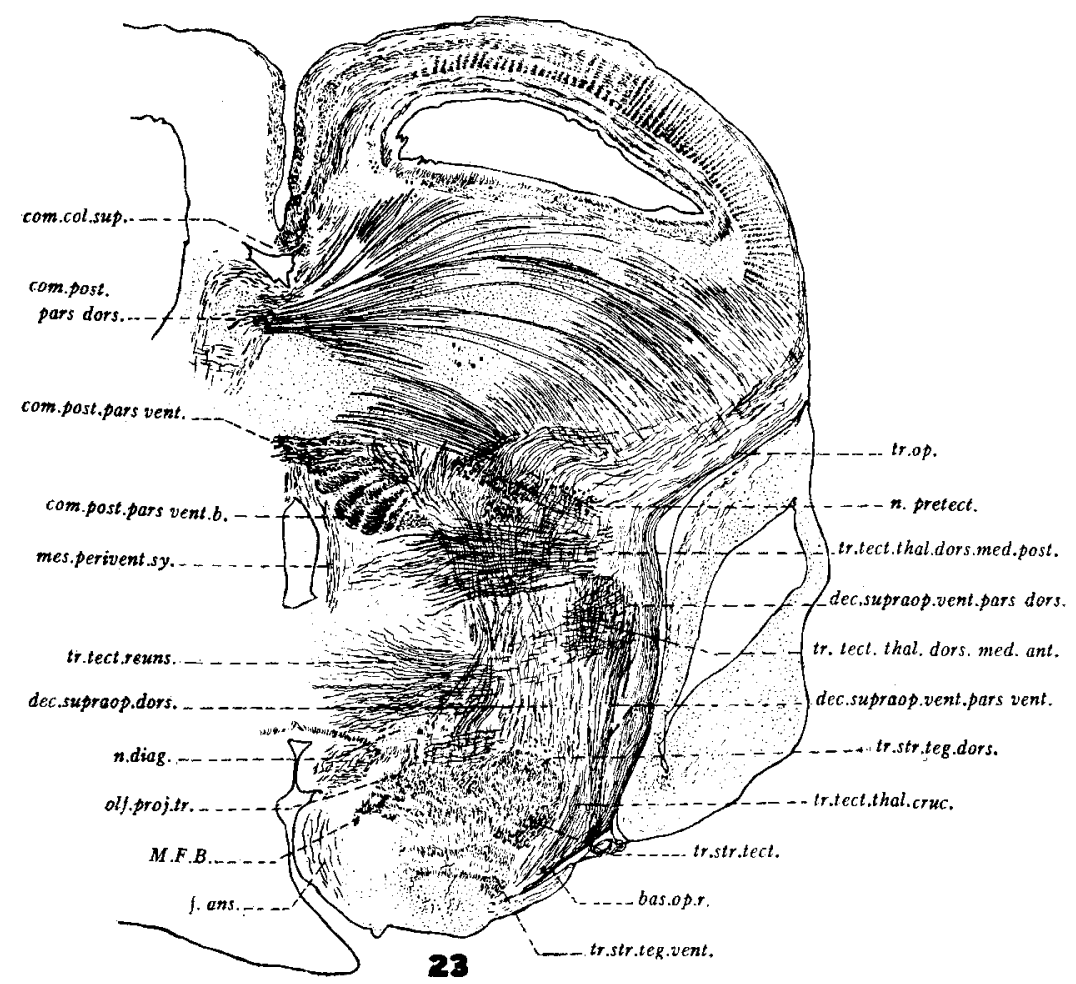

Fig. 23 A cross section illustrating particularly the relations of the two divisions of commissura posterior. Cajal preparation. $\times 15$. bas.op.r., basal optie root; com.col.sup., commissura colliculi superioris; com.post.pars dors., commissura posterior pars dorsalis; com.post.pars vent., commissura posterior pars ventralis; com.post.pars vent. $b$, that portion of the commissure which passes ventralward toward the medial longitudinal fasciculus; dec.supraop.dors., decussatio supraoptiea dorsalis; dec.supraop.vent.pars dors., decussatio supraoptica ventralis pars dorsalis; dec.supraop.vent.pars vent., decussatio supraoptica ventralis pars ventralis; f.ans., fibrae ansulatae; M.F.B., medial forebrain bundle; mes.perivent.sy., mesencephalie periventricular system; n.diag., nucleus diagonalis; n.pretect., nucleus pretectalis; olf.proj.tr., olfactory projection tract; tr.op., tractus opticus; tr.str.tect., tractus strio-tectalis; tr.str.teg.dors., tractus strio-tegmentalis dorsalis; tr.str.teg.vent., tractus strio-tegmentalis ventralis; tr.tect.reuns., tractus tectoreuniens; tr.tect.thal.dors.med.ant., tractus tecto-thalamicus dorsomedialis anterior; tr.tect.thal.dors.med.post., tractus tecto-thalamicus dorsomedialis posterior; tr.teet.thal.erue., tractus tecto-thalamicus erueiatus. 


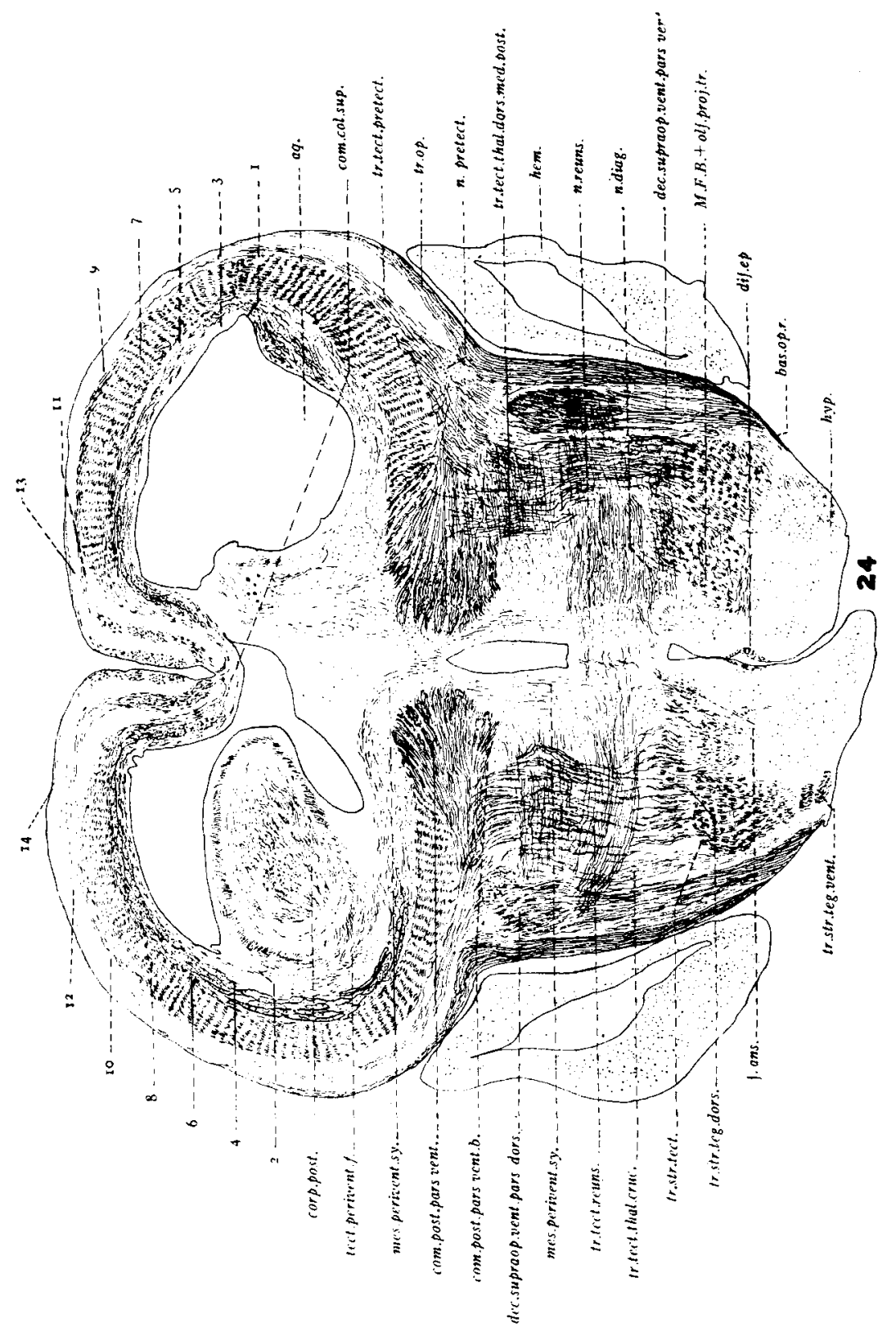


internal to the basal optic root fibers, from which they can easily be distinguished by their greater size and relatively brighter color. (In our silver preparations they are colored brown while the basal optic root fibers are black.) The striotectal fibers run almost directly dorsalward, swinging a little medialward as they pass the tractus tecto-reuniens and the ventral supraoptic system and enter the tectum, where they distribute to the inner layers. Collaterals and apparently some stem fibers end in the tegmental regions of the mesencephalon along the course of the tract. It is undetermined whether or not the tract reaches the roof of the midbrain directly or whether the impulse is carried on by fibers of the next order after a synapse in tegmental regions. We are reasonably certain that in part at least the fibers of our tractus. strio-tectalis reach the optic tectum directly but must admit that our material is not adequate to answer the question fully.

Another problem that arises in connection with this striotectal tract is its possible homology with the isthmo-striatal tract of Edinger ('99). This author has figured in Varanus a tract from the nucleus isthmi to the striatal regions, comparable to one connecting those areas in birds. This isthmostriatal tract appears to occupy the place held in the forebrain

Fig. 24 A cross section passing on the left side through the anterior end of corpus quadrigeminum posterius. Cajal preparation. $\times 15$. aq., aqueduct; bas.op.r., basal optic root; com.col.sup., commissura colliculi superioris ; com.post. pars vent., commissura posterior pars ventralis ; com.post.pars vent.b., commissura posterior pars ventralis b; corp.post., corpus quadrigeminum posterius ; dec.supraop.vent.pars.dors., decussatio supraoptica ventralis pars dorsalis; dec.supraop.vent. pars vent., decussatio supraoptica ventralis pars ventralis; dif.ep., differentiated ependyma; f.ans., fibrae ansulatae; hem., hemisphere; hyp., hypothalamus; mes. perivent.sy., mesencephalic periventricular system; M.F.B. + olf.proj.tr., medial forebrain bundle and olfactory projection tract; $n$.diag., nucleus diagonalis; n.pretect., nucleus pretectalis; n.reuns., nucleus reuniens; tect.perivent.f., tectal periventricular fibers; tr.op., tractus opticus; tr.tect.pretect., tractus tecto-pretectalis; tr.tect.reuns, tractus tecto-reuniens; tr.tect.thal.cruc., tractus tecto-thalamicus eruciatus; tr.tect.thal.dors.med.post., tractus tecto-thalamicus dorsomedialis posterior; tr.str.tect., tractus strio-tectalis; tr.str.teg.dors., tractus strio-tegmentalis dorsalis; tr.str.teg.vent., tractus strio-tegmentalis ventralis; $1-14$, see footnote, p. 143). 
complex by either our ventral tegmental or strio-tectal tract. In our material we have been unable to follow either of these bundles back to nucleus isthmi. This may be due to incomplete impregnation of our material or Edinger's tract may not be the homologue of those of our description. The direction of conduction of the strio-tectal tract is not definitely known.

Tractus hypothalamo-tegmentalis. Besides the longer paths, relatively short fibers from the various nuclei of the hypothalamus pass to other nuclei of that region or to the tegmental part of the midbrain in company with the forebrain fibers. This connection is strengthened by crossed fibers between these regions which run with the postoptic fibers (see discussion of that complex). These are not illustrated in the figures.

\section{Optic tract (figs. 3-7, 9, 10, 12-14, 16-28)}

In the frog, Wlassak ('93) described the optic tract as consisting of three divisions: a larger marginal and smaller axial and basal portions. The homologue of Wlassak's largest division of the optic tract is evident in the alligator; the others are less clearly followed.

In the alligator, the optic fibers on entering the brain form the marginal bundle (figs. 16-28) which, after crossing in the optic tract decussation, assumes a position on the lateral border of the thalamus. In this decussation the fibers are arranged in relatively large bundles, which interlace in the chiasma region. A detailed description of this bundle arrangement in alligator was given by Gross ('03). The fiber bundles run backward and dorsalward, retaining their extreme lateral position until they terminate for the most part in the tectum mesencephali. They run internal to the extreme outer cell layer, the stratum zonale, and distribute largely to the inner band of gray, with which they form the so-called stratum opticum. Collaterals of the fibers just described, and a considerable number of terminal fibers as well, end in the lateral geniculate body. A few fine fibers, whether stem 
or collateral fibers has not been determined, end in the more lateral portion of the cell mass which we have termed nucleus dorsolateralis anterior. Possibly they may have previously synapsed in the lateral geniculate body but we are of the opinion that such is not the case. The number of these fibers is small, but their relation with the lateral somatic area of the thalamus is at least suggestive of the future differentiation in this region of another optic thalamic center, whether avian or mammalian we are not prepared to say. ${ }^{2}$

We have not been able to identify, in our alligator material, an axial bundle distinctly separate from the marginal one. However, certain of the more dorsal fibers of the optic chiasma region and those forming the more medial part of the optic tract swing somewhat away from the main bundle for a short distance in its course lateralward, intermingling in part with the extreme lateral portion of the forebrain fibers and then rejoin the main tract (figs. 19 and 20). These fibers are gray in color in the silver preparations and are not sharply differentiable from the fibers of tractus tecto-thalamicus cruciatus.

These fibers enter the lateral geniculate body, in the main, on the ventral and medial aspects of that nucleus. Some evidently go to the tectum without synapsing in the nuclear mass; in this course they accompany the ventrolateral tectothalamic path which connects the lateral geniculate and the deeper layers of the optic tectum. All of these considerations, namely their difference in staining reaction, their more dorsal position in the optic chiasma region, their more medial course, their intimate relation to the supraoptic complex, and their connection with the deeper layers in the optic tectum, were described as characteristic of the axial optic bundle in Necturus (Herrick, '17). In Necturus, however, the tract appears to run somewhat deeper in the diencephalon and to be more distinctly separate from the marginal bundle, while

\footnotetext{
'The portion ' $n$ ' of the nucleus dorsolateralis anterior obviously will ultimately become a distinct nuclear mass, if the main portion of the nucleus does differentiate into the somatic portion of the mammalian anterior nucleus, as seems at least possible.
} 


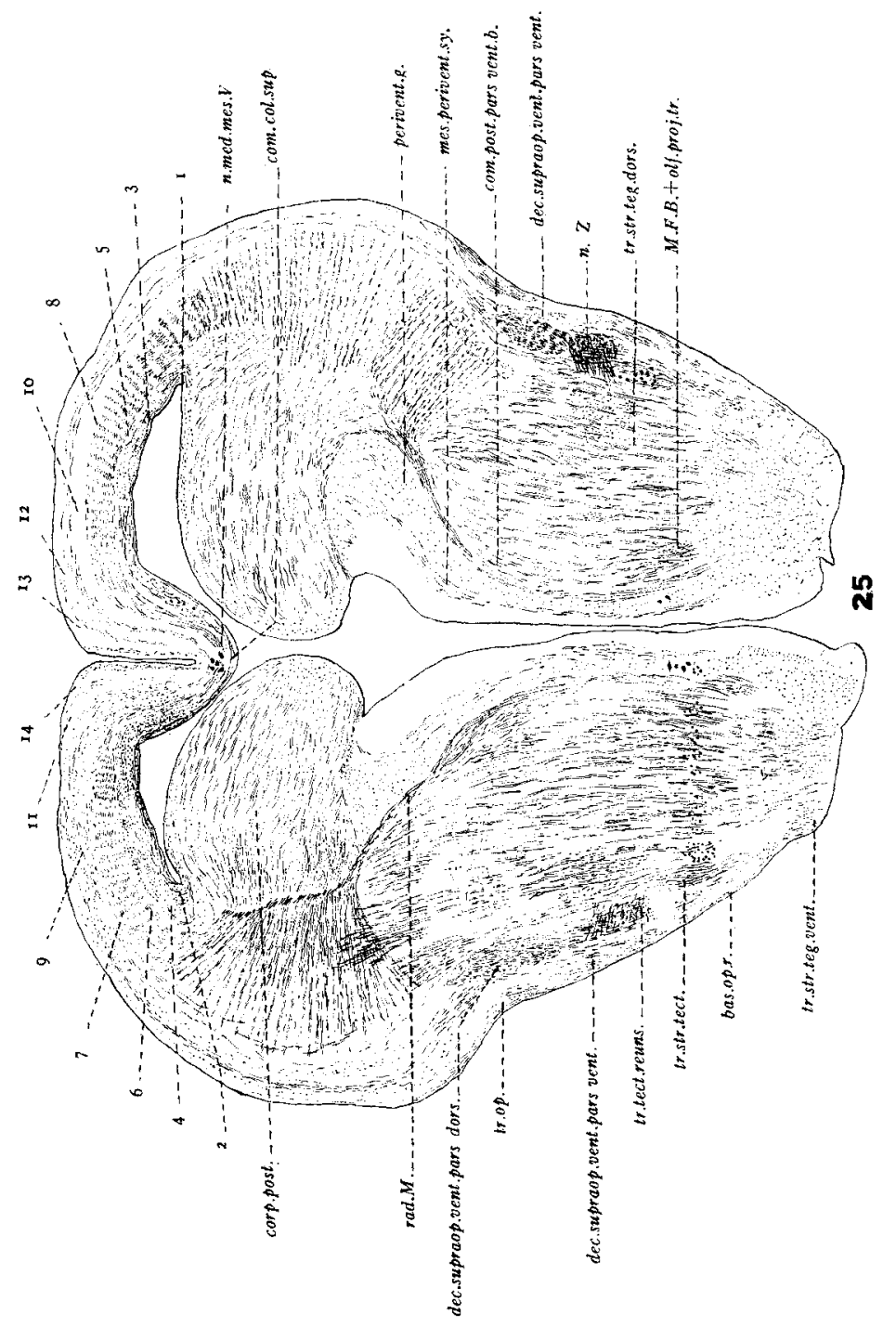


in Reptilia the two bundles form a more or less continuous fiber band which maintains in part the characteristics of both the marginal and axial bundles of Amphibia.

Bellonci ('88) in his work on the central optic connections in vertebrates described the optic paths in such reptilian forms as snake, turtle and lizard. He found that in addition to a superficial optic path there were also found two more or less distinct, deeper paths. The more lateral of these two paths crosses by itself and runs for a short distance separate from the superficial tract and then again joins it. This appears to be the homologue of our pars axillaris. The more medial group he describes as crossing in the more basal portion of the thalamus and then passing outward and upward to become in part intermingled with the fibers of the peduncle; ultimately they rejoin the optic tract. This last described bundle may be the homologue of the axillary bundle described by Herrick ('17) for Necturus and by Wlassak ('93) for frog rather than the tractus opticus pars axillaris of our account. Our preparations do not show the bundle so described by Bellonci unless the tractus tecto-thalamicus cruciatus should prove to be its representative. However, this last mentioned tract, so far as may be determined in our material, belongs to the postoptic or supraoptic complex and has been described by us as one of its components (see description of tractus tecto-thalamicus cruciatus, p. 186). Cajal ('96) has regarded a similar bundle in reptiles as composed in part of optic and

Fig. 25 Cross section caudad to figure 24, through corpus quadrigeminum posterius and hypothalamus. Note particularly the component of commissura posterior (com.post.pars vent.b) which is passing caudad to this level. Cajal preparation. $\times 15$. bas.op.r., basal optic root; com.col.sup., commissura colliculi superioris; com.post.pars vent.b, commissura posterior pars ventralis b; corp.post., corpus quadrigeminum posterius; dec.supraop.vent.pars dors., decussatio supraoptica ventralis pars dorsalis; dec.supraop.vent.parsvent, decussatio supraoptica ventralis pars ventralis; mes.perivent.sy., mesencephalic periventricular system; M.F.B. + olf.proj.tr., medial forebrain bundle and olfactory projection tract; n.med.mes. $V$, nucleus medialis of mesencephalie $\mathrm{V} ; n . Z$, nucleus $\mathrm{Z}$ associated with tractus tecto-reuniens; perivent.g., periventricular gray; rad.M., radiations of Meynert; tr.op., tractus opticus; tr.str.tect., tractus strio-tectalis; tr.str.teg. dors., tractus strio-tegmentalis dorsalis; tr.str.teg.vent, traetus strio-tegmentalis ventralis; tr.tect.reuns., tractus tecto-reuniens. 1-14, layers of optic tectum, see footnote, p. 143. 


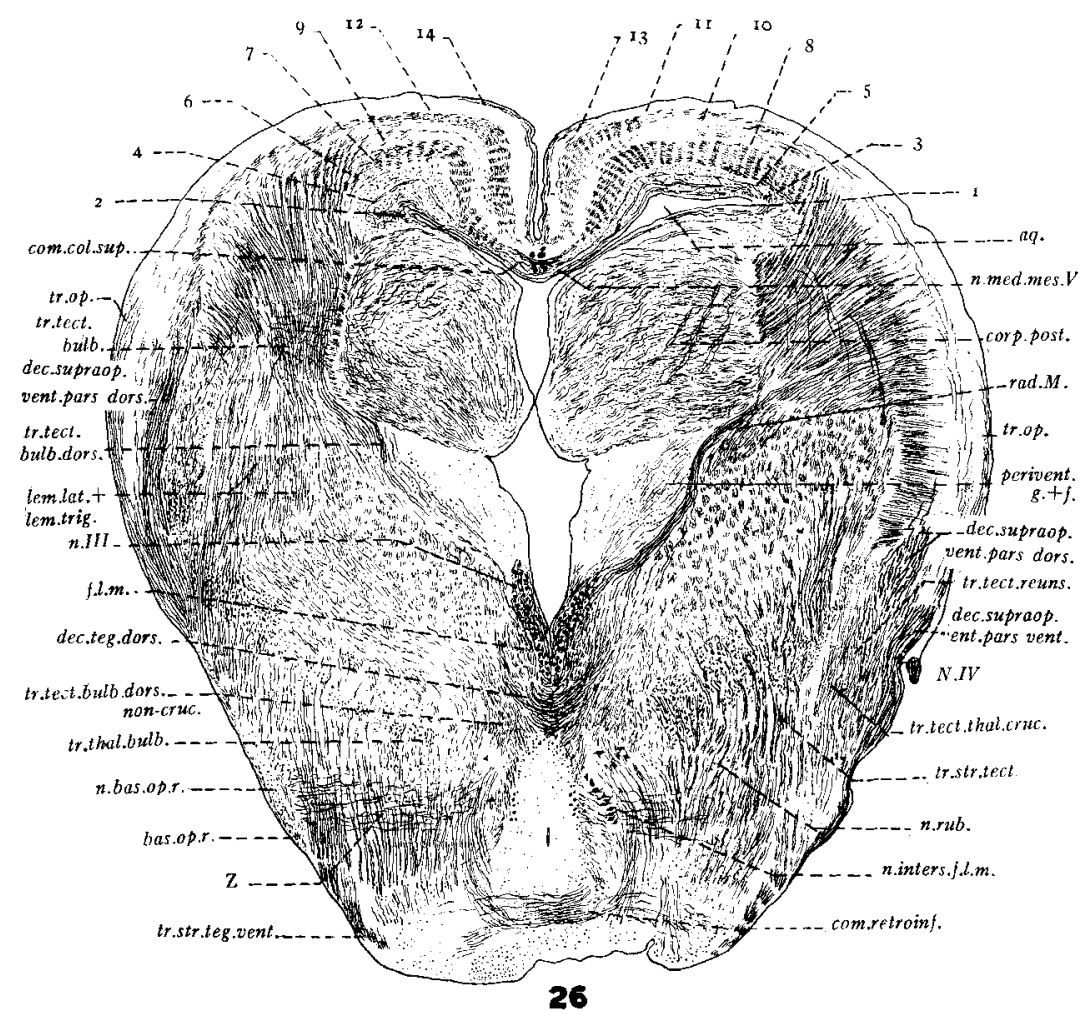

Fig. 26 Transverse section through the optic tectum, corpus quadrigeminum posterius and nuclei of the IIIrd nerve. The figure shows the relative positions of many of the tracts related to the tectum. Attention is particularly directed to the tract labeled $\mathrm{Z}$, being the connection between the nucleus of the basal optic root and the interstitial nucleus of the fusciculus longitudinalis medialis which was recently described by Beccari ('23) for Varanus. aq., aqueduct; bas.op.r., basal optic root; com.col.sup., commissura collieuli superioris; com. retroinf., commissura retroinfundibularis; corp.post., corpus quadrigeminum posterius; dec.supraop.vent.pars dors., commissura supraoptica ventralis pars dorsalis; dec.supraop.vent.pars vent., decussatio supraoptica ventralis pars ventralis; dec.teg.dors., decussatio tegmentalis dorsalis; f.l.m., fasciculus longitudinalis medialis; lem.lat. + lem.trig., lemniseus lateralis and lemniscus trigemini; n.bas. op.r., nucleus of basal optic root; n.inters.f.l.m., nucleus interstitialis of the fascieulus longitudinalis medialis; n.med.mes.V., nucleus medialis of the mesencephalie V; n.rub., nueleus ruber; $n . I I I$, nueleus IIIrd nerve; $N . I V$, IVth nerve; perivent.g. $+f$. , periventrieular gray and fibers; rad.M., radiations of Meynert; tr.op., tractus opticus; tr.str.teet., tractus strio-teetalis; tr.str.teg.vent., tractus strio-tegmentalis ventralis; tr.tect.bulb., tractus teeto-bulbaris; tr.tect.bulb.dors, tractus tecto-bulbaris dorsalis; tr.tect.bulb.dors.non-cruc., tractus tecto-bulbaris 
in part of supraoptic fibers but is not certain of these relations and components. Evidently the only way in which this question can be definitely answered is by experimental degeneration methods and it is our hope that this may be possible in the near future.

Basal optic root (figs. 20-26). As was previously stated, Wlassak ('93) described a basal optic bundle in frogs. Herrick ('17, p. 243) identified this in Necturus but stated that his preparations do not conclusively demonstrate that its fibers are derived from the optic nerve. In a later publication ('25) he says that this doubt in his mind is now removed and he describes the basal optic tract (tractus opticus accessorius posterior of Bochenek) in Amblystoma and Rana as part of the tractus opticus system. It is impossible in our preparations to be certain that the fibers enter with incoming optic bundles, although the experimental work of Marburg ('03) and others would appear to indicate that such is the case. Our material at present is inadequate for determining the question. Behind the chiasma the bundle continues caudad along the lateral surface of the hypothalamus and ends about the level of the nuclei of the third nerve, in a cell mass termed by other workers, the basal optic ganglion (of our terminology, the nucleus of the basal optic root, fig. 26). This nucleus has a definite connection with the dendrites of the ventral interstitial nucleus of the median longitudinal fasciculus and with the nuclei of the oculomotor nerve through a tract previously described in Varanus by Beccari ('23). De Lange has labeled a tract ('13, figs. 23-27, pp. 99-102) in a cross-section of the brain of Draco volans the 'basales opticus Wurzel.' Presumably this is a tract homologous with our basal optic root; although no reference has been made to it in the text. Kappers ('21, p. 864, fig. 463) has copied this figure from de Lange but the label has been omitted (whether intentionally or not is unknown).

dorsalis non-erueiatus; tr.tect.thal.cruc., traetus tecto-thalamicus erueiatus; tr.tect. reuns., tractus tecto-reuniens; tr.thal.bulb., tractus thalamo-bulbaris; $Z$, tract between nueleus of the basal optie root and the interstitial nucleus of the faseiculus longitudinalis medialis and oculomotor nucleus; 1-14, see footnote, p. 143. 

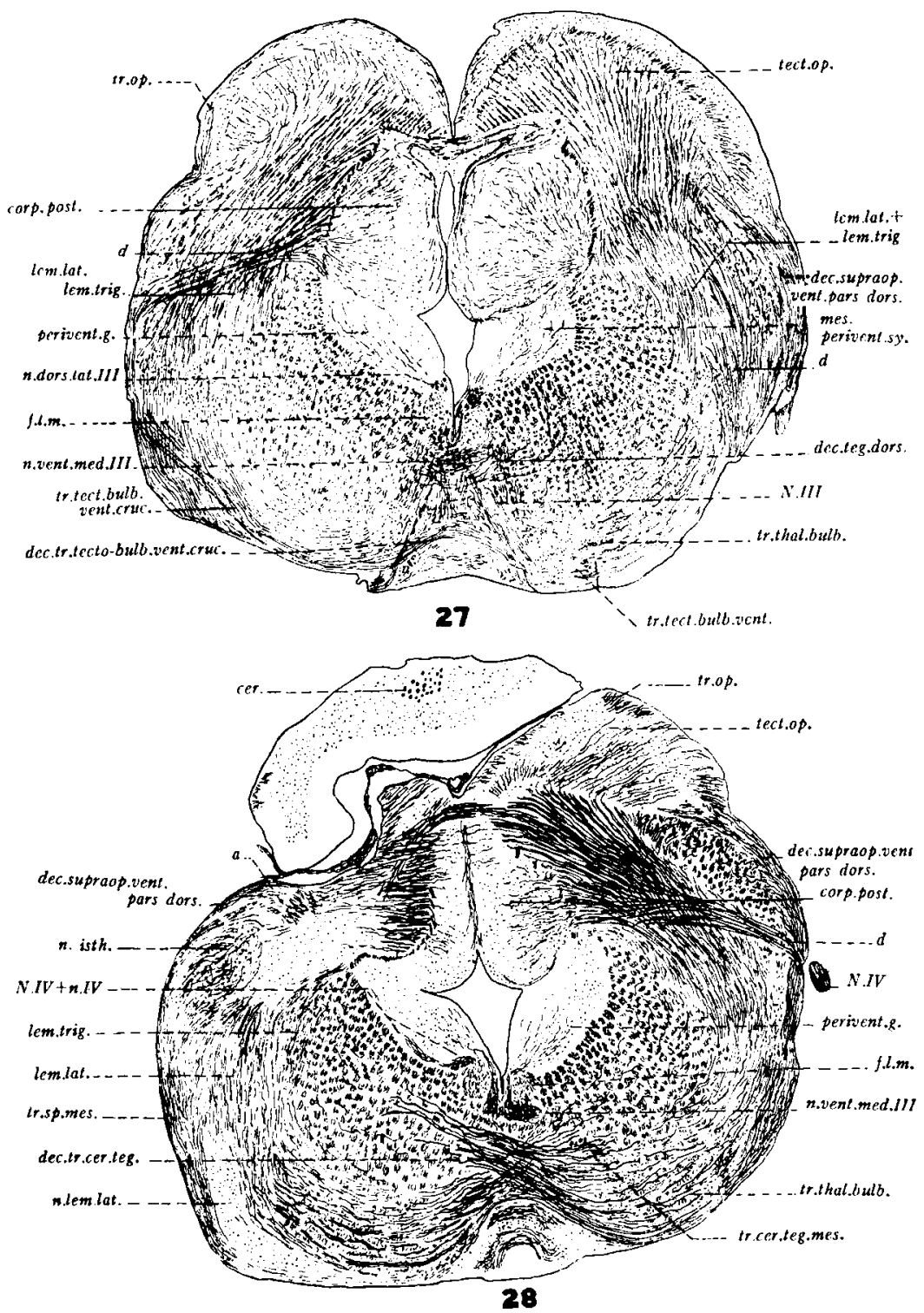

Fig. 27 Transverse section drawn from a Cajal preparation through the corpus quadrigeminum posterius and the nuclei of the IIIrd nerve. $\times 15$. corp. post., corpus quadrigeminum posterius; $d$, fibers of tractus tecto-reuniens and intermingled ventral supraoptie fibers (pars ventralis); dec.supraop.vent.pars dors., decussatio supraoptica ventralis pars dorsalis; dec.teg.dors., decussatio teg- 


\section{Tecto-thalamic and thalamo-tectal paths}

In the alligator and the turtle the thalamus and the midbrain roof are very intimately interrelated by means of a considerable number of fiber tracts. For convenience in description these have been subdivided into several groups, yet they must be regarded as belonging to a broad system of fibers which connects the thalamus from near its anterior end and throughout its extent with the midbrain roof. This constitutes a type of connection which it would seem to us is of importance in gaining an understanding of the factors which operated in producing the reptilian thalamus, which represents so marked an advance in differentiation over the thalamus of the amphibian brain. Certain of these tracts are concerned primarily with relating the tectum and the thalamus of the same side. They have been described below under the designation of uncrossed tecto-thalamic pathways. Others are concerned in relating tectum and thalamus of opposite sides and in establishing commissural relations be-

mentalis dorsalis; dec.tr.tecto-bulb.vent.cruc., decussatio tracti tecto-bulbaris ven. tralis cruciatus; f.l.m., fasciculus longitudinalis medialis; lem.lat. + lem.trig., lemniscus lateralis and lemniscus trigemini; mes.perivent.sy, mesencephalic periventricular system; n.dors.lat.III, nucleus dorsolateralis of IIIrd nerve; n.vent. med.III, nueleus ventromedialis of IIIrd nerve; $N . I I I$, IIIrd nerve; perivent.g., periventricular gray; tect.op., tectum opticum; tr.op., tractus opticus; tr.tert. bulb.vent., tractus tecto-bulbaris ventralis; tr.tect.bulb.vent.cruc., tractus tectobulbaris ventralis cruciatus; tr.thal.bulb., tractus thalamo-bulbaris.

Fig. 28 The plane of this figure is through the most posterior part of corpus quadrigeminum posterius, being further caudad on the left side. Consequently on the left side nucleus isthmi and its connections anteriomedialward with corpus quadrigeminum posterius are to be seen. Cajal preparation. $\times 15$. $a$, connection between nucleus isthmi and corpus quadrigeminum posterius ; cer., cerebellum; corp.post., corpus quadrigeminum posterius; $d$, tractus tecto-reuniens intermingled with a few fibers of decussatio supraoptica ventralis pars ventralis; dec.supraop. vent.pars dors., decussatio supraoptica ventralis pars dorsalis; dec.tr.cer.teg., decussatio tracti cerebelli tegmentalis; f.l.m., fasciculus longitudinalis medialis; lem.lat., lemniscus lateralis; lem.trig., lemniscus trigemini; n.isth., nucleus isthmi; n.lem.lat., nucleus lemnisci lateralis; n.vent.med.III, nucleus ventromedialis of IIIrd nerve; $N . I V$, IVth nerve; $N . I V+n . I V$, IVth nerve and nucleus of the IVth nerve; perivent.g., periventricular gray; tect.op., tectum opticum; tr.cer. teg.mes., tractus cerebello-tegmentalis mesencephali; tr.op., tractus opticus; tr.sp.mes., tractus spino-mesencephalicus; tr.thal.bulb., tractus thalamo-bulbaris. 

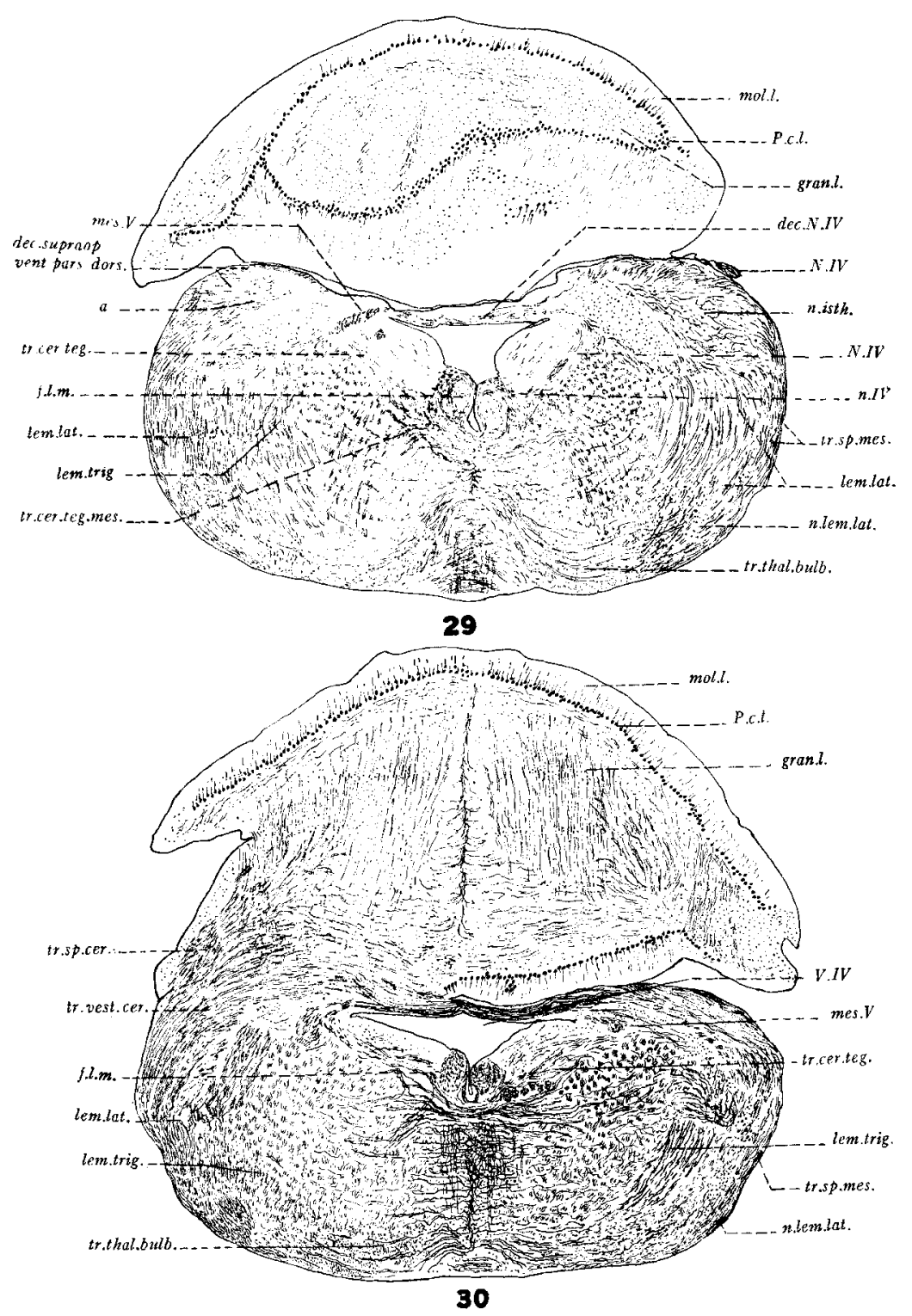

Fig. 29 Figure illustrating particularly the relations of nucleus isthmi with lemniscus lateralis and decussatio supraoptica ventralis pars dorsalis. The nucleus, root fibers and emergent IVth nerve are also shown. Transverse section. Cajal preparation. $\times 15$. a, connection between nucleus isthmi and corpus 
tween the tecta, hypothalami and thalami. These make up the so-called supraoptic or postoptic decussations.

\section{Uncrossed tecto-thalamic and thalamo-tectal paths}

For convenience in description the paths have been described as if running from the thalamus to the tectum. Certain of these bundles carry impulses in both directions, while for others the direction of conduction is as yet not known. Where there is definite knowledge regarding the direction in which the impulse passes, it is indicated in the nomenclature of the tract and stated in the deseription of it.

Diencephalic periventricular system (figs. 19-21). In the silver preparations in the region of nucleus dorsomedialis anterior thalami, bundles of fine fibers of grayish color run ventralward to just above the level of the sulcus medius thalami, then swing lateralward across the thalamus ventral to nucleus lateralis. Then running caudad at the same time swinging dorsolateralward around the ventrolateral portion of nucleus lateralis, they join the ventrolateral tecto-thalamic path and appear to accompany it to nucleus pretectalis and probably to the tectum (figs. 20 and 21). The diencephalic periventricular system is joined by small bundles of fibers from the preoptic and hypothalamic regions.

quadrigeminum posterius; dec.N.IV, decussation of IVth nerve; dec.supraop. vent.pars.dors, decussatio supraoptica ventralis pars dorsalis; f.l.m., fasciculus longitudinalis medialis; gran.l., granular layer; lem.lat., lemniscus lateralis; lem.trig., lemniseus trigemini; mes. $V$, mesencephalic Vth root; mol.l., molecular layer; $N . I V$, IVth nerve; n.IV, nucleus of IVth nerve; n.isth., nucleus isthmi ; n.lem.lat., nucleus of lemniscus lateralis; P.c.l., Purkinje cell layer; tr.cer.teg., traetus cerebello-tegmentalis; tr.certeg.mes., tractus cerebello-tegmentalis mesencephali; tr.sp.mes., tractus spino-mesencephalicus; tr.thal,bulb., tractus thalamobulbaris.

Fig. 30 Transverse section through medulla, on the left side at the level of the cerebellar peduncle. Cajal preparation. $\times 15$. f.l.m., fasciculus longitudinalis medialis; gran.l., granular layer; lem.lat., lemniseus lateralis; lem.trig., lemniscus trigeminus; mes.V., mesencephalic Vth root; mol.l., molecular layer; n.lem.lat., nucleus lemnisci lateralis; P.c.l., Purkinje cell layer; tr.cer.teg., tractus cerebello-tegmentalis; tr.sp.cer., traetus spino-cerebellaris; tr.sp.mes., tractus spino-mesencephalicus; tr.vest.cer., tractus vestibulo-cerebellaris; tr.thal.bulb., tractus thalamo-bulbaris; $V . I V$, ventriculus quartus. 

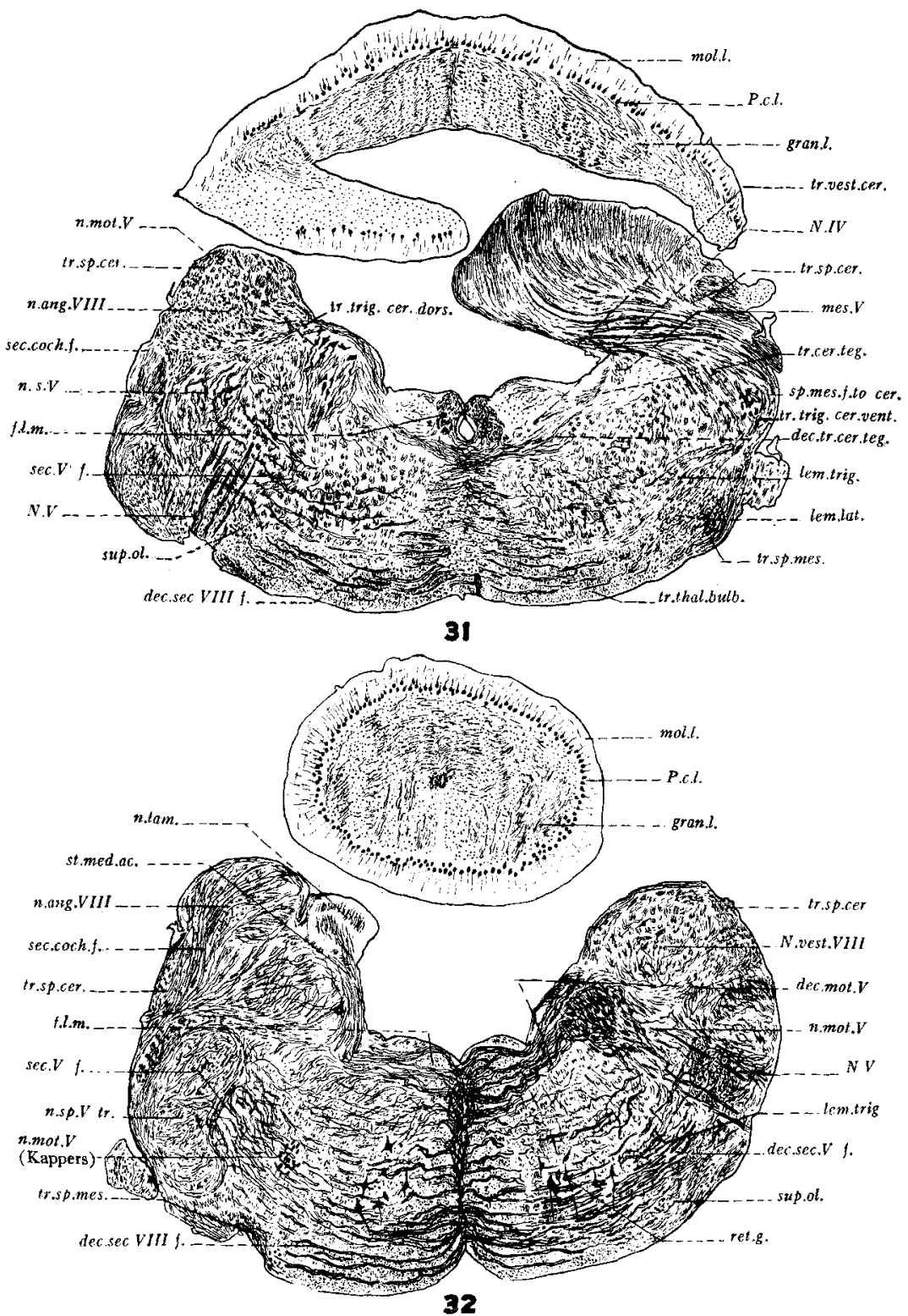

Fig. 31 This figure was drawn from a section somewhat caudad to that illustrated in figure 30. The cerebellar pedunele is shown here on the right side and the beginning of the nucleus of motor $V$ th nerve on the left. Transverse section. Cajal preparation. $\times 15$. dec.sec.VIII $f$, decussating secondary VIIIth fibers; 
The diencephalic periventricular system is composed functionally of the following components: 1) The first type consists of short fibers which form a connection between nucleus dorsolateralis anterior and nucleus dorsomedialis anterior. These fibers are not shown in the figures but are easily visible in the preparations as fibers of short course found on the dorsal side of the bundle, accompanying it for a part of its course and interconnecting the above mentioned nuclei. 2) There are found longer fibers which appear to come from the pretectal nucleus or the tectum or both. Only in degeneration preparations could it be determined which of the two regions is the source of these fibers, since the medial tecto-thalamic path is so intermingled with the other tecto-thalamic paths that it becomes impossible to distinguish definitely their course. These fibers can be observed as forming synaptic relations with the dendrites of cells of nucleus dorsomedialis anterior (fig. 8,b) and nucleus dorsolateralis anterior (fig.

dec.tr.cer.teg., decussatio tracti cerebello-tegmentalis; f.l.m., fasciculus longitudinalis medialis; gran.l., granular layer; lem.lat., lemniseus lateralis; lem.trig., lemniscus trigemini; mes.V., mesencephalic Vth root; mol.l., molecular layer; mislabeled n.ang.VIII, n. vest. of VIIIth nerve; n.mot.V., nucleus of motor Vth nerve; n.s. $V$, nucleus of sensory Vth nerve; $N . I V$, IVth nerve; $N . V$., Vth nerve; P.c.l., Purkinje cell layer; sec.V.f., secondary Vth fibers; sec.coch.f., secondary cochlear fibers; sp.mes.f. to cer., spino-mesencephalic fibers to cerebellum; sup.ol., superior olive; tr.cer.teg., tractus cerebello-tegmentalis; tr.sp.cer, tractus spinocerebellaris; tr.sp.mes., tractus spino-mesencephalicus; tr.thal.bulb., tractus thalamo-bulbaris; tr.trig.cer.dors., tractus trigemino-cerebellaris dorsalis; tr.trig. cer.vent, tractus trigemino-cerebellaris ventralis; tr.vest.cer., tractus vestibulocerebellaris.

Fig. 32 This drawing shows on the right side the nucleus of the motor Vth nerve and on the left certain of the cochlear nuclei. Transverse section. Cajal preparation. $\times 15$. dec.mot.. ., decussating motor Vth; dec.sec. $V f$, decussating secondary Vth fibers; dec.sec.VIII f., decussating secondary VIIIth fibers; f.l.m., fasciculus longitudinalis medialis; gran.l., granular layer; lem.trig., lemniscus trigemini; mol.l., molecular layer; n.ang.VIII, nueleus angularis VIIIth; n.lam., nueleus laminaris; n.mot.V., nucleus of motor Vth nerve; n.mot.V.(Kappers), a secondary motor Vth, nucleus according to Kappers; n.sp.V.tr, nucleus of the spinal Vth tract; N.vest.VIII, vestibular component of VIIIth nerve; N.V., Vth nerve; P.c.l., Purkinje cell layer; ret.g., reticular gray; sec.coch.f., secondary cochlear fibers; sec.F.f., secondary Vth fibers; st.med.ac., stria medullaris acustici; sup.ol., superior olive; tr.sp.cer., tractus spino-cerebellaris; tr.sp.mes., tractus spino-mesencephalicus. 

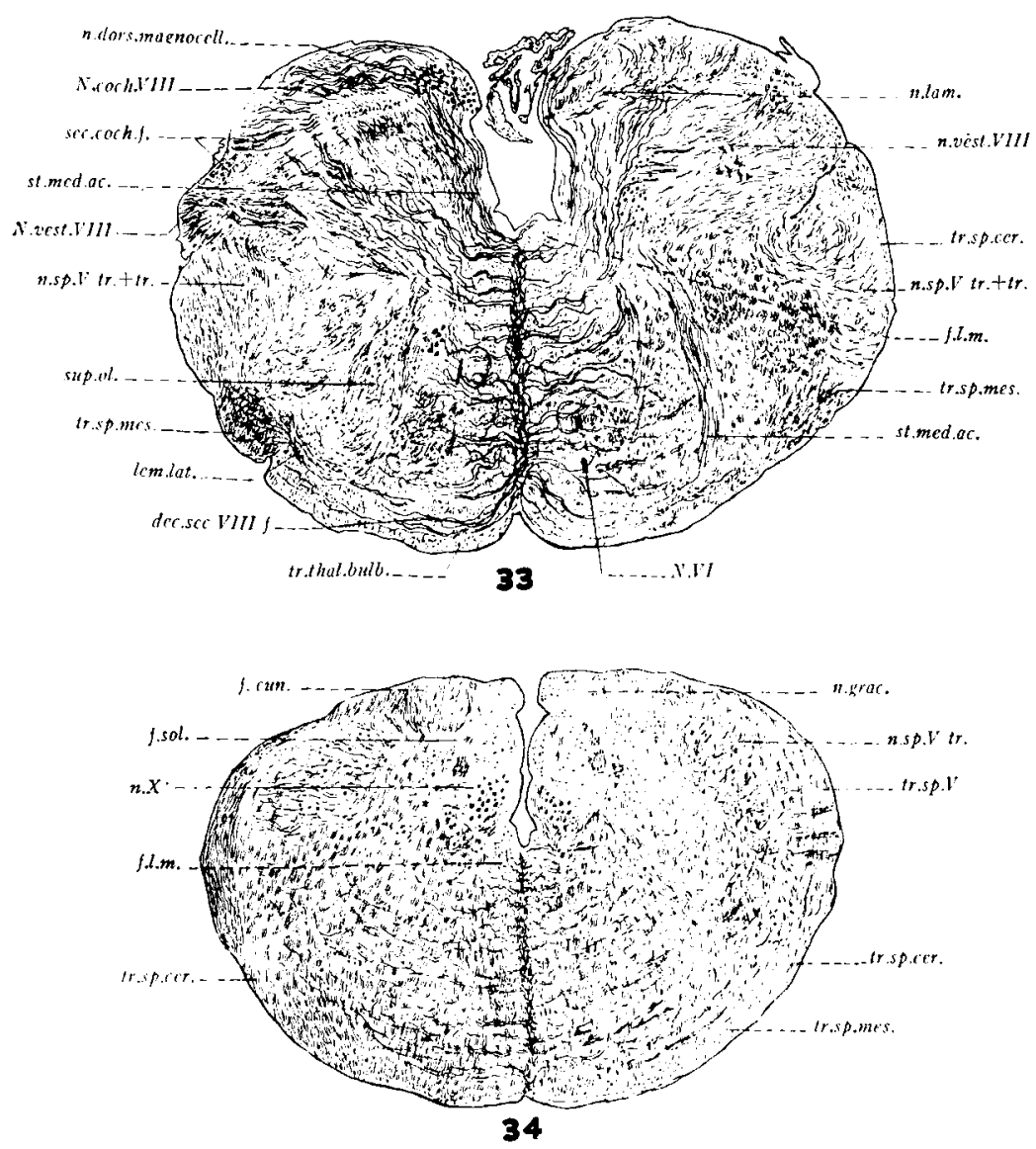

Fig. 33 Transverse section through the entrance of the VIIIth nerve showing two of the main cochlear nuelei. The erossed and uncrossed fibers of stria medullaris acustici (st.med.ac.) are shown in the drawing and something of their relation with the triangular shaped portion of the superior olive. Secondary cochlear fibers running lateralward along the surface of the medulla, particularly to the upper portion of superior olive are to be seen on the right of the figure. Cajal preparation. $\times 15$. dec.sec.VIII $f$., decussating secondary VIIIth fibers; f.l.m., fasciculus longitudinalis medialis ; lem.lat., lemniscus lateralis; N.coch.VIII, cochlear component of the VIIIth nerve; ndors.magnocell., nucleus dorsalis magnoeellularis; n.lam., nucleus laminaris; n.sp.V tr. $+t r$., spinal Vth nueleus and traet; n.vest.VIII., nucleus vestibularis of VIIIth nerve; N.vest.VIII., restibular VIIIth nerve; N.VI, VIth nerve; sec.coch.f., secondary cochlear fibers; st.med.ac., stria medullaris acustici; sup.ol., superior olive; tr.sp.cer., tractus 
$8, a)$. Some of the cell bodies of the latter nucleus even send their dendrites toward the midline between the cells of nucleus dorsomedialis anterior in order to reach the diencephalic periventricular system (fig. 8,a). One may safely conclude then that the impulses are discharged largely at least into the thalamus. 3) The small bundle from the preoptic and hypothalamic regions suggests that these areas may be under the influence of the tectum, but individual fibers could not be traced after they had joined the main bundle.

Tractus tecto-thalamicus dorsolateralis. In the anterior part of the thalamus the fibers of the diencephalic periventricular system lie medial to ventrolateral tecto-thalamic path and are accompanied on their lateral border by fine bundles of fibers which reach the dorsolateral part of nucleus dorsolateralis anterior. We have termed the latter bundles tractus tecto-thalamicus dorsolateralis (fig. 20). The direction of conduction is, however, not known.

Tractus tecto-thalamicus dorsomedialis anterior (figs. 2223). For convenience it is described and named as if it ran from thalamus to tectum. It connects nucleus rotundus thalami and the optic tectum. In the alligator the fibers appear in great numbers in the posterior part of the nucleus. They run directly lateralward until they reach the dorsal division of the ventral supraoptic decussation on its way to the midbrain. They run in part dorsal to the fibers of the decussation, and in part intermingled with them, and accompany them to the more peripheral portion of the optic tectum, prohably synapsing in part in nucleus pretectalis (figs. 24-27 included with the tract labeled dec.supraop.vent.pars dors.).

spino-cerebellaris; tr.sp.mes., tractus spino-mesencephalicus; tr.thal.bulb., tractus thalamo-bulbaris.

Fig. 34 Figure drawn through medulla at the point where the central canal is beginning to widen out into the fourth ventricle. The drawing was made to show fasciculus gracilis, fasciculus cuneatus and their associated nuclei. Cajal preparation. $\times 15$. f.cun., fasciculus cuneatus; f.l.m., fasciculus longitudinalis medialis; f.sol., fasciculus solitarius; n.grac., nucleus gracilis; n.sp.V tr., nucleus of the spinal Vth tract; n.X., nueleus Xth nerve; tr.sp.cer., tractus spino-cerebellaris; tr.sp.mes., tractus spino-mesencephalicus; tr.sp.V., tractus spinalis V. 
We do not know positively the direction of conduction of this path but our Cox preparations indicate that it is in part at least tecto-thalamic.

In the turtle the fibers of the dorsomedial tecto-thalamic tract are numerous. A greater number of the fibers appear to extend no further than nucleus pretectalis, the tract being then joined by fibers which run between that nucleus and the tectum (tractus tecto-pretectalis). Otherwise the relations of the tract in alligator and turtle are very similar.

Tractus tecto-thalamicus dorsomedialis posterior (figs. 2324 ) ; tractus tecto-thalamicus medialis (fig. 22). The posterior portion of the dorsomedial tecto-thalamic tract arises from nucleus circularis (and possibly from other nuclei of the region) and runs across the thalamus as a distinct tract until its lateral border is reached. There it swings dorsal to the anterior division of the tract and in company with it and with the dorsal division of the ventral supraoptic commissure passes to nucleus pretectalis and tectum. The direction of conduction is not known. The tract is joined in course by fibers from the posterior and probably the anterior medial thalamic nuclei which appear to accompany it to the tectum. This latter tract (which we have termed tractus tecto-thalamicus medialis) is small, consisting in our material of fine scattered fibers which run dorsalward from the nuclei, across the fibers of tractus habenulo-peduncularis and then appear to join tractus dorsomedialis posterior on its ventral side and accompany it tectalward.

Tractus tecto-reuniens (figs. 23-28). Edinger ('99) has figured in part the course of the tractus tecto-reuniens in Varanus (plate 1, figs. 1-3) but has not been able to follow it to the tectum. Of the nucleus reuniens he says, "Er hat grosse multipolare Ganglionzellen und entsendet nach jeder Seite markhaltige Nervenfasern, die weithin bis nahe an die Peripherie des Zwischenhirnes treten, dann aber der Verfolgung verloren gehen." He believed, however, that they pass to the tectum, basing his conclusions on an analogous tract in birds. De Isange ('13) has described and figured a tractus 
tecto-reuniens in several reptiles. In the alligator, the tract which we believe to be homologous with the tractus tectoreuniens of this description runs directly lateralward and then curves slightly dorsolateralward from the nucleus reuniens until it reaches the more lateral portion of the thalamus (figs. 22-25) carrying with it some fibers from the opposite side (fig. 22). Then we can follow some of the fibers dorsalward, running medial to the ventral division of the ventral supraoptic commissure (fig. 26) and ventral to the mingled fibers of the dorsal supraoptic decussation and the anterior division of the tractus tecto-thalamicus dorsomedialis.

The major portion of the fibers of the tractus tecto-reuniens become intermingled with a nuclear mass which is situated near the lateral surface of the thalamic wall just above the lateral forebrain bundle at the level of the nucleus entopeduncularis. This nucleus appears to contribute to the tract tectalward. Nothing short of degeneration preparations, in our opinion, could settle the question as to what percentage of the tecto-reuniens system synapses in this nuclear mass (labeled nucleus $Z$ in figure 25). We feel reasonably certain that some of the fibers can be traced dorsalward without synapse in the nucleus. As the tract passes nucleus pretectalis collaterals appear to be given off. It ends chiefly in the deeper layers of the tectum but some of the fibers, in company with the pars ventralis of the ventral supraoptic decussation, pass to corpus quadrigeminum posterius (figs. $28-28, d)$.

Tractus tecto-pretectalis (fig. 24). Throughout its extent the nucleus pretectalis, in both the turtle and alligator, is closely related to the deeper portions of the tectum and its medial wall on the one hand and to the thalamic nuclei and particularly to nucleus rotundus on the other. The thalamic connections have been described with several of the tectothalamic tracts. The fibers which form the connection between the nucleus pretectalis and the tectum have been designated the tractus tecto-pretectalis. An examination of the 
figures shows that the bundle forms an integral part of the tecto-thalamic system.

Tractus tecto-thalamicus ventrolateralis (figs. 19-22). Tractus tecto-thalamicus ventrolateralis probably conducts in both directions. For the sake of clearness of description it is here given as if passing from thalamus to tectum. Arising partly from the whole extent of the lateral geniculate body, and including also the lateral part of the dorsal supraoptic decussation, the fibers of this tract run almost directly dorsal. ward-somewhat posterior-and just internal to the optic tract. Intermingled with these are fibers of tractus tectothalamicus cruciatus, which apparently have not synapsed in the nucleus of the latter tract but are passing directly to the tectum. When the upper part of the thalamus has been reached, the tract swings medialward toward the habenula (fig. 21), however, not reaching it but passing posterior to it and entering for the most part the medial side of the tectum. On their way many fibers appear to synapse in nucleus pre. tectalis and others may reach nucleus lentiformis mesencephali. From this nucleus fibers pass to the deeper parts of the tectum and to the medial wall. Anteriorly tractus tecto thalamicus dorsolateralis is not sharply separable, on its medial border, from the fibers of the diencephalic periventricular system. As the more caudal portion of tractus tectothalamicus ventrolateralis is reached, this system is gradually replaced medialward by the fibers of the tractus tectothalamicus cruciatus (most of which in this region have not synapsed in nucleus tractus tecto-thalamicus cruciatus) and by the fibers of the dorsal supraoptic decussation.

The tractus tecto-thalamicus ventrolateralis as found in the alligator may be said, in general terms, to provide a connection between the lateral geniculate body and the tectum and in this sense foreshadows the mammalian peduncle of the superior colliculus. In addition it specifically connects the nuclear mass associated with tractus tecto-thalamicus cruciatus (which nucleus (n.tr.tect.thal.cruc., figs. 5, 6 and 22) we consider at present a part of the lateral geniculate body) 
and the tectum. This latter connection is probably both crossed and uncrossed and appears to make up the large portion of the fibers of the tract.

2. Crossed tecto-thalamic and thalamo-tectal paths (Supraoptic decussations)

The so-called supraoptic or postoptic complex includes quite a number of more or less distinct fiber tracts, in part distributing to the same side from which they arise, partly decussating and partly commissural. Possibly there is no group of fibers whose relations have seemed more confusing or whose homologies in the various forms have proved more baffling than those making up this complex. A number of investigators, Edinger ('99), de Lange ('13), Cajal ('96), C. L. Herrick ('93), C. Judson Herrick ('17, in Necturus), Kappers ('21), Beccari ('23) and others, have described and figured various components of this complex, but differences in materials studied and methods and terminology used make it extremely difficult and in some cases impossible to correlate the findings. The majority of the accounts deal with medullated fibers. However Cajal and C. J. Herrick used silver material and in part at least describe the non-medullated tracts.

For convenience in description, since the various tracts are relatively distinctly separated by position and medullation, the complex has been rather arbitrarily divided into a number of more or less interrelated parts. It was hoped that by this method the details might be more intelligible to the reader and it was conjectured that it might be easier to check the descriptions with those given for other forms.

The following terminology has been employed:

Decussatio supraoptica ventralis

Pars dorsalis

Pars ventralis

Decussatio supraoptica dorsalis

Tractus tecto-thalamicus et hypothalamieus cruciatus

Fibrae ansulatae

Short decussating fibers between preoptic and hypothalamic centers 
Herrick has described in Necturus ('17) a postoptic complex, one very important portion of which is a tractus tectothalamicus et hypothalamicus cruciatus. He has shown it to be divided into an anterior and a posterior division, the first being concerned primarily with the superior colliculus and the latter with tuberculum posterius. 'The ventral part of the thalamus, the lateral regions of the hypothalamus and the so-called nucleus of the tuberculum posterius receive fibers from each of these divisions. Tractus thalamo-hypothalamicus et peduncularis cruciatus is also described by Herrick ('17) in Necturus as another large component of this postoptic decussation. According to his description, these fibers arise from the dorsal part of the thalamus, and pass downward lateral to the lateral forebrain bundle. The myelinated portion of this tract crosses dorsal to the decussating fibers of the tractus tecto-thalamicus et hypothalamicus cruciatus and caudad to them and then turns upward and, just above the lateral forebrain bundle, through which its fibers have passed, swings back into the ventral part of the thalamus and the peduncular regions.

The general relations of the parts so described for Amphibia will be seen to compare with those in the following accounts for reptiles. When it comes to homologizing special tracts one immediately encounters difficulties. In their relations to the colliculi the anterior and posterior portions of Herrick's tractus tecto-thalamicus et hypothalamicus cruciatus correspond to the dorsal and ventral divisions of the commissura supraoptica ventralis of the present description, but so soon as the details are considered the tracts in the two groups do not wholly agree. In the same way there are certain points of resemblance between the tractus thalamo-hypothalamicus et peduncularis cruciatus of Necturus and the dorsal supraoptic decussation of the present description but the homologies must not be considered too closely. Recently Larsell ('23) has shown in the frog the presence of a commissura transversa (comparable in part to the decussatio supraoptica ventralis, of the present description) which ac- 
cording to his account, ends partly in nucleus isthmi. This nucleus, he believes with Kappers, is to be compared with the medial geniculate nucleus of higher forms.

It is quite clear that in the alligator and turtle the commissura supraoptica ventralis corresponds in the main with Gudden's commissure of Mammalia with the exception that in reptiles the chief connection of this tract is with the tectum, while in mammals it is with the medial geniculate body. It is, however, not the commissura transversa of Edinger ('99) which is represented by the dorsal supraoptic decus. sation.

De Lange ('13, p. 78) has shown in a drawing of a cross section of Varanus salvator, a mass of fibers in the midline which he has labeled the decussatio supraoptica. In general position the tract resembles the dorsal rather than the ventral supraoptic decussation of the present account. The homologies here are not quite clear to us, especially since in a series of outline drawings of the diencephalic and mesencephalic centers of Alligator sclerops, which occur at the end of his 1913 paper, de Lange undoubtedly has labeled the dorsal supraoptic commissure of the present account as the transverse decussation.

Kappers ('21) has figured in several reptiles both dorsal and ventral supraoptic decussations or commissures as he terms them. The latter is figured in the brain of Crocodilus porosus (fig. 464, p. 865 ; figs. 461 and 462 , p. 862). The two divisions mentioned in the present account of Alligator mississippiensis are grouped as one in Kappers' account. $\mathrm{He}$ finds that the ventral supraoptic commissure is connected with the inferior colliculus and possibly with nucleus isthmi, although this last connection did not stand out definitely in his preparations. The dorsal supraoptic commissure he considers the homologue of Meynert's commissure, stating that it arises first in reptiles, being particularly clear in Crocodilia and that it is apparently concerned with the interrelating of the neostriatal regions. It has not been possible to demonstrate this connection with the neostriatum in the alligator 
and turtle material available. Quite possibly the tracts are present but are not impregnated in the silver preparations used. They are not, however, demonstrable in the material stained for medullated fibers. Other relations of the decussation are relatively clear, as will be seen from the subsequent account. In birds, connections of the regions of the neostriatum through the dorsal supraoptic decussation, have been described.

Decussatio supraoptica ventralis, pars dorsalis (figs. 1929). In the chiasmal region (fig. 19) of the alligator, these commissural fibers appear in the midline forming a compact body of decussating fibers just behind the optic tracts. This pars dorsalis is the most anterior part of the postoptic complex at its decussation. It then turns posteriorward and lateralward for the first part of its course, and is surrounded by optic tract fibers (fig. 20). As the optic tract fibers turn dorsalward, the fibers of this dorsal part of the ventral supraoptic decussation swing inward and occupy a position internal to the optic tract fibers, following a course parallel to them, then pass caudad and dorsalward to the midbrain (figs. 2129). During their course through the posterior part of the thalamus they are joined by the anterior division of the dorsomedial tecto-thalamic tract, more dorsal fibers of the pars dorsalis of the decussatio supraoptica ventralis crossing those of the tractus tecto-thalamicus dorsomedialis anterior at right angles (fig. 23). Gradually (with the dorsomedial tectothalamic portion occupying in general the more dorsal part of the bundle) the two become more or less intermingled. They thus run together to the tectum and apparently distribute there to the same regions. Near the posterior part of the thalamus the posterior division of the dorsomedial tectothalamic tract swings inward dorsomedial to the fiber complex and runs to the tectum. Some of its fibers appear to be mingled with those of the complex just described. Just medial to the main tract lies the pretectal nucleus. The fibers of the dorsal division of the ventral supraoptic decussation with their accompanying tecto-thalamic fibers reach the more pe- 
ripheral cell layers of the optic tectum throughout the greater part of its extent. These are true commissural fibers uniting the optic tecta of the two sides throughout practically their whole extent. A small slip of the tract runs back into the nucleus isthmi (figs. 28 and 29). This nucleus is probably the forerunner of the medial geniculate body of higher forms and so this connection, while small, is of considerable theoretical interest (see the account of the connections of nucleus isthmi, p. 206).

In the turtle (Chrysemys marginata) the dorsal part of the decussatio supraoptica ventralis consists of a relatively large mass of fibers which cross behind the optic decussation and then pass directly dorsolateralward, immediately internal and somewhat mingled with the optic fibers. Some of them may synapse as they pass across the thalamus. The material available is not suitable for answering that question.

Decussatio supraoptica ventralis, pars ventralis (figs. 19-28). At nearly the same level (fig. 19) of the chiasmal region in which the dorsal part of the ventral supraoptic commissure is found but somewhat farther ventralward and slightly posterior, occurs the ventral division of the ventral supraoptic decussation. In the alligator these fibers, similar to those of the dorsal portion, are concerned in part in placing the tecta of the two sides in relationship with each other. They are clearly distinguishable from the optic tract, among which they lie for a part of their course, by reason of their more brilliant coloring. After their decussation the dorsal and ventral portions of the ventral supraoptic decussation run backward practically as a single band of fibers until they are separated by the tractus tecto-reuniens which swings in between them, ventral to the dorsal division. Very shortly after their separation the ventral part of the ventral supraoptic decussation begins to swing dorsalward, a few strands at a time, first between the optic tract and the tractus tectoreuniens and then farther dorsalward between the optic tract and the dorsal part of the ventral supraoptic decussation, and so reaches the more peripheral cell layers of the tectum, 
where its fibers distribute. Some of the fibers of the tract appear to join the tractus tecto-reuniens and to distribute with it to the most posterior part of the optic tectum and to the corpus quadrigeminum posterius (the combined tracts have been labeled $d$ in figs. 27 and 28). The corpus quadrigeminum posterius, it must be remembered, is submerged beneath the surface in the alligator and turtle brains and in eertain other reptilian brains.

The above account of the ventral division of the ventral supraoptic decussation is based on a study of the alligator brain. In the turtle this tract does not appear as clearly differentiated from the dorsal division of the decussation (at least such is the case in the material studied); it lies just ventral to the latter and keeps that position in its course across the thalamus to the tectum where it distributes to the inner cell layers, a small strand of it reaching the posterolateral portion of the region as in the alligator.

Tractus tecto-thalamicus cruciatus (figs. 21-26). This tract appears to be the homologue of the tractus opticus commissuralis described in the chameleon by Cajal ('96). Edinger ('99) saw the bundle in reptiles but was not able to decide fully whether or not it was optic. In our opinion the tract belongs, at least for the most part, to the postoptic or supra. optic complex. So far as we have been able to follow the bundles they decussate in the chiasmal ridge and do not enter with the optic nerve, though it is self evident that it has not been possible to follow independently every fiber. Consequently, there may be some optic fibers intermingled with them. It is hoped that experimental work to be undertaken in the near future may enable a more decisive answer. The crossed tecto-thalamic tract appears as a band of fine, unmedullated fibers which crosses the dorsal part of the chiasmal ridge and swings internal to the optic tract, from which it is distinguishable because of the difference in coloring of its fibers. After being joined by the axones of cells situated in the more posterior and lateral part of the nucleus preopticus, and possibly in the hypothalamic nuclei also, the crossed tecto- 
thalamic tract swings between the lateral forebrain bundle and the ventral supraoptic decussation and, turning dorsalward in this position, reaches its nucleus (nucleus tracti tectothalamici cruciati, figs. 5, 6 and 22) which lies between the tracts just mentioned and which we have considered with the lateral geniculate body (p. 122). In this nucleus part of the fibers of the crossed tecto-thalamic tract end; others pass to the midbrain without a synapse in this region, accompanying the ventrolateral tecto-thalamic tract. Some of the more posterior of the crossed tecto-thalamic tract, however, run to the midbrain as a distinct bundle. In course the fibers of this bundle run dorsalward, medial to the ventral supraoptic decussation and the tracts associated with its two portions. Tractus tecto-thalamicus cruciatus appears to end partly in nucleus pretectalis (fig. 24); probably other fibers reach the tectum directly.

Decussatio supraoptica dorsalis (figs. 17-18, 20-23). These fibers have been figured in the reptilian brain by Edinger ('99), de Lange ('13), and other observers under the name of the decussatio transversa, and by Kappers ('21, p. 865, fig. 464) in Crocodilus porosus as decussatio supraoptica dorsalis (Meynert). In the alligator the fibers making up the tract cross in the chiasmal ridge in the same bundle as do the fibers of the lateral part of the crossed tecto-thalamic tract; then they swing dorsalward and lateralward across the ventral part of the thalamus among the fiber groups of the lateral forebrain bundle. Some of the fibers of this medial part, especially the more anterior ones, appear to accompany the thalamo-striatal fibers to the dorsal part of the thalamus. A large part of the fibers end in the nucleus decussationis supra. opticae dorsalis which lies in the lateral part of the thalamus medial to the nucleus tracti tecto-thalamici cruciati. This nucleus is just dorsal to the lateral forebrain bundle (fig. 17). This nucleus is probably not the cell mass described by Edinger for reptiles and certainly not the one described later by de Lange ('13) for these forms as the nucleus decussationis transversae. 
The posterior fibers of the dorsal supraoptic commissure run posterocaudad so intermingled with the forebrain bundles that the ultimate termination of all the parts of the complex have not been determined. In part they reach the more posterior part of the optic tectum, some of them may synapse in tegmental regions but we are not certain of this connection. As was stated in the general description of the postoptic system (p. 183) we have been unable to establish any connection with the neostriatal regions such as Kappers believes to be present.

Fibrae ansulatae (figs. 21-24). The ansulate fibers first appear as fine darkly staining bundles which cross in the chiasmal ridge posterior to the components of the supraoptic system so far discussed. After their decussation the fibers run obliquely dorsocaudad and so reach the region medial to the medial forebrain bundle and the olfactory projection tract. As they swing caudalward and upward they lie ventral to the interstitial nucleus of the medial longitudinal fasciculus and gradually. become a part of that fasciculus. They probably represent the crossing of certain components of that fasciculus. They have been described by Bellonci ('88) and Beccari ('23). Their relations in the alligator are in agreement with those described for other reptiles. These fibers are not the commissura ansulata described by Joustra ('18) and Larsell ('23), which lies in the mesencephalon.

Summary of the fiber systems of the supraoptic decussations. The writers realize fully that in the foregoing account of the supraoptic complex the separating of the mass of fibers into independent tracts represents an arbitrary division of groups of fibers which functionally are intimately interrelated. However, this seemed to offer the best method of presenting the mass of detail necessary for a clear understanding of the various connections of the group. But, while the finer relations and connections of the various systems are intricate, the functional pattern of the postoptic complex is relatively simple. The postoptic decussating fibers consist primarily of: 1) commissural fibers between the tecta and between the dorsal and ventral thalami of the two sides; 2) 
crossed and uncrossed thalamo-tectal and tecto-thalamic tracts; 3) crossed and uncrossed tecto-hypothalamic tracts; 4) commissural fibers between preoptic nuclei and hypothalamic regions near the postoptic decussation; 5) the interrelation of components of the medial longitudinal fasciculus through the fibrae ansulatae. In addition to all these there is the connection of the ventral supraoptic decussation with the nucleus isthmi and the tegmental relation of the dorsal supraoptic system which we have not been able thus far to analyze completely. Thus it appears that primarily the postoptic decussation is concerned first, by a system of commissural and decussating fibers, in putting into relationship the tectum of one side with that of the other and the thalamus of one side with that of the other, and secondly in relating the ventral part of the thalamus with the tectum. In addition to these there is the interrelation of bulbar and tegmental areas through the ansulate commissure and probably part of the dorsal supraoptic complex. The tracts of the supraoptic com. plex are partly represented in fishes; the main functional systems appear to be represented in Amphibia; in reptiles we find an exaggeration which places it among the outstanding fiber systems of the tectum and thalamus. This development is undoubtedly associated with the greater development of these regions in reptiles as compared with lower forms and is particularly concerned with the influence which the highly developed tectum must have on the developing thalamus (see also the discussion at the end of the paper).

\section{Lemniscus systems}

The secondary ascending sensory pathways are prominently represented in the reptilian brain. Correlated with this prominence of the secondary ascending pathways is the appearance of well developed neothalamic centers and of the neopallial cortex in the forebrain. Several of these ascending pathways form their chief connections, at least so far as number of terminating fibers is concerned, within the tectal centers and then reach thalamic centers through the highly 
developed tecto-thalamic system. Certain of these ascending sensory tracts have been quite completely described for reptiles, while others have been only incidentally mentioned. In the following account only a brief summary will be given of such tracts as correspond with previous descriptions, while more attention will be devoted to details which appear to represent original matter. The following accounts present the observations made on the preparations at our disposal; its incompleteness is fully realized.

1. Trigeminal lemniscus (figs. 26-32). Kappers ('21) emphasizes the probability of trigeminal lemniscus connections, an assertion based on the size and development of the neothalamic nuclei, although he was unable to identify the tract in his material. Secondary ascending pathways from the sensory and spinal Vth nuclei can, in the alligator brain, be traced cephalad to the tectal centers and represent at least an anlage of the trigeminal pathways of higher forms, although they are predominately trigemino-tectal rather than trigemino-thalamic. It is not possible at every level to demark clearly this tract from other bulbo-thalamic pathways, since, as in mammals, it tends to form a part of the general lemniscus system. However, its general position can be made out easily.

Throughout the caudal portion of the medulla, fibers can be seen arising from the nucleus of the spinal $V$ th tract and decussating in the midline (fig. 32). After crossing they lie at first somewhat medialward, but soon swing lateralward to take a position ventral and medial to the spinal Vth nucleus and dorsal to the spino-mesencephalic tract. In this ventromedial position these trigeminal fibers then run forward, receiving additional fibers at every level. When the region of the chief sensory nucleus of the Vth is reached, there is observed a particularly large number of decussating Vth fibers, which join the tract. Apparently some uncrossed fibers also enter it, but it is not possible in the material at hand to determine this fact conclusively. These decussating fibers from the spinal and sensory nuclei of Vth consist of two main types 
of fibers, which cross together and which ean be differentiater? from each other only as they pass to their several destinations. They are partly trigemino-cerebellar (nucleo-cerebellar or ventral arcuates-see account of trigeminal comnections, $p$. 214) and partly a trigemino-tectal path, with which latter path we are at present concerned. As the trigemino-cerebellar fibers of Vth pass around the sensory Vth nucleus, the trigeminal lemniscus fibers retain their former position ventro-medial to the nucleus but turn cephalad and pass toward the tectum and thalamus. In front of the nucleus they swing dorsalward and so lie in the mesencephalon dorsal to the forebrain bundles and medial to the lateral fillet. The more dorsal of the fibers swing upward with the lateral lemniscus fibers to end in the deeper layers of the optic tectum (stratum lemnisci). It is altogether probable that some of these fibers extend forward into the thalamic region, but they could not be demonstrated to our complete satisfaction in the preparations at hand. The path, with some spinal lemniscus fibers, in all probability runs to the nucleus rotundus. Throughout its course the trigeminal lemniscus has been internal to and intimately associated with the lateral lemniscus until that tract swung forward to the inferior colliculus. The trigeminal lemniscus, for a part of its course, is closely related to the spino-mesencephalic path (the forerunner of the spinal lemniscus system) until the two became separated by the intervening lateral lemniscus. The three together form a part of the great sensory ascending system which is collectively known in mammals as the fillet or lemniscus path.

In connection with the other great sensory paths of the reptilian brain the presence of a dorsal funiculus in the spinal cord should be mentioned. Zeehandelaar ('19) in Varanus and Crocodile, has called attention to the presence of a more anterior nucleus of Goll (nucleus gracilis) and a more posterior nucleus of Burdach (nucleus cuneatus). In Alligator mississippiensis two nuclear groups, not always entirely distinct, have been identified in connection with the dorsal funiculus (fig. 34). The medial nucleus (nucleus of 
Goll) extends through nearly the posterior half of the medulla up to about the level of the nucleus magno-cellularis of the cochlear VIIIth. Its cells are scattered among the fibers of the fasciculus. From these cells a secondary tract can be traced downward and then medialward where it joins the decussating fibers coming from the nucleus of the spinal Vth. It undoubtedly decussates with these spinal Vth fibers and possibly accompanies them cephalad (see, however, tr. thalamo-bulbaris, p. 201). These decussating fibers probably constitute the beginning of the medial fillet of higher forms as the term is used in its more limited sense, i.e., exclusive of spinal and trigeminal lemnisci, although in the material available there is no evidence that they reach the higher centers.

2. Lateral lemniscus (figs. 26-33). Beccari ('12), de Lange ('16), Schepman ('18), and Joustra ('18), have all contributed to our understanding of the cochlear component of the VIIIth nerve in reptilian forms. Beccari ('12) worked particularly with Lacerta muralis, de Lange ('16) studied a variety of reptilian forms, among them giving figures of Alligator sclerops (de Lange's figures are also copied by Kappers, '21, pp. 400-401, figs. 182 and 183). Schepman ('18) presents figures of crocodile (Kappers, '21, fig. 184, p. 402, since Schepman's original paper was not available). A summary of the results of these workers is given by Kappers and it is unnecessary here to go into the details of the position of the cochlear nuclei and the distribution of their various com. ponents except in so far as they directly concern the midbrain centers with which this communication deals more particularly. The bulbar centers and the secondary cochlear connections are in part labeled in our figures and are, so far as we have studied them, essentially the same in Alligator mis. sissippiensis as in previously described reptilian forms.

The superior olive in the alligator, as Kappers has pointed out, really consists of two main nuclear masses. The larger, posterior portion is irregularly triangular in cross section and lies in intimate relation with the crossed and uncrossed fibers of stria medullaris acustici. Gradually this portion 
decreases in size and disappears except ventralward where it becomes more or less continuous with a smaller cell group to which the name of superior olive is also applied, and which runs forward for some distance in company with the lateral lemniscus fibers.

The tract with which we are particularly concerned in this account is the lateral lemniscus. This arises in morphologic relation with the superior olive, although our silver preparations do not permit us to trace axones of its cells into the tract. Consequently the relation may be merely one of position rather than actual synaptic relation. Part of the fibers pass with no evident synaptic relation in course from the cochlear nuclei, particularly nucleus dorsalis magnocellularis, directly into the lateral lemniscus by way of striae medullares acustici, crossed and uncrossed, without coming into synaptic relation with the olive. From the level of the upper region of the superior olive the lateral lemniscus fibers swing dorsalward and forward toward the dorsal regions of the midbrain, where the larger portion of them turn medialward to distribute to the corpus quadrigeminum posterius and the smaller number dorsomedially to the optic tectum (figs. 26 and 27). Thus both these areas receive the secondary cochlear impulses, although the corpus quadrigeminum posterius receives much the larger amount of fibers. Lateral lemniscus fibers end in nucleus isthmi and fibers from that nuclear mass pass to the corpus quadrigeminum posterius (the peduncle of the inferior colliculus). Groups of cells forming the nucleus of the lateral lemniscus may be found more or less intermingled among the fibers of that bundle.

Accompanying the lateral lemniscus, really combining with it to form a broad fillet path, are the secondary trigeminal fibers medially and the spino-mesencephalic tract laterally. All of these reach the optic tectum but the lateral lemniscus is concerned primarily with corpus quadrigeminum posterius. The last two may reach the dorsal diencephalic centers, although the evidence for this latter connection is not clear at present. Here are represented the great sensory ascending 
pathways which together with the optic are making possible the differentiation of the great somatic sensory centers of the forebrain, thalamus and tectum.

3. Tractus spino-mesencephalicus (figs. 28-34). In Kappers' recent book ('21, p. 849, fig. 452) under the discussion of the midbrain and diencephalon of reptiles he has shown a cross section of a chameleon brain with a tract labeled tractus spino-mesencephalicus. The following reference is made to it in the text: "Direkt unterhalb des Endkernes der lateralen Schleife, im Anschluss an ihn, enden auch bei den Reptilien sekundäre Fasern des spinalen Trigeminuskernes; vitale Edinger'sche Fasern des Kopfes, vielleicht begleitet von solchen aus dem Rückenmarke selber. Von diesen Fasern begeben sich mehrere in die tiefen Schichten des Tectums ( $T r$. spino- et bulbo-mesencephalicus et tectalis), das sich dadurch als ein Korrelationsgebiet von optischen und vitalen sensiblen Reizen kennzeichnet."

The spinal component is relatively clear in Alligator mississippiensis and has suggestive relations. As the tract appears at the upper levels of the cord and the lower levels of the medulla it lies just ventral to the spino-cerebellar fasciculus (fig. 34), and as that fasciculus swings dorsolateralward around the lateral border of the spinal nucleus of the Vth, the spino-mesencephalic tract also turns a little dorsalward but for the most part runs almost directly cephalad, in the ventrolateral position which it has occupied since its entrance to the medulla. This keeps it ventromedial to the spinal $V$ th nucleus (figs. 32, 33) and, as the upper border of the superior olive is reached, ventrolateral to the superior olive (fig. 31) and later lateral to the lateral lemniscus and as the lemniscus swings dorsalward the fibers of the spino-mesencephalic tract are not clearly definable from it (fig. 31). Tractus spinomesencephalicus is crossed by secondary cochlear fibers from the tuberculum acusticum to the superior olive and lies partly medial to and is slightly crossed by the emergent roots of motor Vth. In front of the sensory Vth nucleus part of the fibers of the tract swing upward toward the ascending cere- 
bellar tracts (fig. 31) and so enter the anterior part of the cerebellum, running to the roof nuclei of both the same and the opposite side. The number of these cerebellar fibers is relatively small but the position and relations suggest the ventral spino-cerebellar tract of mammalian forms. (It is not to be inferred however that the spino-cerebellar tract previously described is necessarily the homologue of the dorsal spino-cerebellar tract of higher forms. Observers in general have been inclined to consider it the homologue of a part of Gowers' complex. The cells of origin of neither tract are known in the alligator material). In front of the level of the sensory Vth tract the lateral lemniscus swings dorsolateralward to enter the nucleus isthmi and the tectal regions. It becomes closely associated laterally with this spino-mesencephalic tract which distributes with it to the optic tectal regions; some of the fibers swing forward to enter the more anterior portions of the tectum and the adjoining mesencephalic region. Possibly some reach corpus quadrigeminum posterius within the lateral lemniscus. Other fibers of this tract may reach the posterior part of the diencephalon. However, this statement is made tentatively since they are so intermingled with other fibers that it becomes impossible to be certain just which components become diencephalic. It has seemed to us that this tract is possibly the anlage of the spino-thalamic tract of mammals. It is undoubtedly the homologue of spino-tectal tracts described for several forms. Considered from the standpoint of function, it is probably not so essential to determine whether the tract reaches the dorsal thalamus directly, since with the broad tectal connections which are present in the highly developed tecto-thalamic system, the impulse may readily be brought to diencephalic centers. The trigeminal component of this tract which Kappers emphasizes in his account (see the quotation at the beginning of this section) is also clearly present in the alligator. It is composed apparently of crossed fibers from the sensory nucleus of the other side-part of the ventral arcuates-a considerable proportion of which distribute as a sepa- 
rate nucleo-cerebellar tract to the cerebellum (see account of the trigeminal connections). The rest join the spino-mesencephalic tract, the fibers intermingling with this fiber bundle. So far as the preparations available show, the two systems become indistinguishable from each other. It affords another trigemino-tectal system. Other trigeminal fibers of the second order as has been previously stated, accompany the lateral lemniscus path cephalad to reach tectum and thalamus.

Summary. A consideration of the significance of the reptilian lemniscus systems will be reserved until the discussion at the conclusion of this communication. However, there are certain considerations of special interest which may well be emphasized at this time. They are as follows: 1) The anlagen for all the main ascending sensory systems of Mam: malia are represented in the reptilian brain with the exception of a clearly defined medial lemniscus system and even for that there are evident anlagen. 2) The presence of these systems is associated with the presence of a relatively well developed neothalamus and a neopallial cortex-a point which has been emphasized by Edinger and Kappers. 3) While these lemnisci are associated undoubtedly with the developing neothalamus and in part may reach that region directly, it must be remembered that their main connections are with the tectal region, particularly with the optic tectum. In the brain of Alligator mississippiensis this represents the region of the highest development. All the great sensory paths tend to converge here. Much of the thalamic differentiation is under the influence of the tectum and molded very largely by the bulbo-tectal and optic tracts and then by the tecto-thalamic connections.

\section{Posterior commissure}

This commissure (figs. 22-25) is divided into the two general divisions, commonly recognized in birds. The more ventral portion begins close to the habenular commissure. In association with this division are found the three nuclei which have been recently described by Beccari ('23) for 
Varanus and which had been identified previously, in part at least, by de Lange ('13) and Kappers ('21) for various Reptilia, particularly for Chelone. We found it exceedingly difficult to homologize the findings of the various observers with one another and with our own material. The following brief survey attempts such a homology so far as our present material will permit.

A large celled nuclear mass surrounds the more laterally directed fibers of the ventral division of the posterior commissure (fig. 12). This is the nucleus of the posterior commissure described by de Lange for turtle and probably the nucleus dorsalis of the posterior commissure of Beccari's terminology. That the nuclei of the two sides are related through the posterior commissure is evident in our alligator material. That these nuclear masses are crossed by fibers of the dorsal supraoptic system and that they may be in synaptic relation with this system is also easily recognizable in our material. A bed nucleus is found partly scattered among the commissural fibers and partly ventral to them. This con. sists of smaller, more scattered cells except along the ventral border where the cells are arranged in relatively definite rows. This ventral portion blends with the cell mass known as the nucleus interstitialis of the posterior commissure (Beccari, '23) although the latter consists of larger cells (fig. 10). The interstitial nucleus is particularly associated with those fibers of the posterior commissure which turn ventralward toward the medial longitudinal fasciculus. A separate portion of these interstitial cells form the ventromedial group of Beccari's terminology and are so labeled in our figures (fig. 10). Fibers of the posterior commissure come into relation with the medial longitudinal fasciculus in our material, apparently forming one of its components. This agrees with Held's views regarding the components in Mammalia (Elliot Smith in Cunningham's Anatomy), but Edinger thought the tract should be considered a separate one although in apposition with the medial longitudinal fasciculus. The posterior commissure component is indistinguishable from the other 
components of the fasciculus in the reptilian material available. Other fibers of the ventral component of the posterior commissure appear to be in synaptic relation with nucleus circularis and nucleus lentiformis mesencephali and quite possibly with the dorsocaudal portion of the thalamus generally, although they are so intermingled in the region that it is difficult to trace the individual fibers with any degree of assurance. Short fibers are contributed from the periventricular gray.

The dorsal division of the posterior commissure (fig. 23), the anterior limit of which lies somewhat caudad to that of the ventral division, contains many more fibers than does the ventral part. Posteriorly it cannot be sharply differentiated from the commissure of the superior colliculus. This dorsal division of the posterior commissure is concerned, in so far as it is known to us, almost exclusively in interrelating the tectal regions of the midbrain. The connection is broad, relatively larger than in forms below reptiles and in mammals, and its development goes hand in hand with the great size and apparently great importance (if one may judge by the number and variety of the tectal fiber connections) of the tectal centers in Reptilia.

Commissure of the superior colliculus (figs. 23 and 26)

The optic tecta are interrelated by a commissure which is continuous in front with the dorsal division of the posterior commissure and which extends caudad above the ventricle throughout the extent of the optic tectum. While relatively small at any one level, taken as a whole a considerable number of fibers decussate in it. There appear to be fibers crossing in it from all of the various fiber layers of the optic tectum. Just under the commissure, in the midline and between it and the ventricle, lie the cell bodies of the medial portion of the mesencephalic nucleus of the trigeminal nerve. 
Fasciculus longitudinalis medialis (figs. 14-16, 26-31)

This fasciculus in the alligator, as in other vertebrates, extends dorsocaudad from the nucleus of the medial longitudinal fasciculus (figs. 10,12, 13, 26) to the level of the nuclei of the oculomotor nerves. It lies slightly lateral and ventral to these nuclei and consequently near the floor of the ventricle and close to the midline. It occupies this position in relation to the floor of the ventricle throughout its course in midbrain and medulla until it becomes continuous with the ventral ground bundle of the cord.

Fasciculus longitudinalis medialis in the various vertebrate types has received considerable attention from observers. Associated with its study are the names of Kölliker ('93), Pedro Ramón y Cajal ('97), de Lange ('07), Flechsig ('11) and many others. The methods most generally employed, aside from the study of normal material, were those of operative experimentation or of the study of embryological development associated, as it is, with different periods of myelinization of the various components (Flechsig, '11). A detailed account of various fiber bundles, particularly in Mammalia, together with a summary of the more important literature, may be found in the texts of Cajal ('11) and Kölliker ('93) or in the report of de Lange ('07) before the International Congress of Psychiatry and Neurology. An account of this literature would unnecessarily lengthen the present paper and only such references are given as pertain directly to reptilian material. To this latter group belongs the work of Cajal ('97), as it relates to this fasciculus in reptiles. $\mathrm{He}$ found the tract in Varanus consisted of ascending paths from the reticular gray of the bulb, the nucleus of Deiters and the trigeminal centers, while the descending paths were contributed by the nucleus of Edinger, the optic lobes and the thalamic nucleus of the fasciculus. Interfascicular gray provided both ascending and descending fibers. From the posterior commissure were fibers, part of which on reaching the fasciculus made a T-shaped division and contributed both 
ascending and descending bundles. He described commissural fibers from the fasciculus which accompanied the postoptic or supraoptic decussation and crossed in the posterior part of the chiasmal ridge. (These are the fibrae ansulata of other observers.)

The components of the medial longitudinal fasciculus, as far as we could obtain them in our material, agree substantially with those given by Cajal and in part by Becari ('23). Experimental research and degeneration material would be necessary for a complete and satisfactory analysis. Our results may be briefly summarized as follows.

Fasciculus longitudinalis medialis receives homolateral and contralateral fibers from Deiters' nucleus (not illustrated) and also fibers from the nucleus magnocellularis (Beccari, '12; de Lange, '13; Kappers, '20). The larger proportion of the fibers are crossed. The nuclei of the eye-muscle nerves (figs. 26-29) are interrelated through this fasciculus. As the dorsal tecto-spinal tract swings ventro-medialward toward its partial decussation in the dorsal fountain or dorsal tegmental decussation of Meynert (fig. 26) tectal fibers accompany it on its medial border and enter the fasciculus longitudinalis medialis. These are partly crossed and partly uncrossed. Some fibers of the posterior commissure (figs. 24-25; also see the account of this system) enter the fasciculus directly, others only after a synapse in the nucleus of that commissure. These appear to be entirely uncrossed.

There appears to be a contribution to the medial longitudinal fasciculus from the cerebello-tegmental (or cerebellomotor) tracts (figs. 30-31). This contribution consists of fiber bands which connect various ones of the cranial nerve nuclei with the cerebellum, the fibers rumning only for short distances. Our material suggests a connection of the trigeminal centers with the medial longitudinal fasciculus, but one is not certain that the fibers do not swing dorsalward without any real comnection. The relation of the fibers of the ansulate commissure with the fasciculus which was described by Edinger and Cajal and more recently by Beccari ('23) is plainly 
evident in the material. The significance of this crossing has not been ascertained as yet.

Fasciculus geniculatus descendens (figs. 17 and 18), Fasciculus pretectalis descendens (figs. 17, 18)

In 1923, Beccari described in Varanus a descending tract from the lateral geniculate body which he termed the fasciculus geniculatus descendens and another from the geniculato pretectale, known as fasciculus pretectalis descendens. There are indications of these tracts in our silver preparations but they are so intermingled with the fibers of other systems that it has not been possible to follow them definitely in this material. They are more evident in the preparations stained for medullated fibers, although even there they are not as clear and complete as one could wish. We have been able in the sagittal series to carry them back to the posterior end of the diencephalon, but beyond that point they could not be differentiated from the other fiber bundles of the region. We know nothing of the direction of conduction. Fibers from the nucleus pretectalis appear to join the fasciculus preteetalis descendens. Figures 17 and 18 illustrate these fasciculi in Alligator mississippiensis.

\section{Tractus thalamo-bulbaris (figs. 26-30)}

In figure 26, a fair sized, cross cut fiber bundle has been labeled tractus thalamo-bulbaris, following the terminology of de Lange ('13) who has given the name of tractus thalamobulbo-spinalis to a similarly situated tract in Varanus. Cephalad to figure 26, this bundle breaks up into smaller groups of fibers which are so intermingled with the dorsally running fibers of the dorsal supraoptic and dorsal strio-tegmental systems that it is not possible to indicate them accurately in the drawings although they are more or less distinguishable in the preparations because of their lighter staining and their cross cut appearance. Behind the level of figure 26, they gradually swing ventralward and become so closely re- 
lated with the ventral tecto-bulbar system, that in our preparations the two tracts from this level on are indistinguishable from each other. The bundle can be traced into the bulb region; there are even indications that it receives or gives fibers which have their termination or origin on the other side of the bulb, decussating fibers apparently being associated with the tract.

As must be clear from the above account, although we have used the terminology of de Lange, we have no evidence for the direction of conduction nor the nucleus of origin of the thalamo-bulbar path. As a matter of fact its relation to the ventrolateral area of the diencephalon is strongly suggestive of an ascending sensory system rather than a descending path. This is particularly true if one has regard for Kap pers' view that the ventrolateral area represents the anlage for the ventral and lateral thalamic nuclei of higher forms (p. 132). Every effort was made to homologize the thalamobulbar tract of our description with an ascending sensory system, possibly even medial lemniscus, but our material at present affords no direct evidence for such a homology. Consequently the foregoing description must be regarded as incomplete and the nomenclature as tentative.

\section{Descending paths from tectal centers}

A considerable amount of work, in part experimental, has been devoted to an analysis of the descending tracts of the quadrigeminal bodies in various forms. It is unnecessary here to go into a complete review of the literature; accounts of some of the more outstanding results are to be found in the papers of Pawlov ('00) and de Lange ('10). Certain points, however, are of special interest. Munzer and Weiner ('98) described the uncrossed superficial tecto-bulbar tract in birds (the ventral tecto-bulbar of our terminology). They believed it had its termination in a gray mass which they considered the homologue of the mammalian trapezoid body. Pawlov described a similar tract in Mammalia under the name of fasciculus tecto-tuberantialis. However, he found no con- 
nection of this tract with the trapezoid nucleus but rather with the homolateral pontine gray. De Lange ('10) in rabbits described an uncrossed ventral tecto-bulbar path as terminating in relation to the pontine nuclei. Dorsal tecto-bulbar and crossed ventral tecto-bulbar tracts were described by de Lange for rabbit. De Lange ('10 and '13) has described the tecto-bulbar tracts in various reptiles, more particularly Varanus and Chelone. The following account of the tracts in Alligator mississippiensis shows that they present the relations typical for reptiles and mammals.

Tractus tecto-bulbaris dorsalis (fig. 26). The cell bodies of the neurons, the neuraxes of which form the dorsal tectobulbar tract, lie in the optic tectum. These neuraxes run ventromedially along the outer margin of the periventricular gray forming the radiations of Meynert; a certain number of collaterals and possibly certain stem fibers reaching that area (fig. 26). A certain proportion of them course medially just ventral to the medial longitudinal fasciculus, from which it is not possible to differentiate them thereafter. This tract is undoibtedly homologous with the medial tecto-spinal path of Mammalia. De Lange has described it for Reptilia and figured it in Varanus salvator ('13, p. 121). The decussation of this tract is the homologue of the mammalian dorsal fountain decussation (figs. 26-27).

Accompanying these crossed fibers ventralward but lying lateral to them is an uncrossed portion of the complex. It has been labeled the uncrossed tractus tecto-bulbaris dorsalis. This latter tract does not decussate in the midline, but turns caudalward as an uncrossed path lying mediodorsal to the thalamo-bulbar path during its course through the midbrain. It could not be followed through the medulla in the material studied. It probably reaches the cord and so is homologous with the mammalian tract of the same name. De Lange ('13) mentions this uncrossed part of the dorsal tecto-bulbar tract.

Tractus tecto-bulbaris ventralis (fig. 27 ). In figure 27 are shown the decussating fibers of the ventral tecto-bulbar tract already described for several reptiles as a partially decussat- 
ing and partially non-decussating tract (Varanus and Chelone, particularly by de Lange, '13). The fibers arise in the tectal region, and pass ventralward in separate strands and near the ventral part of the midbrain turn caudalward, partly before and partly after crossing. The tract from this point on is not very clear in the material available.

\section{Mesencephalic periventricular system}

In our material the mesencephalic periventricular system, which is composed of fine fibers of grayish black color, forms a distinct band connecting the more dorsal portions of the mesencephalon with the hypothalamic regions. Its fibers arise in part from the deeper fiber layers of the optic tectum (layers 2, 4, and part of 6 of Cajal's description, Cajal, '96, and de Lange, '11, figs. 37-39, p. 115). They follow the course of the ventricle except that for the most part they pass ventral to the anterior attachment of the corpus quadrigeminum posterius as it bulges inward under the optic tectum (fig. 24). Some few fibers which pass to the ventricular margin of the corpus quadrigeminum posterius appear to contribute to this tract (fig. 24). The tract, maintaining its periventricular position, passes medialward and then ventralward to end in the ventral thalamic and the hypothalamic regions (figs. 24, 25). In the more dorsal part of their course the above described periventricular fiber's are accompanied by bands of fibers which enter the corpus quadrigeminum posterius surrounding. it peripherally on all sides and so forming a layer of fibers which in all directions penetrates the cell mass from its surface (fig. 24). These fibers, as is evident, interrelate the optic and auditory mesencephalic centers. The posterior part of this mesencephalic periventricular system both receives and gives fibers to the central gray and connects that region as well as the tectum with hypothalamic and interpeduncular areas. The tract here is much smaller but still discernible. Some of its fibers appear to reach the nucleus of the IIIrd nerve (figs. 26, 27). Behind the nucleus of the third nerve the periventricular system becomes much reduced; the tectal com- 
ponent appears to be lost, so far as could be determined, and the mesencephalic periventricular system becomes continuous with the short fibers making up the bulbar periventricular system. In the region of the IVth nucleus, near the line between bulb and the mesencephalon, fibers from the cerebellotegmental system contribute to the central gray and so come into relation with the periventricular system.

It will be seen from the above account that the so-called periventricular system does not consist of a single tract, but of a series of fiber tracts which may be subdivided into two main portions: 1) an anterior portion concerned primarily with the interrelating of the tectum, ventral thalamus, and hypothalamus ; 2) a posterior portion exhibiting some of these connections but concerned primarily with tecto-tegmental connections. The direction of conduction is unknown; quite probably the fibers may carry impulses in both directions. Some of these fibers, however, conduct impulses from the basal centers to the tectum, since Cajal ('11, p. 213) in his chrome silver pictures of the optic tectum of Lacerta muralis has shown that the layers to which these fibers may be traced are made up of neuraxes which synapse with the dendrites of the cell layers directly overlying them.

The periventricular system deserves special emphasis with reference to the following consideration. This system is essentially a dorsoventral correlation system in contrast to the anterioposterior correlation tract furnished by the fasciculus longitudinalis medialis. The periventricular system connects nuclei which lie in neighboring or closely related cross-sectional areas, but yet widely separated. This separation may be, in some cases, in a dorsoventral direction, as is the case with the tecto-hypothalamic components. Some of the fibers of the system are intrinsic to the mesencephalon. They belong essentially to the regional correlation system rather than to the longitudinal conducting pathways, and undoubtedly represent the elaboration of a system, phylogenetically as old as the vertebrate nervous system. 
Fiber connections of the nucleus isthmi

The presence of the nucleus isthmi in certain reptiles has already been demonstrated; for example, by Joustra ('18) and Kappers ('21) in the chameleon. In Alligator mississippiensis (figs. 15, 18, 28 and 29) it lies at the level of the emergent root of the IVth nerve where the medulla is going over into the mesencephalon and occupies a dorsolateral position close to the surface of the brain and just behind the corpus quadrigeminum posterius. In all forms in which it has been described, including Reptilia, it has been shown to be essentially a way-station in the course of the lateral lemniscus. It receives both terminal and collateral fibers of that tract. It has a distinct connection with the corpus quadrigeminum posterius, this bundle being indicated in figures 28 and 29 under the label $a$. This is in all probability mainly a quadrigemino-isthmal path.

The bundles which connect the nucleus isthmi and the optic tectum (the isthmo-tectal tract of Kappers, '21) are not so clear in the silver preparations and so are not labeled in the figures. They are very evident in our Weigert preparations running dorsally and forward from the upper portion of the nucleus to the tectum. This description is in agreement with that given by Larsell ('24) for frog, in which form his silver preparations permitted the recognition of both tecto-isthmal and isthmo-tectal fibers. Without doubt both are present in the alligator. In amphibians (Larsell, '24) the nucleus isthmi has been shown to receive fibers from his transverse decussation (commissure of Gudden, ventral supraoptic decussation of our terminology). Kappers speaks of being unable to definitely establish a connection of his decussatio supraoptica ventralis with nucleus isthmi. In the preparations available for study in a series of Alligator mississippiensis prepared by the Cajal method such a connection is demonstrable (figs. 28 and 29). An account of its relations and connections is given in this communication under the description of the dorsal division of the ventral supraoptic decussation. This connec- 
tion has considerable significance, since it means certainly a commissural connection between two nuclei isthmi and possibly also a crossed interrelation between them and the tecta of the two sides. Larsell ('24) has shown that both afferent and efferent impulses reach nucleus isthmi in the frog.

Optic fibers have been traced to this nucleus in reptiles by several observers. Bellonci ('88), who has carefully studied this region, has claimed their presence, but Kappers ('21) and his students were unable to find this optic connection in the material at their disposal. This optic connection cannot be demonstrated in the series of sections of the nervous system of Alligator mississippiensis nor of Chrysemys marginata at hand in this laboratory. Fine commissural fibers interconnect the two nuclei, crossing in the anterior medullary velum.

Joustra ('18) and Kappers ('21) have pointed out that nucleus isthmi of reptiles is in all probability the forerunner of the mammalian medial geniculate body. It certainly receives connections which are characteristic of that nucleus in higher forms, namely the lateral lemniscus fibers. Its connection with the corpus quadrigeminum posterius becomes the homologue of the mammalian peduncle of the inferior colliculus. A third connection, which Kappers could not demonstrate to his satisfaction in the material at his disposal, can be demonstrated in our preparations of Alligator mississippiensis; namely, the homologue of the mammalian Gudden's commissure, the decussatio supraoptica ventralis pars dorsalis of the present account.

Larsell ('24) has described the presence of the nucleus isthmi in the frog, obtaining essentially the same connections as those described for reptiles. He believes with Kappers that the nucleus is the homologue of the mammalian medial geniculate body, at least in the frog.

In the sagittal sections of Chrysemys marginata which are at hand, the nucleus isthmi stands out very clearly as a distinctly rounded mass just behind the optic tectum and caudad and lateral to the inferior collicular region. It lies just in 
front of the decussating IVth nerve. Its connections are the same as those described for Alligator mississippiensis except that the connection through the ventral supraoptic com. missure cannot be clearly traced in our material. The fiber path between the nucleus isthmi and the tectum is particularly well impregnated in a chrome-silver sagittal series and shows that there is a quite extensive connection between the two areas.

In the cell preparations of our collection, nucleus isthmi is seen to consist of two nuclear masses, a larger lateral portion and a smaller medial portion (fig. 15).

\section{Cerebellar connections}

Many of the fiber tracts which characterize the cerebellum of higher forms are to be found in Reptilia. Certain of these have been described previously for reptiles. Where this is the case, their relations will be briefly summarized in the following account, with references to the literature where a more complete description may be found. Other tracts, which so far as is known to us have not been previously described for the reptilian brain, will be given a more detailed accounting. The tracts found in the brain of the Alligator mississippiensis in the materials available for study were as follows :

Tractus cerebello-tegmentalis mesencephali (fig. 29). Kappers ('21, p. 687) describes such a tract under the name of brachium conjunctivum anterius. He says of it:

Die wichtigste eferente Bahn ist das Brachium conjunctirum anterius, dessen Ursprungsverhältnisse schwer zu ermitteln sind. Sie :cheinen wenigstens teilweise aus Zellen hervorzugehen, welche in vordern Abschnitt der Kleinhirn-Oblongata-Verbindung einen Kern bilden, lateral und frontal von den bereits erwähnten Dachkernen. Wahrscheinlich entstehen sie auch teilweise aus den Dachkernen selber. Die Zahl dieser Fasern ist relativ gering; ein ebenso grosses Säuger-Kleinhirn hat deren viel mehr (dort sind jedoeh anch die Nuclei dentati, oder laterale Kleinhirnkerne, ganz stark entwickelt).

There are no figures illustrating its position in reptiles and, so far as is known to us, no more definite account of it. 
It is believed that the tract called the cerebello-tegmentalis mesencephali in the following description represents this brachium conjunctivum anterius of Kappers.

The cells of origin of tractus cerebello-tegmentalis mesencephali appear to us to lie partly in the deeper and more central gray stratum of the cerebellum and partly in a small nucleus which Kappers has mentioned as the possible homologue of the nucleus dentatus of higher forms. The fibers swing ventralward around the ventricle just cephalad to the cerebello-tegmental tract and decussate under the fasciculus longitudinalis medialis, but relatively farther dorsalward than in higher forms. After their decussation the fibers turn cephalad to the tegmental areas of the midbrain in the region of the nucleus ruber, but it has not been possible to determine that they actually come into relation with that nuclear mass. These fibers give off collaterals to the tegmental region of the same and opposite side during their course. The tract with its nucleus of origin is discerned relatively more clearly in the sagittal series of Chrysemys marginata than in the silver preparations of the alligator brain.

Larsell ('23) described a brachium conjunctivum in the frog. He regarded it as arising in part from the nucleus cerebelli, while other fibers were added from the more dorsal region of the cerebellum. These latter, he believed, were probably axones of Purkinje cells. After leaving the cerebellum the fibers ran downward and forward and decussated to the other side, through a commissure which he termed the ansulate commissure. After decussation the fibers could be followed forward in the stratum griseum but could not be traced to their final termination. The ansulate commissure of Larsell's description we believe to be homologous with the one so figured by Joustra ('18). The commissure indicated by this latter worker lies in the posterior mesencephalic region at the level of the posterior quadrigeminal body; consequently it is homologous, at least in part, with our decussation of the cerebello-tegmental tract (fig. 28). It appears obvious that the commissura ansulata to which Larsell refers 
can not be regarded as the homologue of the fibrae ansulatae of Bellonci ('88), of Kappers ('21), Beccari ('23) or of our own account. If we are correct in our interpretation of Lar. sell's nomenclature, the tract described by him as the brachium conjunctivum of frog agrees substantially with the tractus cerebello-tegmentalis mesencephali of our description.

Tractus cerebello-tegmentalis (figs. 30-31). This tract comprises a portion of the inferior cerebellar commissure, which has been described as consisting in part at least of efferent cerebellar fibers (Kappers, '21). Many of the fibers of this cerebello-tegmental tract arise from the same side of the cerebellum. They swing medialward, being continuous anteriorly with the fibers of the tractus cerebello-tegmentalis mesencephali, suggesting that the tractus cerebello-tegmentalis mesencephali may probably be regarded as a differentiated portion of the cerebello-tegmental tract. The tract sends fibers to the motor Vth nucleus, dorsal to which it passes (fig. 31) and then decussates in the midline ventral to the fasciculus longitudinalis medialis to which they give collaterals and possibly also stem fibers, both before and after decussation (fig. 31). Some small bundles derived from the cerebello-tegmental tract can be traced to the reticular nuclei, not as clearly defined tracts but as small bundles of fibers. In general, they spread into the gray of the upper medulla homologous with the tegmental regions of the pons of the higher forms. This tract places the motor nuclei of $V$ th and undoubtedly other bulbar nuclei under the influence of the cerebellum, this in part through the connection with the fasciculus longitudinalis medialis. Tractus cerebello-tegmentalis is evidently figured by Kappers ('21, p. 685, fig. 369) for Crocodilus porosus under the name of tractus cerebellomotoris.

Tractus spino-cerebellaris (figs. 30-34). This tract has been so generally recognized (Edinger, '08; de Lange, '16; Kappers, '21, and others) that only the briefest account of it need be given, since in Alligator mississippiensis it has essen 
tially the same relations described for other reptiles. It runs along the lateral surface of the medulla at first ventral to the spinal Vth nucleus, gradually turns dorsalward swinging lateral to this nucleus and enters the cerebellum along the anterolateral margin of its attachment to the brain stem. After its entrance some of the fibers swing dorsalward at once and then running forward end in the granular cell layer close to the Purkinje cells. The majority of fibers turn almost directly medialward and cross to the opposite side, where they reach the deeper portions of the cerebellar gray. Their exact termination is not known. In horizontal sections of Chrysemys marginata which were studied, this tract is clearly evident. It has the same relations as those just described for the alligator.

Attention should be drawn here to the small cerebellar component which accompanies the tractus spino-mesencephalicus in the alligator. Its course has been described under the account of that tract (see description of lemniscus systems). Its position and relations suggest Gowers' ventral spino-cerebellar tract of mammals, although it may be that the reptilian spino-cerebellar tract also carries fibers which in higher forms are incorporated in Gowers' tract. Suitably prepared material of the reptilian cord is not at present available for determining this question.

Tractus vestibulo-cerebellaris and cerebello-vestibularis (figs. 30-31). These tracts are present, and have been previously described for reptiles (Beccari, '12; Kappers, '21) so that special consideration need not be given them; they are mentioned to call attention to their position as shown in the figures. The fibers arise and end in Deiters' nucleus and the anterior cerebellar nuclei. Associated with this is the tractus cochleo-vestibulo-cerebellaris (Kappers, 20) which comes from the nucleus laminaris and Deiters' nucleus, swings dorsalward along the dorso-lateral border of the medulla above the vestibulo-cerebellar tract, and enters the cerebellum near the posterior border of the peduncle. Both the cochleovestibulo-cerebellar and the vestibulo-cerebellar tracts appear to be associated primarily with the roof nuclei. 
Tractus tecto-cerebellaris. This tract (not illustrated) appears in the series of the Chrysemys marginata. It has not been possible to identify it in the alligator series, though this seems due to incomplete impregnation rather than to absence of the tract. In Chrysemys it passes ventralward from the more caudal portion of the optic tectum, then turns caudalward swinging below the decussating fibers of the IVth nerve and so soon as the anterior border of the cerebellum is reached turns dorsalward, distributing in its anterior portion to the granular layer just under the Purkinje cells. Throughout its course it occupies a relatively medial position, lateral, however, to the mesencephalic root of the Vth nerve. This tract has been described for vertebrates below reptiles and for mammals, but not previously for Reptilia.

\section{Trigeminal connections}

The sensory nuclei of the trigeminal nerve within the medulla and the cells of origin for the motor root of that nerve have been described and figured for various reptiles, among them the Alligator sklerops (Kappers, '20), so that only a brief summary of the relations of these primary centers as observed in Alligator mississippiensis will be given. This seems necessary so as to afford a background for the description of the secondary and tertiary connections by means of which impulses brought in by this nerve are carried to other brain centers.

The position of the motor nucleus may be observed by consulting figures 11, 15, 31 and 32 . The motor nucleus lies at the level of exit of the motor fibers. Its typically large cells lie medial to the sensory nucleus and form an eminence on the floor of the fourth ventricle. Neuraxes from these cell bodies can be traced unmistakably into the root fibers, so that in part at least the motor fibers are homolateral. Contralateral fibers are possibly also present, for there is a broad connection between the trigeminal motor nuclei and certain of the decussating fibers appear to pass directly into the root (fig. 32). The evidence is not as clear as for the homolateral 
fibers. A smaller, more ventrally placed motor nucleus has been described for Crocodilia by Kappers ('21). Its position is indicated in figure 32 , but we have no knowledge of its connections.

The descending or spinal root of the $\mathrm{Vth}$ and its associated gray are very large in the alligator. It forms one of the most conspicuous fiber and cell masses in the lateral half of the medulla from the point of entrance of the sensory $V$ th fibers to the beginning of the cord, where it goes over into the dorsal horn and its associated tract. Its most cephalad portion is enlarged and shows much cellular structure with some evidence of cell grouping; this portion is comparable to the chief sensory nucleus of higher forms. It is interesting in this connection to note that the somatic component of the $\mathrm{X}$ th nerve, while not large in reptiles, is comparatively distinct and sends its fibers in part at least into the nucleus of the spinal Vth tract. Consequently the tracts arising from this nucleus, whether nucleo-cerebellar or to tectum and diencephalon, may carry impulses which have entered the medulla through the Xth nerve as well as the Vth.

The mesencephalic root of the Vth can be traced forward in the Weigert series to the tectal portion of the midbrain where its cells of origin lie near the midplane and just over the aqueduct. In the alligator material the cells are not particularly well impregnated so that, although the large oval cell bodies (figs. 15, 25, 26) stand out clearly, it is not possible to determine much in regard to the processes. In some of the turtle material, certain cells of the nucleus are fairly well impregnated and it can be seen that some of them are apparently multipolar cells and others unipolar.

The cells of the mesencephalic root of the Vth have been accurately plotted for Alligator sclerops by van Valkenburg ('11, p. 382). He divided them into a medial group and a lateral and intermediate group. He found the great majority of the cells, particularly those of the medial group, in the rostral third of the tectum. The cells of the medial group are particularly evident in our preparations and are labeled in the figures 15,25 and 26. 
It will be seen from the foregoing account, which agrees in general with previous descriptions for reptiles, that the trigeminal nuclei are relatively highly developed in the reptilian brain. Consequently one expects to find numerous and important secondary connections.

Kappers has pointed out that the increased size and differentiation of primary trigeminal centers and the development of the thalamic nucleus rotundus undoubtedly go hand in hand and predicts the presence of a Vth lemniscus although he could not differentiate it in the material studied (for a discussion of this see the account of the trigeminal lemniscus). Kappers speaks also in general terms of connections with other bulbar nuclei and states that many of the decussating fibers so clearly arising from the sensory Vth nuclei are concerned with this function. In the following account the connections of the sensory and motor nuclei are given separately.

The cells which make up the nucleus of the descending root of the $V$ th and its chief sensory nucleus send neuraxes across the midline forming a distinct trigeminal decussation (fig. 32). Certain of these fibers distribute to bulbar centers as Kappers has pointed out. The chief sensory nucleus sends many short fibers into the motor Vth nucleus of the same side. Other fibers appear to pass through the homolateral motor nucleus and, crossing with the motor decussating fibers, pass to the motor $V$ th of the other side, but the fibers are too intermingled to be certain of this connection.

The trigemino-cerebellar connections (fig. 31) are well developed in the alligator. They are of two types, crossed and uncrossed. The uncrossed fibers (tractus trigemino-cerebellaris dorsalis) pass dorsomedially from their cell bodies in the chief sensory nucleus and, passing just lateral to the motor nucleus of the Vth, turn dorsalward into the cerebellar peduncle and swing up into the cerebellum (fig. 31). Other fibers (tractus trigemino-cerebellaris ventralis) cross as decussating $\mathrm{V}$ fibers to the other side and passing directly lateralward take a position at first just ventral to the sensory $V$ 
nucleus and dorsal to the lateral lemniscus. They swing gradually dorsalward around the spinal $\mathrm{V}$ nucleus, occupying a position on the extreme lateral border of the medulla until the upper border of the sensory nucleus is reached, then they turn dorso-medially and enter the cerebellum (fig. 31). These represent the $V$ th component of the ventral superficial arcuates of higher forms. Fibers from the fifth nucleus of the same side join them but the path is chiefly a crossed path. Besides these fibers from the chief sensory nucleus of $V$ to the cerebellum, there are fibers from the spinal $V$ th nucleus at various levels which reach the cerebellum, since the ascending secondary trigeminal path (which we have termed the trigeminal lemniscus) contributes to the ventral trigeminocerebellar tract just described. Behind the level of the sensory $\mathrm{V}$ nucleus fibers from the spinal portion contribute to the dorsal nucleo-cerebellar tract. As was mentioned previously, there are probably impulses entering through the somatic sen sory component of the vagus which, after a synapse, send their impulses to the cerebellum along with those which have come in by way of $\mathrm{V}$.

In addition to these connections, Kappers has raised the question of the entrance of direct root fibers of the Vth into the cerebellum, much after the way in which direct vestibular fibers reach that center. These direct root fibers of the Vth, entering as a part of the sensory root, appear to join the nucleo-cerebellar fibers from the sensory $V$ th nucleus without synapsing in that nucleus. However, they are so intermingled with these nucleo-cerebellar fibers that it has not been possible to trace them through individually and thus be certain of their ultimate course. They appear to pass directly to the cerebellum. They are not shown in the drawings.

\section{DISCUSSION}

It is evident that a pattern exists in the reptilian midbrain and thalamus which markedly foreshadows the condition found in the brains of higher forms. In the alligator one finds the structure suggestive in particular of avian forms, 
yet showing many relations characteristic of mammalian types. Since this is the case, a brief survey of these conditions and a discussion of the possible significance seems to us justified.

The cerebellum in the alligator presents practically all the main fiber connections which have been described for the mammalian superior and inferior cerebellar peduncles and which are characteristic of the mammalian vermis. In our materials the least clearly differentiated of these is the cerebello-rubral tract. Purkinje cerebellar cells are present and well developed as are also the molecular and granular layers; probably also the anlage of a dentate nucleus. The cerebellum has no hemispheres, nor has it brachia pontis, with their characteristic cortico-ponto-cerebellar paths. This is to be expected in a brain in which the highest cortical association centers apparently are lacking as yet.

In the tectal regions, the homologues of both the superior and inferior colliculi are present, although the inferior colliculi or corpora quadrigemina posteriora do not lie on the surface, as in mammalian forms, but are rolled in adjacent to the ventricle. In Reptilia, the corpus quadrigeminum posterius does not show a high degree of cellular differentiation or arrangement but it presents the characteristic connections with the lateral lemniscus which mark it as a tectal acoustic correlation center. Associated with this tectal center and interrelated with it by a broad fiber tract, which may be regarded as the forerunner of the brachium of the corpus quadrigeminum posterius, or the peduncle of the inferior colliculus, is the so-called nucleus isthmi. This nucleus receives direct fibers from the lateral lemniscus and also, in the alligator at least, from the dorsal division of the ventral supraoptic commissure, in part the commissura transversa of Gudden. These connections would appear to indicate, as Kappers has already pointed out, that the reptilian nucleus isthmi is the forerunner of the medial geniculate body of higher forms. It is true that the reptilian nucleus isthmi lies relatively farther caudad than does the mammalian medial geniculate in reference to 
the corpus quadrigeminum posterius in Mammalia. This is explicable on two grounds. In the first place, the reptilian corpus posterius lies relatively farther cephalad because it is rolled in under the optic tectum instead of lying on the surface as in higher forms. In the second place, the more important connections of the nucleus isthmi at this phylogenetic state probably are caudad rather than cephalad.

Within the optic tectum or the superior collicular region one finds a remarkably distinct differentiation of the nuclear mass into layers clearly comparable with the avian conditions, and exhibiting rather more differentiation than one finds in Mammalia. The optic tectum far surpasses the cortical areas of the reptilian hemispheres, both in number of layers and cellular differentiation within the layers, with the possible exception of the layer of projection cells within the hippocampus (Crosby, '17). Optic fibers distribute to its outer cell layers throughout practically its entire extent. Many of the lateral lemniscus fibers to this region as well as to the corpus quadrigeminum posterius bring with them trigeminal lemniscus and spinotectal fibers, these latter being the forerunner of the spinal lemniscus fibers of higher forms. Thus the superior colliculus represents primarily a center for optic correlations, but the resultant impulses will be greatly modified by the impulses brought in by other lemniscus systems.

The transition areas in the posterior part of the diencephalon and the beginning of the mesencephalon near the highly developed tectal regions are occupied in part by a group of nuclei which serve as way-stations between the tectal areas and other centers. To this group belong nucleus pretectalis, nucleus lentiformis (de Lange, '13), 'geniculato pretectalis' (Beccari), and possibly other of the nuclear masses in this region. These nuclei serve partly as receptive centers for incoming stimuli, passing toward the tectal areas (nucleus pretectalis, for example), and partly as centers of distribution for outgoing impulses.

One of the most noticeable features is the intimate relation existing between the roof of the midbrain and the centers of 
the diencephalon, many of which are connected with the tectum by one or more fiber tracts, so that a large proportion of the fiber tracts of these regions belong to the tecto-thalamic or thalamo-tectal type. The decussating components of this type, as well as a considerable number of commissural fibers between the tecta or thalami of the two sides, have been shown to be provided for by the postoptic complex.

This intimate interrelation between the optic tectum and the thalamus has put the developing somatic centers of the dorsal thalamic region particularly under the influence of the somatic impulses which have been correlated in the highly differentiated tectum. Into this same dorsal thalamus come also optic fibers (to the lateral geniculate body). It is possible that trigeminal and spinal lemniscus fibers may reach nucleus rotundus; certainly the impulses will do so after a synapse in the tectum. In contrast with the thalamus of lower forms, the dorsal somatic centers, the neothalamic regions in the reptile, show a great advance in richness of fiber connections and in nuclear differentiation and approach the condition found in birds and lower mammals.

Johnston ('15), Crosby ('17) and others have shown that in the anterior part of the hemisphere, folded inward into intimate relation with the underlying striatal complex and lying out in the dorsolateral hemisphere wall, there is a cortex which is concerned primarily with the correlation and association of non-olfactory impulses. This region is closely related to the dorsal regions of the thalamus by way of the lateral forebrain tract, thus providing ample opportunity for sensory material correlated in these thalamic nuclei to reach the developing cortex. The development of the somatic thalamic centers and of the non-olfactory cortex within the hemisphere go hand in hand, the former providing the highly correlated material which is apparently a prerequisite for cortical development, the latter taking this highly correlated material and spreading it out through thin layers of cells, beginning the pattern of projection centers which is clearly marked out in lower mammalian brains (Elliot Smith, '10). 
However, it must be borne in mind that the advance in the thalamic pattern is in turn made possible by the development and differentiation of the bulbar and midbrain centers. There has been progress in all these regions, a striking example of the interrelation and interdependence of the various parts of the vertebrate central nervous system.

The nuclei of the dorsal thalamus which are concerned par. ticularly in the interrelation and correlation of tectal and forebrain centers and which serve as way-stations for ascend. ing paths from lower centers to forebrain are nucleus medialis, anterior and posterior, nucleus rotundus and nucleus reuniens (probably the forerunner of the mammalian nucleus medialis), in part nucleus dorsolateralis anterior and possibly nucleus posterocentralis. A short résumé of their main connections may be useful.

Nucleus rotundus, nucleus medialis anterior and posterior, and nucleus reuniens, Kappers regards as forming a medial group which, from certain similarities of connections and arrangement, suggests the medial nucleus of mammalian forms. He regards nucleus rotundus, probably inclusive of our nucleus medialis posterior, as the homologue of the large-celled medial nucleus, nucleus reuniens as massa intermedia, and nucleus medialis anterior as the smaller-celled mammalian medial nucleus. There is little doubt in our minds that these nuclear masses, exclusive of nucleus rotundus, are the representatives of the medial group in higher animals but the determination of the position of nucleus rotundus in the evo. lutionary development is dependent upon a greater knowledge of its fiber relations in the various forms than we at present possess. Particularly desirable would be a demonstration of its connections with the lemniscus systems, if perchance this connection is present in the alligator. Whatever one may say of the homologies, certain outstanding fiber connections are suggestive of possible differences in activity in these nuclear groups. Each of the four nuclear masses has its own definite, distinct fiber connection with the striatum on the one hand and with the tectum on the other. It has not 
been possible so far to carry direct lemniscus impulses into any of these centers, but impulses brought forward by these systems undoubtedly reach the areas by tectal connections and may even form direct connections.

Nucleus dorsolateralis anterior is related to the hemispheres by fibers which in part at least are thalamo-striatal. It receives impulses from the tectum although the connection is small, as far as one may judge from the fibers impregnated in our material. It does not receive direct lemniscus fibers so far as known, but must receive indirectly some impulses ascending to optic tectum by way of the trigeminal system. It is larger, but in cell type and general position appears to accord with the nucleus lateralis described for turtle. It is the probable homologue of some avian somatic nucleus, even possibly of mammalian nucleus lateralis, although at present we have little direct evidence to prove the latter assumption, and are inclined to think such is not the case. It is not to be regarded as the homologue of the nucleus ventrolateralis figured by Kappers ('21) for reptiles, which cell mass he regards as representing the combined nucleus lateralis and nucleus ventralis of Mammalia. To our minds it appears most probable, from the facts now available, that the nucleus dorsolateralis anterior is the anlage of the somatic portion of the anterior nucleus of higher forms but the data are not at present sufficient for a final statement regarding the homology. In this connection the nucleus dorsomedialis anterior may be considered.

This nucleus is the forerunner of a part of the nucleus anterior of higher forms. It probably receives mamillothalamic fibers (de Lange and Beccari); it certainly is interrelated with the preoptic areas, the surrounding thalamic nuclei and the tectum. It receives few fibers from the striatal regions, so far as our preparations show. It forms only the dorsomedial portion of the nuclear mass which Kappers considers nucleus anterior in Alligator sklerops, the lateral portion being occupied by a large celled nucleus which we have termed nucleus dorsolateralis anterior. It does not appear 
from the findings in our material that nucleus dorsomedialis anterior of our nomenclature is primarily a somatic center. One may, however, regard the nucleus dorsolateralis anterior, as we have stated previously, as the anlage of the portion of the nucleus anterior in Mammalia which has connections with the frontal cortical areas or the somatic part of nucleus anterior.

Lateral geniculate body in Reptilia is relatively very large and receives incoming optic fibers. It is intimately interrelated with the tectal areas, and is connected with lower centers, as is indicated in our material and has been clearly shown by Beccari ('23). It does not show any definite connections with the forebrain bundle in our material and Beccari apparently found none in Varanus. The peduncle which Edinger considered as running forward into the hemisphere, Beccari ('23) homologizes with his descending path. On these grounds this latter author raises the question as to the real homology of the mammalian with the reptilian lateral geniculate body.

It would appear to us that even the absence of a connection of the lateral geniculate body with the telencephalic centers is not to be regarded necessarily as an indication that that nuclear mass is other than a forerunner of the mammalian nucleus of the same name. Rather it indicates that phylo. genetically the nuclear group differentiates as a way station for fibers passing to and from the tectum. The marked differentiation of these tectal areas affords a center for high optic correlation and the forebrain connections develop consequently late. We would regard as related conditions the great tectal development and the absence of any large optic connection forward into the forebrain. The intimate relation of the lateral geniculate body and the optic tectum is maintained throughout phylogeny. This has a special indication in the relative position of the nuclear mass. In lower vertebrates (Amphibia and Reptilia) this nucleus begins relatively far forward in the thalamic regions. As the rest of the dorsal thalamus becomes more highly differentiated phylogeneti- 
cally, the lateral geniculate body maintains its relation to the tectum and so becomes relatively farther posterior until it forms part of the metathalamic region in higher forms. It is doubtful if this would have occurred if early there had been a stronger and more intimate interrelation between the telencephalon and the optic thalamic centers than between the tectum and these same thalamic areas.

In a paper now in press Herrick ('25) has demonstrated the presence in certain Amphibia (frog) of a connection between the thalamic optic center, presumably the anlage of the lateral geniculate body of higher forms, and the forebrain areas. On this ground one would certainly expect to find a telencephalic connection for the lateral geniculate body of Reptilia. Such a connection does not appear to be demonstrable in the material available. Everyone familiar with silver impregnation methods realizes that the lack of a given fiber tract in such material must always be regarded as negative rather than positive evidence for the actual absence of the fiber system. We are still of the opinion, however, that the relative shifting of the lateral geniculate body during phylogeny from a comparatively anterior to a distinctly posterior position is indicative that tectal rather than telencephalic connections play the predominant rôle in its development in earlier phylogenetic stages.

In contrast with the optic thalamic centers the medial group of thalamic nuclei early acquire large forebrain connections. In the reptilian thalamus these nuclei lie in the middle and posterior regions of the diencephalon, behind the anterior end of the lateral geniculate body. As development goes on the former differentiate cephalad and become entirely anterior to the last mentioned nucleus. The pattern laid down here in turn determines that of the cortical regions of the forebrain.

Johnston ('16) has shown that in reptiles (particularly in turtle and lizard) the most anterior somatic cortex can be proved experimentally to belong to the motor type. Recently, Bagley and Richter ('24) have demonstrated, by electrical 
stimulation, the presence in the alligator of a motor area which is situated mainly in the anterior, dorsal portion of the hemisphere but which, to quote these authors, "does not coincide absolutely with any one definite cytoarchitectonic field". According to the evidence in the present paper the sensory impulses extending furthest anterior in their course from thalamus to forebrain belong to the general sensory type and as they have striatal connections during early phylogenetic development it is to be expected that they will be represented next in the cortex and that their projection center will lie just posterior to that of the motor. The presence of such an area for reptiles has not as yet been demonstrated.

The optic cortical center of higher forms according to this reasoning one would expect to find farther posterior since the thalamo-cortical component for the optic system becomes of great importance later in evolutionary history. This theory accords well with the facts pointed out by Elliot Smith ('10) for the marsupial brain, where he clearly demonstrates that the fibers from the dorsal thalamus pass by the shortest possible routes to the projection centers of the cortex; fibers from the anterior part of the thalamus reach the most anterior sensory area, directly posterior to the motor projection center, those from the intermediate regions go to the lateral cortical areas, while the optic nuclei which occupy the posterior position in the thalamus send their fibers to the pos terior part of the hemisphere. The pattern of the somatic cortex then is determined by that of the dorsal thalamus, while that in turn is a direct outgrowth of the pattern of tectum and bulb. All the parts are intricately related and interdependent.

A glance at the brief résumé of the connections of the epithalamic and hypothalamic centers (p. 144) will show how large a rôle olfactory correlation still plays in this region in the reptilian brain. ${ }^{3}$ It will be remembered that the most highly differentiated cortex within the reptilian brain is the hippocampus and that there is a pyriform lobe cortex as

\footnotetext{
${ }^{3}$ Material at hand indicates an accessory olfactory bulb in alligator also, although the romero-nasal nerve has never been demonstrated here.
} 
well, so that one would expect to find highly developed olfactory correlation centers within the diencephalon.

But while the sensory correlation centers are developing within the reptilian forebrain, midbrain and thalamus, there is also a development and differentiation appearing on the outgoing or motor side of the arc. This is noticeable in the size and differentiation of the forebrain bundles, particularly the lateral forebrain bundle. The strio-thalamic, thalamo-striatal and strio-tegmental tracts, which become incorporated for the most part in the internal capsule in higher forms are relatively well developed. Associated with this strio-tegmental connection is the differentiation of the tegmental regions of the forebrain, marked particularly by the beginning of a nucleus ruber (de Lange, '12) and other differentiated tegmental nuclei. The high degree of differentiation on the motor side marks the developing of forebrain control of the activities of the lower centers, foreshadowing the great part which the cortex is to play in the strengthening or inhibiting of motor activities.

\section{BIBLIOGRAPHY}

Bagley, C., AND Richter, C. P. 1924 Electrically excitable region of the forebrain of the alligator. Arch. Neurol. and Psychiat., vol. 11, pp. $257-263$.

Beccari, Nello 1912 La costituzione, i nuclei terminali e le vie di connessione del nervo acustico nella Lacerta muralis, Merr. Arch. Ital, di Anat. e di Embr., vol. 10, fasc. 4 .

1923 Il centro tegmentale o interstiziale ed altre formazioni poco note nel mesencefalo e nel diencefalo di un rettile. Arch. Ital. di Anat. e di Embr, vol. 20, fasc. 4.

BeLlonci, J. 1888 Über die centrale Endigung des Nervus optieus bei den Vertebraten. Zeitsch. f. wissensch. Zool., Bd. 47.

Crosby, Elizabeth C. 1917 The forebrain of Alligator mississippiensis. Jour. Comp. Neur., vol. 27.

Edinger, Ludwig 1888 Untersuchungen über die vergleichende Anatomie des Gehirns. I. Das Vorderhirn. Frankfurt a. M.

1896 Idem. III. Neue Studien über das Vorderhirn der Reptilien. Frankfurt a. M.

1899 Idem. IV. Studien über das Zwischenhirn der Reptilien. Frankfurt a. M.

1908 Vorlesungen über den Bau der nervösen Zentralorgane des Menschen und der Tiere. Siebente Auflage, Bd. 2. Leipzig.

Edinger, Ludwig, AND WaLLenberG, A. 1899 Untersuchungen über das Gehirn der Tauben. Anat. Anz., Bd. 15. 
Flecisia, P. 1911 Ueber den hinteren Langsbündel. Arch. f. Psychiat. u. Nervenkrankheit., Bd. 49.

Gage, Susanna Phelphs 1895 Comparative morphology of the brain of the soft shelled turtle (Amyda mutica) and the English sparrow (Passer domesticus). Proc. Am. Microse. Soc., vol. 17.

Gross 1903 Die Sehnervenkreuzung bei Reptilien. Zool. Jahrb. Anat. u. Ontog., Bd. 17, Heft 4. Reviewed in Zool. Centralbl. for 1903, Bd. 10, S. 869-70.

GuRdjian, Elrsha S. 1925 Olfactory connections in the albino rat, with special reference to the stria medullaris and the anterior commissure. Jour. Comp. Neur., vol. 38 .

HeRrick, C. JUDSON 1905 The central gustatory paths in the brains of bony fishes. Jour. Comp. Neur., vol. 15.

1910 The morploology of the forebrain in Amphibia and Reptilia. Jour. Comp. Neur., vol. 20 .

1917 The internal structure of the midbrain and thalamus of Necturus. Jour. Comp. Neur., vol. 28.

1921 The connections of the vomeronasal nerve, accessory olfactory bulb and amygdala in Amphibia. Jour. Comp. Neur., vol. 33.

1925 The amphibian forebrain. III. The optic tracts and centers of Amblystoma and the frog. Jour. Comp. Neur., vol. 39.

HERrICK, C. L. 1890 Notes upon the brain of the alligator. Jour. Cin. Soc. of Nat. Hist., vol. 12.

1891 Contributions to the comparative morphology of the central nervous system. II. Topography and histology of the brain of certain reptiles. Jour. Comp. Neur., vol. 1.

1893 Contributions to the comparative morphology of the central nervous system. II. Topography and histology of the brain of certain reptiles. Jour. Comp. Neur., vol. 3.

Hines, Marion 1923 The development of the telencephalon in Sphenodon punct tatum. Jour. Comp. Neur., vol. 35.

Humphrey, O. D. 1894 On the brain of the smapping turtle, Chelydra serpentina. Jour. Comp. Neur., vol. 4.

INGVAR, S. 1923 On thalamic evolution. Acta Med, Scand., vol. 59.

Johnston, J. B. 1915 The cell masses in the forebrain of the turtle, Cistudo carolina. Jour. Comp. Neur., vol. 25.

1916 Evidence of a motor pallium in the forebrain of a reptile. Jour. Comp. Neur., vol. 26.

1923 Further contributions to the study of the evolution of the forebrain. Jour. Comp. Neur., vol. 35.

Joustra, N. 1918 Over de Homologie van het Ganglion Isthmi, Psychiat. en Neurolog. Bladen. Amsterdam, vol. 22.

KAPPERS, C. U. ARIF̈NS 1914 Phenomena of neurobiotaxis in the central nervous system. XVIIth Intern. Congress of Med., London.

1920-1921 Die vergleichende Anatomie des Nervensystems der Wirbeltiere und des Menschen. Absch. I and II. Haarlem.

Kappers, C. U. Arjëns, and Theunissen, W. F. 1908 Jie Phylogenese des Rhinencephalons, des Corpus striatum und der Vorderhirn-Commissuren. Folia Neurobiol., Bd. 1. 
KöLLIK.R, A. 1893 Handbuch der Gewebelehre. Zweiter Band. Leipzig.

KöPPEN, M. 1890 Beiträge zur vergleichenden Anatomie des Centralnervensystems der Wirbeltiere. Zur Anatomie des Eidechsengehirns. G. Schwalbe's Morphol. Arbeiten, Bd. 1, Heft 3. Jena.

DE LANGF, S. J. 1907 Sur l'anatomie du faisceau longitudinalis posterior. $\mathrm{I}^{\circ}$ Congres Intern. de Neur., Psych., ete., Amsterdam.

1910 The descending systems of the corpora quadrigemina. Folia Neurobiol., Bd. 3.

1911 Das Vorderhirn der Reptilien. Folia Neurobiol., Bd. 5.

1912 The red nucleus in reptiles. Proc. Kön. Acad. v. Wetensch., April.

1913 Das Zwisehenhirn und das Mittelhirn der Reptilien. Folia Neurobiol., Bd. 7.

1916 Das Hinterhirn, das Nachhirn und das Rückenhirn der Reptilien. Folia Neurobiol., Bd. 10.

LAksfir, O. 1923 The cerebellum of the frog. Jour. Comp. Neur., vol. 36.

1924 The nucleus isthmi of the frog. Jour. Comp. Neur., vol. 36.

MaLONe, E. 1910 Über die Kerne des menschlichen Diencephalon. Abhand. d. Kön. Preuss. Akad. d. Wissenseh., Anhang.

Marburg, O. 1903 Basale Opticuswurzel und Tractus peduncularis transversus. Centralbl. Physiol., Bd. 17.

Meyer, AdoLF 1892 Über das Vorderhirn einiger Reptilien. Zeitseh. wiss. Zool., Bd. 55 .

MUNzer UNd WeIner 1898 Beiträge zur Anatomie und Physiologie des Zentralnervensystems der Taube. Monatschr. f. Psych, u. Neur., Bd. 3.

Palmaren, Alex 1921 Embryological and morphological studies on the midbrain and cerebellum of vertebrates. Acta zool., Bd. 2.

Pawlov, I. P. 1900 Les voies descendantes des tubereules quadrigemeaux superieurs. Le Nevraxe, T. 1.

RABL-R̈̈ckmaRD, H. 1877 Das Zentralnervensystems des Alligators. Zeitsch. wiss. Zool., Bd. 30.

1894 Einiges über das Gehirn der Riesensehlange. Zeitseh. wiss. Zool., Bd. 63.

RAMón Y CAJaL, P. 1896 Estruetura del encéfalo del camaleón. Rev. trim. microg., vol. 1.

1897 El fasciculo longitudinal posterior en los reptiles. Rev. trim. microg., vol. 2.

Ramón y Cajal, S. 1911 Histologie du système nerveux, T. 2, Paris.

Rezse, Albert M. 1908 The development of the American alligator. Smith. Mise. Coll., no. 1791.

1910 The development of the brain of the American alligator: the paraphysis and the hypophysis. Smith. Misc. Coll., no. 1922. 1915 The alligator and its allies. Putnam.

RöThiG, PAUL 1911 Beiträge zum Studium des Zentralnervensystems der Wirbeltiere. 3. Zur Phylogenese der Hypothalamus. Folia Neurobiol., Bd. 5 .

Schepman 1918 De octavo-laterale zintiugen en hun verbindingen in de hersenen der Vertebraten. Dissertatie, Amsterdam. (Quoted from Kappers, '20.) 
SChrofder, K. 1912 Der Faserverlauf im Vorderhim des Huhnes. Jour. f. Psych. u. Neur., Bd. 18.

Sмiтh, G. Ellioт 1910 Some problems relating to the evolution of the brain. The Lancet, Jan. 1, 15, 22.

1919 Account of the central nervous system in Cunningham's Textbook of Anatony. Vth ed. Wood \& Co., New York.

Stieda, Ludwig 1875 Ueber den Bau des centralen Nervensystems der Amphibien und Reptilien. Ueber den Bau des centralen Nervensystems der Schildkröte. Leipzig.

Unger, LuDwig 1906 Untersuchungen über die Morphologie und Faserung des Reptiliengehirns. II. Das Vorderhirn des Alligators. Sitzb. k. Akad. Wien., Math.-nat. Klasse, Bd. 120, Abth. III.

van Valkenburg, C. T. 1911 Zur vergleichenden Anatomie des mesencephalen Trigeminusanteils. Folia Neurobiol., Bd. 5 .

Wrassak, R. 1893 Die optischen Leitungsbahnen des Frosches. Arch. f. Anat. u. Physiol., Suppl.

ZeehandelaAR 1919 De Onto- en Phylogenese der Achterstrengkernen. Dissertatie, Amsterdam. (Quoted from Kappers, '20, vol. 1, p. 165.) 